\title{
El Dominio Salino del norte de Chile y sus yacimientos de minerales industriales
}

\author{
The Saline Domain of northern Chile and its industrial mineral deposits
}

Guillermo Chong Díaz ${ }^{1,}$, Cecilia Demergasso ${ }^{2}$, Javier Urrutia $\mathbf{M e z a}^{3}$, Marina Vargas A. ${ }^{4}$

${ }^{1}$ Departamento de Ciencias de la Tierra, Universidad Católica del Norte, Angamos 06016, Antofagasta, Chile.

${ }^{2}$ Centro de Biotecnología, Universidad Católica del Norte, Angamos 06016, Antofagasta, Chile.

${ }^{3}$ Universidad de Antofagasta, Angamos 601, Antofagasta, Chile

${ }^{4}$ Unidad de Equipamiento Científico MAINI, Universidad Católica del Norte, Angamos 06016, Antofagasta, Chile.

* Autor para correspondencia: (G. Chong) gchong@ucn.cl

\begin{abstract}
Cómo citar este artículo:
Chong Díaz, G., Demergasso, C., Urrutia Meza, J., Vargas, M., 2020, El Dominio Salino del norte de Chile y sus yacimientos de minerales industriales: Boletín de la Sociedad Geológica Mexicana, 72 (3), A020720. http://dx.doi. org/10.18268/BSGM2020v72n3a020720
\end{abstract}

Manuscrito recibido: 21 de Octubre de 2019 Manuscrito corregido: 29 de junio de 2020 Manuscrito aceptado: 2 de Julio de 2020

La revisión por pares es responsabilidad de la Universidad Nacional Autónoma de México.

Este es un artículo Open Access bajo la licencia CC $\mathrm{Y}-\mathrm{NC}$ SA (https://creativecommons.org/licenses/by-nc-sa/4.0/)

\section{RESUMEN}

Se define y describe el concepto "Dominio Salino en el Norte de Chile" como el resultado de la combinación de factores geológicos, geomorfológicos y climáticos/paleoclimáticos. Estos determinan que en la región del Norte Grande de Chile $\left(18^{\circ}-27^{\circ}\right.$ Lat.Sur $)$ la presencia de sales tenga una amplia distribución en suelos, secuencias sedimentarias, cuencas evaporíticas, aguas subterráneas y superficiales y en nieblas dinámicas. Se reconoce la presencia mayoritaria de cloruros, sulfatos, carbonatos, boratos y de otras sales poco comunes en la Naturaleza, como nitratos, yodatos, cromatos, dicromatos, cloratos y percloratos. Este Dominio Salino incluye la formación de los principales yacimientos de Minerales Industriales de Chile, como en el caso de los de nitratos y yodo, sal, litio y otros subordinados, como los de boratos y potasio. Se describen el marco geológico, geomorfológico y climático/paleoclimático, el rol de las sales como agentes de meteorización y erosión y los yacimientos principales. Se reconoce la importancia de estos ambientes salinos como un hábitat excepcional para una variada microbiota con un gran potencial biotecnológico.

Palabras clave: Norte de Ghile, desierto de Atacama, minerales industriales, depósitos salinos.

\section{ABSTRACT}

The concept of "Saline Domain in Northern Chile" is defined and described as a result of the combination of geological, geomorphological and climatic/paleoclimatic factors. These determine that in the Norte Grande region of Chile $\left(18^{\circ}-27^{\circ}\right.$ South Lat.) the presence of salts has a wide distribution in soils, sedimentary sequences, evaporitic basins, underground and surface waters and in dynamic fogs. The majority presence of chlorides, sulfates, carbonates, borates, and other rather unusual salts in Nature such as nitrates, iodates, chromates, dichromates, chlorates and perchlorates is recognized. This Saline Domain includes the formation of some of the main deposits of Industrial Minerals in Chile as in the case of nitrates and iodine, salt, lithium and other subordinates such as those of borates and potassium. The geological, geomorphological and climatic/ paleoclimatic settings, the role of salts as weathering and erosion agents and the main Industrial Minerals saline ore deposits are described. The importance of these saline environments is recognized as an exceptional habitat for a varied microbiota with great biotechnological potential.

Keywords: Northem Chile, Atacama desert, Industrial minerals, Saline deposits. 


\section{Introducción}

Chile, sobre la base de su desarrollo económico, es descrito como un "país minero". En el siglo XVI, su territorio fue una región desconocida y poco accesible, cuya atracción única era la posibilidad de que se constituyera en una fuente de metales preciosos u otros de uso incipiente, por ejemplo, el cobre. Esta situación, comparada con Perú, Bolivia o México en el mismo lapso, fue subordinada con una discreta explotación de oro, plata y cobre (Pederson,1966; Vicuña Mackenna,1968; Villas y Araníbar, 2003; Villalobos, 2009). La mayoría de edad, en lo que a Minería se refiere, se inicia para Chile con la Industria del Salitre, a fines del siglo XIX. Desde entonces, esta actividad ha crecido y hoy posee un liderazgo mundial como productor de cobre, litio, yodo y nitratos naturales y es el principal exportador de sal de Sudamérica (SERNAGEOMIN, 2019).

En este devenir es importante un singular rasgo geológico, que aquí se describe como el "Dominio Salino del Norte de Chile". Este factor es el que genera la presencia, en este territorio, de importantes yacimientos de minerales industriales, algunos únicos a nivel mundial, como los de nitratos, yodo, sal y litio.

Los resultados que aquí se presentan no cubren la totalidad de este "Dominio Salino". No se incluyen descripciones de las secuencias evaporíticas marinas del Jurásico, las formaciones salinas del Mioceno de la Cordillera de la Sal, las secuencias evaporiticas marino/continentales del Mioceno/ Plioceno de la Península de Mejillones y las evaporitas incluidas en algunos paleolagos del Mioceno/ Plioceno de la Depresión Central. El estudio de estas localidades se encuentra actualmente en progreso por los autores del presente trabajo. Asimismo, escapa a la dimensión de nuestro estudio una revisión de la calidad salina de las aguas del Desierto de Atacama.

\section{Dominio Salino}

\subsection{DEFINICIONES}

Chile se divide, administrativamente, en regiones y en su parte norte, entre los $18^{\circ}$ y $29^{\circ}$ de Latitud
Sur, se ubican cuatro de ellas que corresponden, desde el Norte, a Arica - Parinacota, Tarapacá, Antofagasta y Atacama con una superficie del orden de 260,000 $\mathrm{km}^{2}$. Las tres primeras y la mitad norte de la Región de Atacama, se describen como una "región natural", bajo el nombre de Norte Grande de Chile, por la Corporación de Fomento a la Producción de Chile. Esta macroregión posee características geológicas y geográficas específicas siendo relevante, en toda su extensión, la presencia del Desierto de Atacama.

En esta macroregión del Norte Grande se reconoce la abundante presencia de distintas sales, incluyendo varias que constituyen importantes yacimientos. Éstas están presentes en suelos, secuencias sedimentarias, cuencas evaporíticas, aguas superficiales y subterráneas y nieblas dinámicas. En este territorio, con distintas paragénesis y en gran abundancia, se reconocen principalmente cloruros, sulfatos, carbonatos, boratos y sales de escasa presencia en la naturaleza, como nitratos, yodatos, cromatos, dicromatos, cloratos y percloratos. Los compuestos más abundantes son yeso y halita (Chong, 1988).

Esta amplia distribución y variedad de sales es descrita, en este trabajo, como "Dominio Salino del Norte de Chile", incluyendo tanto el núcleo hiperárido del Desierto de Atacama, como el sector árido/semi-árido de la Precordillera/Alta Cordillera. Con la excepción de las potentes secuencias marinas de yeso/anhidrita del Jurásico superior y del Cretácico, todas estas sales son de probada edad cenozoica. Tienen su origen en la actividad volcánica cenozoica, procesos marinos, precipitación atmosférica, erosión de depósitos previos y, en casos, su génesis es incierta. Su mayor presencia es en suelos, cuencas y paleocuencas endorreicas evaporíticas, asociadas a partes distales de conos aluviales coalescentes, y en yacimientos salinos en el caso de nitratos y yodo.

Tanto las condiciones paleoclimáticas como las del clima actual han contribuido a la formación, concentración, circulación y preservación de estas sales. Las condiciones de hiperaridez y aridez generan una alta evaporación que supera 

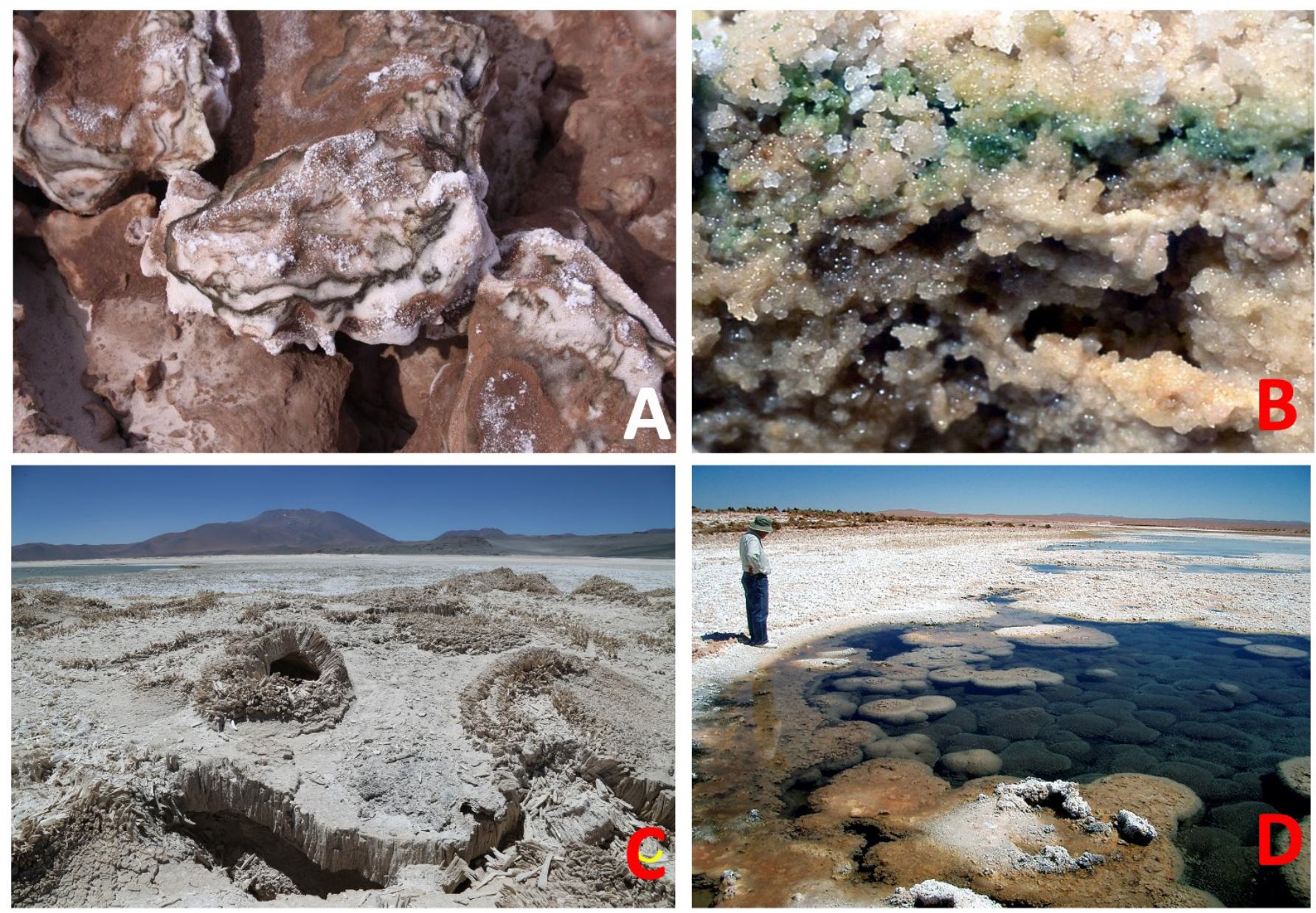

Figura 1 A) Endolitos en costras fósiles de cloruros. Salar Grande ( $\left.20^{\circ} 57^{\prime} \mathrm{S} / 69^{\circ} 48^{\circ} \mathrm{O}\right)$, Cordillera de la Costa, Región de Tarapaca. B) Horizontes bacterianos (tapices bacterianos) en el Salar de Llamará ( $\left.21^{\circ} 23^{\prime} \mathrm{S} / 69^{\circ} 37^{\circ} \mathrm{O}\right)$, Región de Tarapacá. C) Microbialitos fósiles en el Salar de Pajonales ( $\left.24^{\circ} 12^{\prime} \mathrm{S} / 68^{\circ} 15^{\prime} \mathrm{O}\right)$, Región de Antofagasta. D) Microbialitos en lagunas formadas en estructuras de disolución (Puquios) en el Salar de Llamará Región de Tarapacá.

los aportes hídricos, precipitando sales o formando salmueras. Los mismos factores, asociados a las características geomorfológicas del territorio, permiten la conservación de sales solubles, como afloramientos, durante lapsos geológicos.

Estas sales son un agente principal de los procesos de meteorización y erosión de las rocas, formación de suelos y de diversas estructuras. En algunos casos, sus altas concentraciones constituyen los yacimientos de minerales industriales más importantes del país. Adicionalmente, estos ambientes salinos, asociados a condiciones climáticas de hiperaridez y aridez, constituyen un hábitat favorable para el desarrollo de una excepcional, abundante y variada microbiota (Figura 1).

\subsection{FACTORES QUE DETERMINAN EL DOMINIO SALINO}

\subsubsection{MARCO GEOLÓGICO}

Durante el Cenozoico, última etapa del Ciclo Andino, se formaron gran parte de los rasgos topográficos que podemos observar en la actualidad. Esta configuración de los Andes en el Norte Grande de Chile es producto de la Tectónica Andina, cuyas fases más importantes definen Charrier et al., (2007) y Coira et al., (1982).

Es durante este lapso cuando se generan los eventos principales que definen lo que llamamos el "Dominio Salino". Se desarrolla un Arco Volcánico durante el Paleoceno-Eoceno al que 
sucede una disminución del magmatismo durante el Oligoceno y parte del Mioceno Temprano. Luego, desde el Mioceno medio hasta el Presente se desarrolla un nuevo Arco Volcánico. El solevantamiento andino y estructuras asociadas, como los sistemas estructurales de Domeyko y Atacama, definen la actual geomorfología, formando niveles de base regionales y locales.

Esto incluye procesos de erosión y sedimentación de sistemas volcánicos y continentales desérticos que incluirán aportes salinos, el emplazamiento de cuencas endorreicas y lagos asociados. Fuentes principales de los materiales sedimentarios son las rocas generadas durante el volcanismo activo prácticamente durante todo el Cenozoico y parte del Cretácico Superior. El solevantamiento andino agregó un factor que influirá en el desarrollo climático/paleoclimático (Lamb and Davis, 2003; Garreaud et al., 2009; Evenstar et al., 2015. Se crea el Rain Shadow Effect o "Biombo Climático" (Houston and Hartley, 2003) que acentuará la aridez del Norte Grande

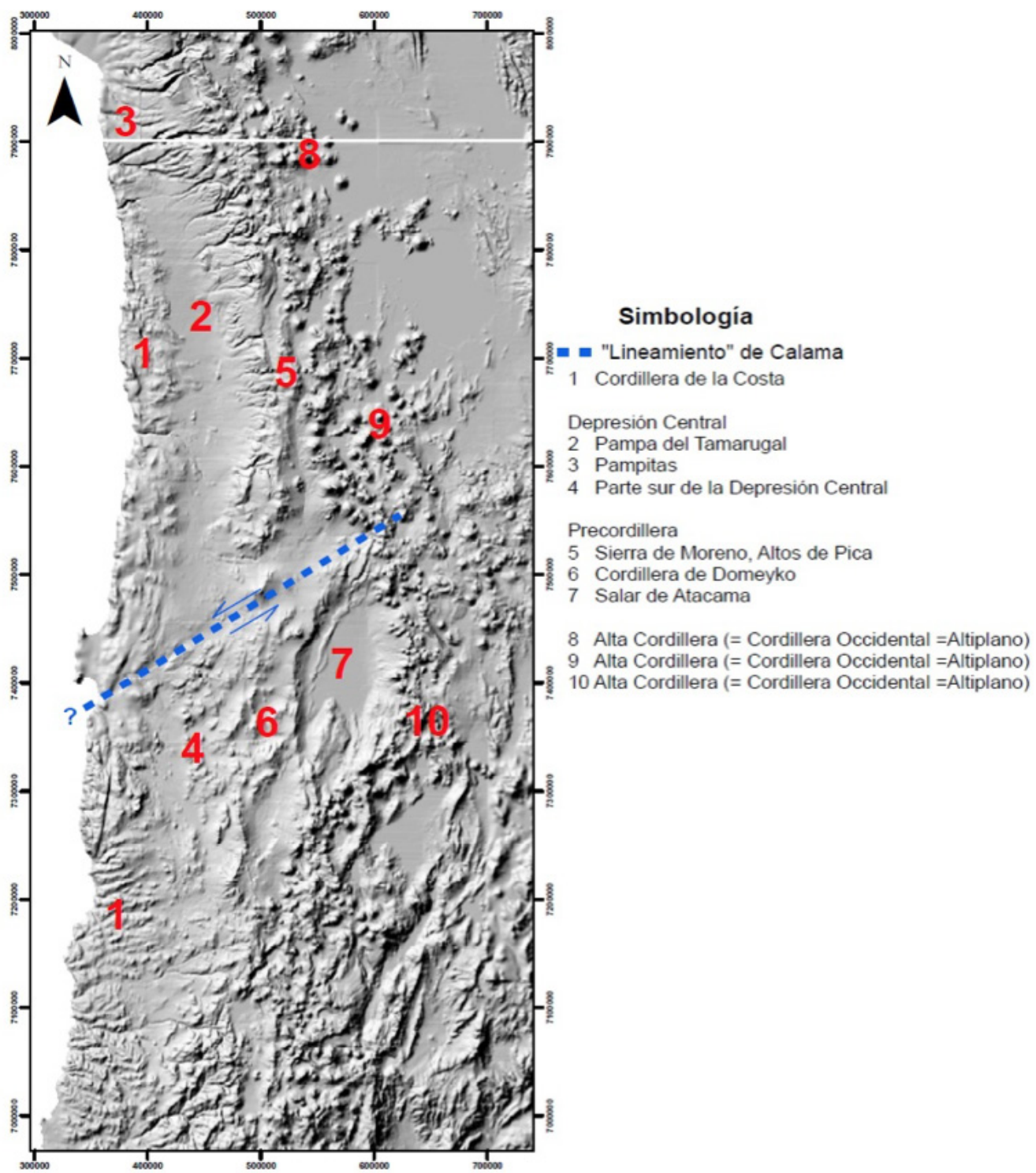

Figura 2 Geomorfología del Norte de Chile. La línea azul muestra un lineamiento regional (Asociado al Lineamiento Calama - Olacapato Toro? (Salfity, 1985)) que desplaza la continuidad norte sur de la Precordillera $(5,6)$. Asimismo, se puede observar que las características geomorfológicas de la Depresión Central $(2,4)$ cambian al norte y al sur de esta estructura. Hacia el norte es prácticamente plana (Pampa del Tamarugal) hacia el sur presenta una serie de serranías y cerros aislados. 
de Chile contribuyendo a la mayor evaporación (Houston, 2006) como asimismo a la conservación de sales solubles en lapsos geológicos en trampas geomorfológicas.

\subsubsection{MARCO GEOMORFOLÓGICO}

El Orógeno Andino se distribuye a través de Chile con cadenas montañosas y serranías separadas por franjas de relieves deprimidos. Su expresión más completa se encuentra en su territorio norte, aproximadamente entre los $18^{\circ}$ y $27^{\circ} \mathrm{S}$, donde este orógeno alcanza un ancho que supera los $700 \mathrm{~km}$. Sus unidades geomorfológicas principales se orientan longitudinalmente con un fuerte control estructural. Corresponden, desde el oeste, a la Cordillera de la Costa, la Depresión Central y la Cordillera Principal, también denominada Cordillera Oeste, Alta Cordillera, Altiplano o simplemente Andes. Esta división incluye una serie de importantes subunidades (Figura 2)

Cordillera de la Costa. Es un relieve maduro, con una altitud promedio del orden de 2500 y máxima de 3114 m s.n.m. (Sierra Vicuña Mackenna, $\left(24^{\circ} 27^{\prime} \mathrm{S} / 70^{\circ} 03^{\prime} \mathrm{O}\right)$, con un ancho promedio del orden de $30 \mathrm{~km}$. Su borde oeste es un acantilado abrupto que puede alcanzar hasta cerca de $1000 \mathrm{~m}$, en partes con angostas terrazas de abrasión y conos aluviales (Figura 3). Estas terrazas aumentan localmente su superficie por el aporte de escasos ríos que llegan al mar como en Arica (18 $\left.28^{\circ} \mathrm{S} / 70^{\circ} 17^{\prime} \mathrm{O}\right)$ o el Rio Loa $\left(21^{\circ} 41^{\prime} \mathrm{S} / 70^{\circ} 06^{\prime} \mathrm{O}\right)$. Su parte más septentrional está cortada por profundas quebradas, algunas de las cuales se asumen como fallas de dirección E-O (Figura 4). Incluye el Sistema de la Falla de Atacama que, en sectores, controla su acantilado costero, define el límite con la Depresión Central o forma bloques en su interior (Figuras 5 y 6 ).

Depresión Central. Es un territorio deprimido, limitado en parte por estructuras, entre la Cordillera de la Costa y la Precordillera, de unos $50 \mathrm{~km}$ de ancho y altitud promedio del orden de 1000 m s.n.m. Es el nivel de base principal antes del Océano, con pendiente regional hacia el oeste y está rellena por los aportes sedimentarios espe-

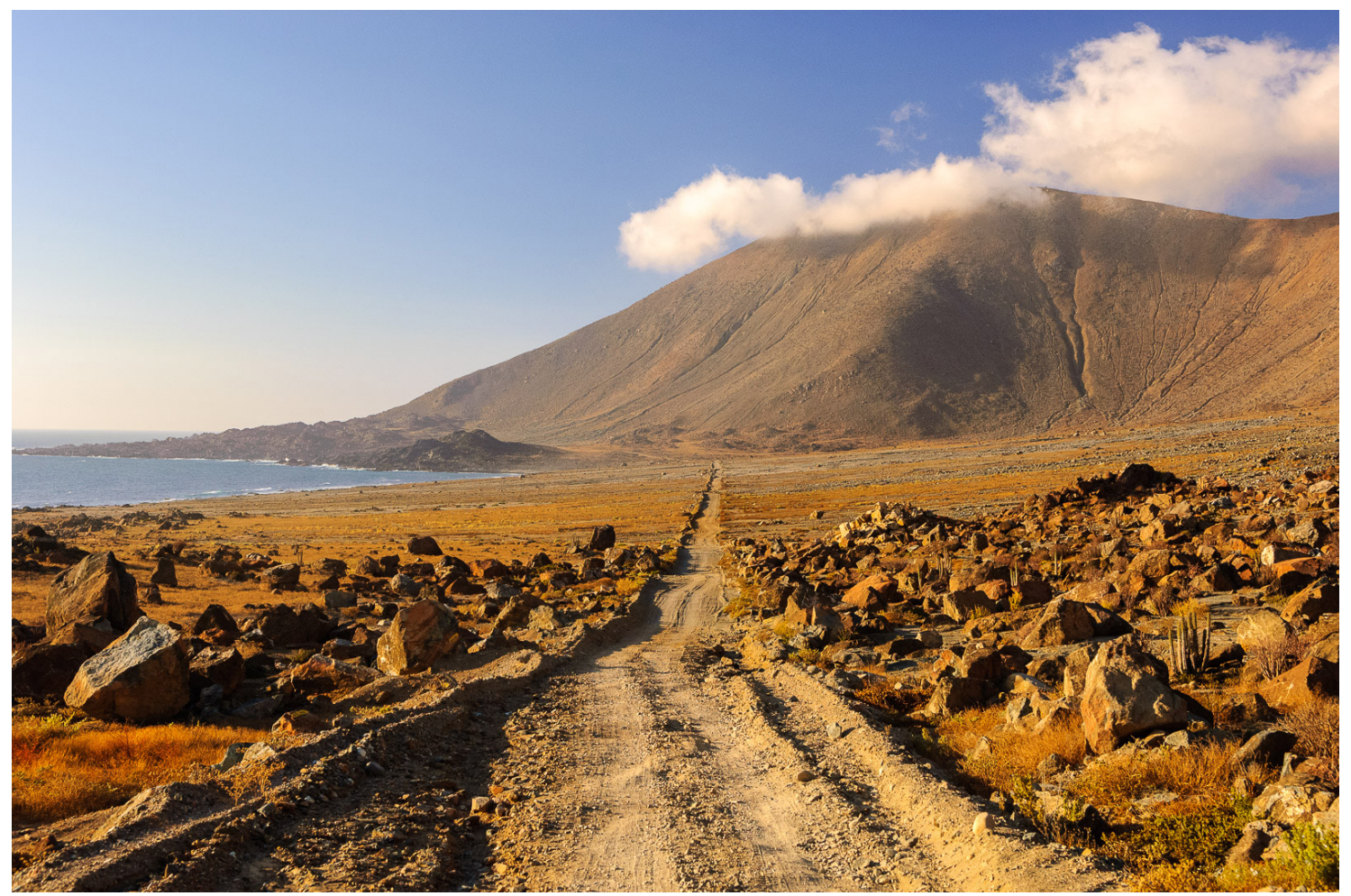

Figura 3 Borde oeste de la Cordillera de la Costa que muestra el Acantilado Costero y terrazas de abrasión cubiertas por aportes aluviales. Sector de Paposo ( $25^{\circ} 01^{\prime} \mathrm{S} / 70^{\circ} 28^{\prime} \mathrm{O}$ ). 


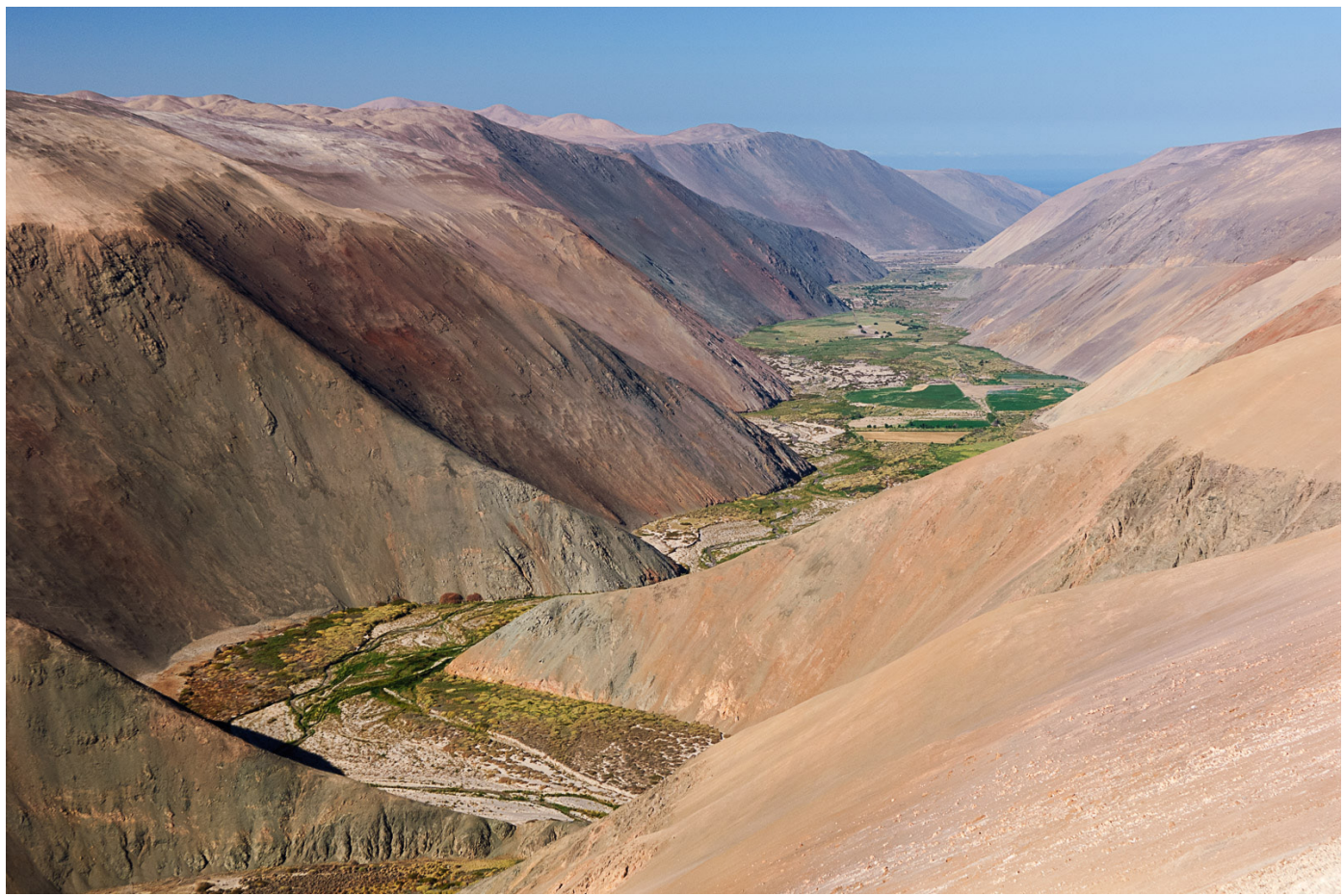

Figura 4 Sector más meridional de la Cordillera de la Costa cortada por profundas quebradas que llegan al mar. Quebrada de Chiza (19 $\left.11^{\prime} \mathrm{S} / 70^{\circ} 06^{\prime} \mathrm{O}\right)$.

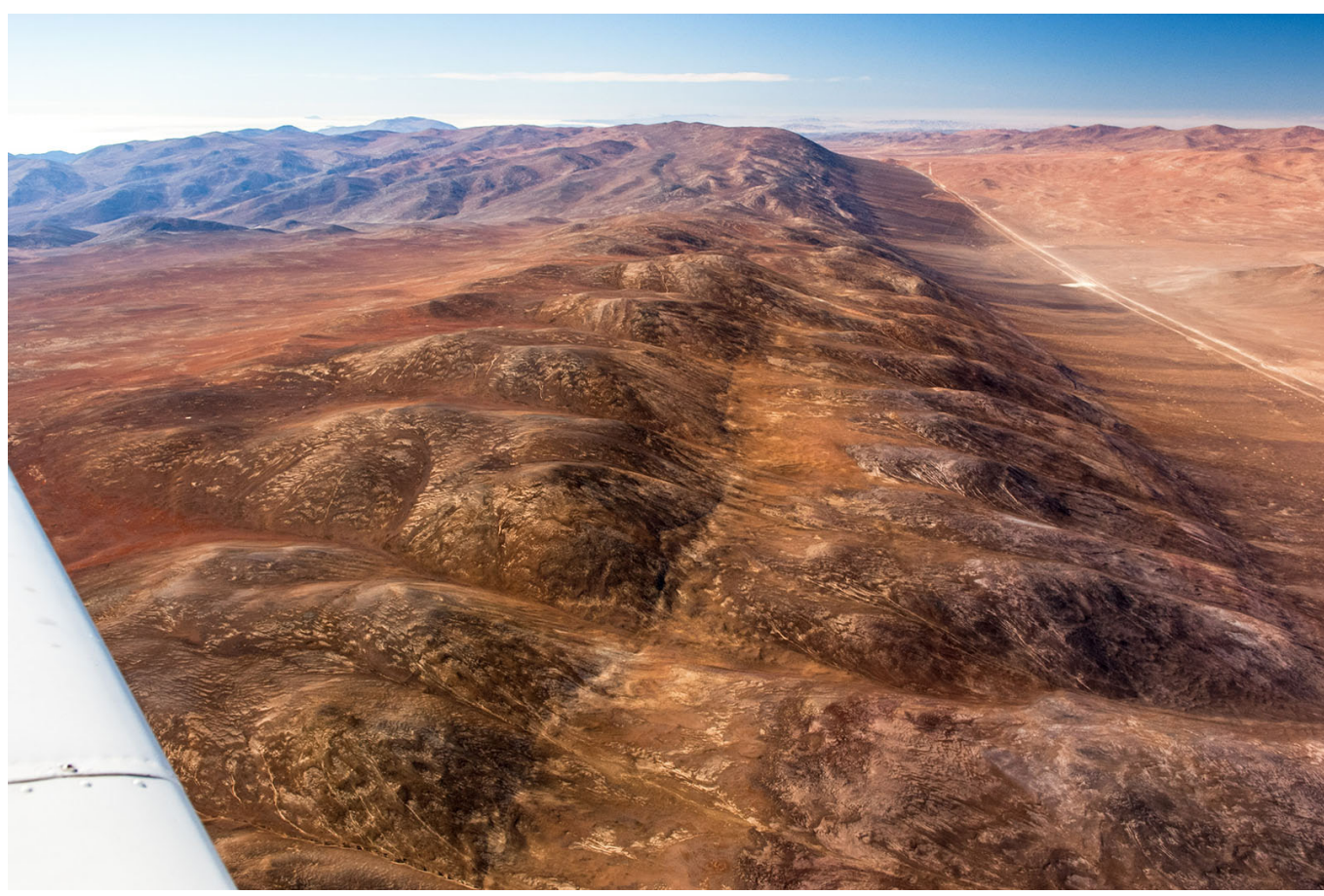

Figura 5 Una falla principal del Sistema de la Falla de Atacama. Sierra Remiendos $\left(24^{\circ} 22^{\prime} \mathrm{S} / 70^{\circ} 22^{\circ}\right.$ O) en la Cordillera de la Costa, Región de Antofagasta. 


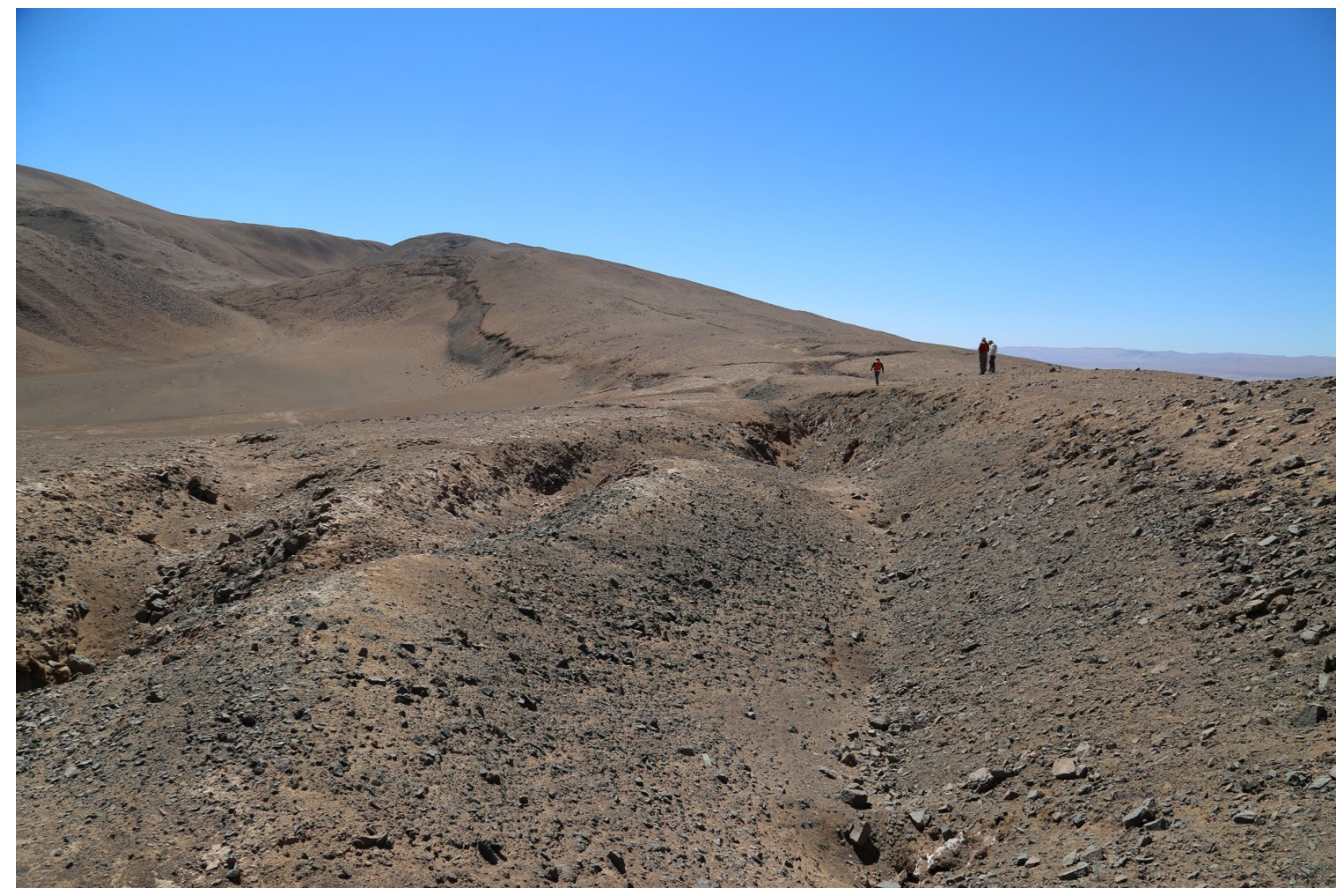

Figura 6 Franja de fallas, del orden de 600 m de ancho, del Sistema de la Falla de Atacama. Borde suroeste del Salar Grande, Cordillera de la Costa, Región de Tarapacá.

cialmente desde la Precordillera y Alta Cordillera. En su parte norte, la Pampa del Tamarugal, tiene un relieve plano, endorreico y muy escasos relieves islas (Figura7). En el sector más septentrional está atravesada por profundas quebradas en sentido E-O y es el nivel de base de profundas quebradas de la Precordillera. Desde aproximadamente los $22^{\circ} 36^{\prime} \mathrm{S}$, presenta numerosas serranías y cerros islas, en partes alineados estructuralmente (Figura 8); rasgo que se acentúa hacia el sur y, desde los $25^{\circ} 24^{\prime} \mathrm{S}$ pierde su identidad, formando parte de un relieve que se eleva, en forma continua desde la Cordillera de la Costa hacia el este. La Depresión Central posee un importante sistema estructural de su basamento principalmente con fallas NS que no está evidenciado debido a la cubierta aluvial.

Precordillera. Es un relieve montañoso (Figura 9) constituido por bloques solevantados tectónicamente, en partes un "horst", como la Cordillera de Domeyko. Alcanza altitudes máximas cercanas a los 5000 m s.n.m. y un ancho del orden de 10 - 15 km. Su límite oeste es la Depresión Central, mientras que el límite este es variable. En su parte norte (Sierra Moreno-Altos de Pica $\left(20^{\circ} 21^{\prime}\right.$ S/68 $\left.68^{\circ} \mathrm{O}\right)$ está directamente unida a la Alta Cordillera, mientras que hacia el sur de los $22^{\circ} 27^{\prime} \mathrm{S}$, su límite oriental corresponde a las Cuencas Preandinas, con los salares de Atacama (23⒉ $\left.23^{\prime} \mathrm{S} / 68^{\circ} 21^{\prime} \mathrm{O}\right)$ y Punta

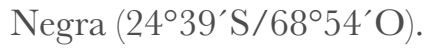

Cuencas Preandinas. Entre la Precordillera y la Alta Cordillera, en la Región de Antofagasta, se reconocen las Cuencas Preandinas. Se trata de cuencas tectónicas que incluyen, en sus partes más bajas, los salares más grandes de Chile, (Atacama y Punta Negra (Figura 10). Su altitud es del orden de 2300 m s.n.m.

Alta Cordillera $(=$ Cordillera Oeste $=$ Altiplano $=$ Andes $=$ Cordillera Principal). Está constituida por un plateau volcánico-sedimentario a unos $4000 \mathrm{~m}$ s.n.m., pendiente regional hacia el oeste denominado Altiplano (Lamb y Hoke, 1997) (Figura 11). Se dispone sobre un basamento Mesozoico-Paleozoico y se le superponen edificios volcánicos del Mioceno - Presente, algunos con altitudes cercanas a los 7000 m, y salares (Figura 12). El Altiplano está mejor representado en la parte central del Norte Grande y desaparece hacia el sur. Hacia el norte, cubre parte de la Precordillera y, en su extremo más septentrional (Arica, 18 $28^{\circ} \mathrm{S} / 70^{\circ} 18^{\prime} \mathrm{O}$ ), prácticamente llega a la costa. 


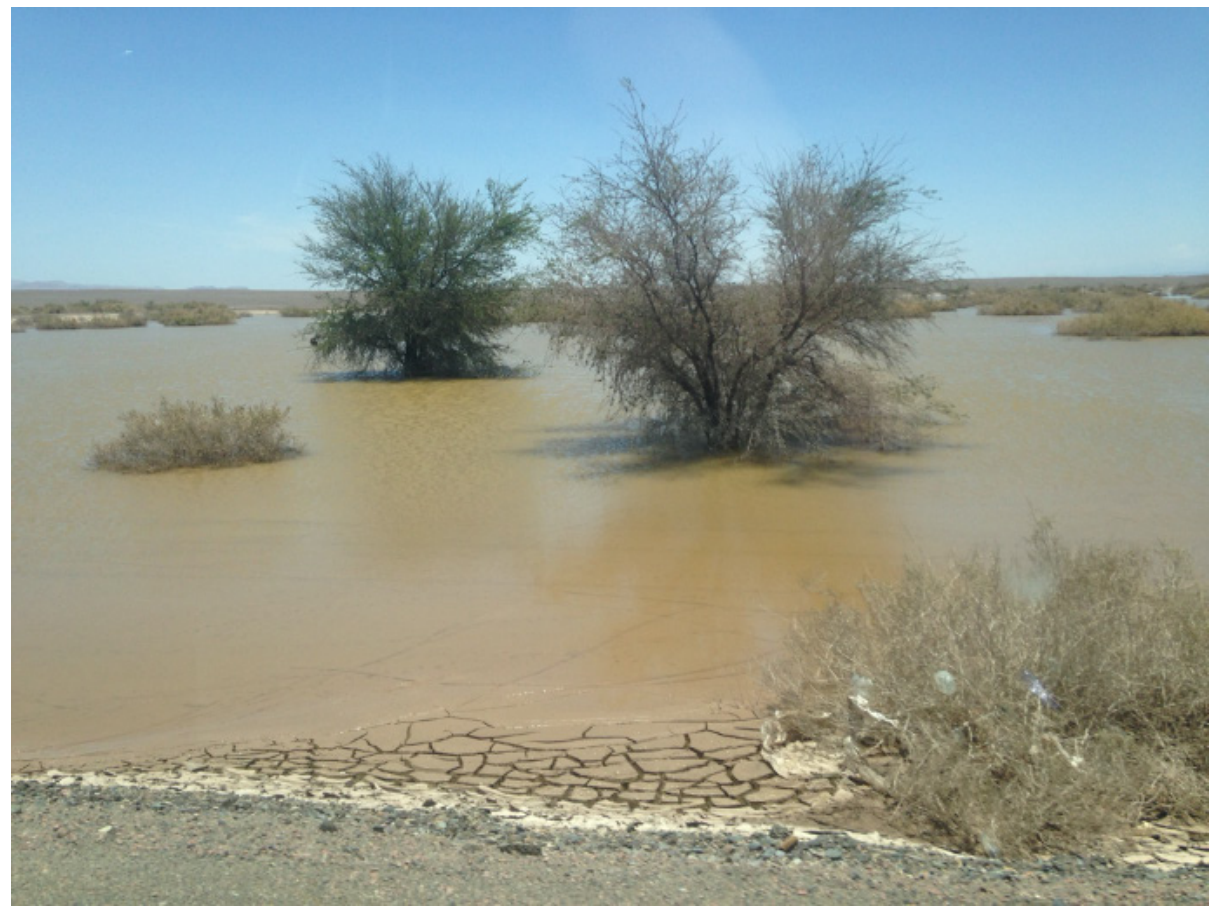

Figura 7 Pampa del Tamarugal, sector de la Cuenca de Llamará $\left(21^{\circ} 23^{\prime} \mathrm{S} / 69^{\circ} 37^{\prime} \mathrm{O}\right)$, parte norte de la Depresión Central. El relieve es plano con pendiente regional hacia el oeste. Se observa inundada por una avenida provocada por aguas Iluvia de precipitaciones excepcionales producidas durante el Ilamado "Invierno Altiplánico" en la Alta Cordillera.

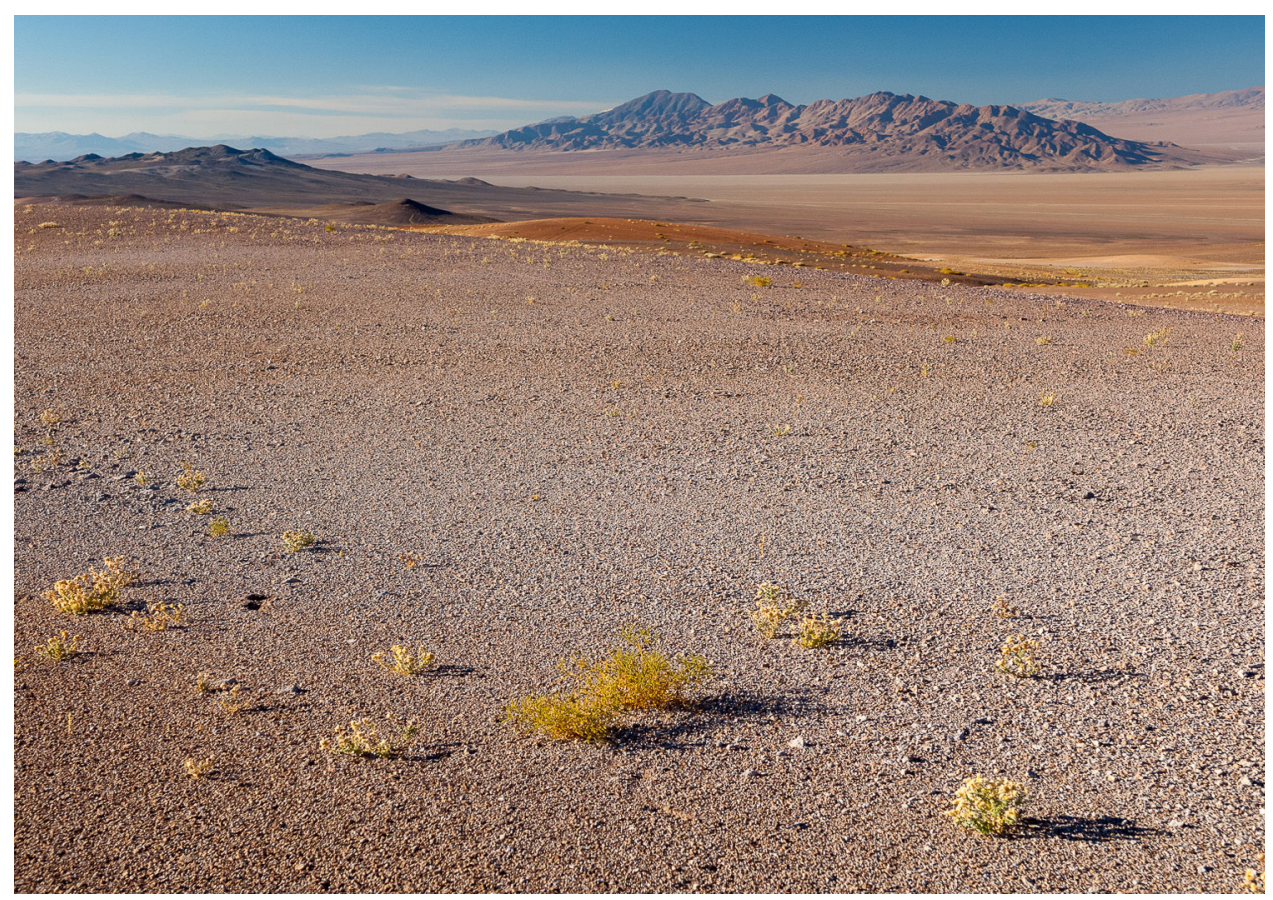

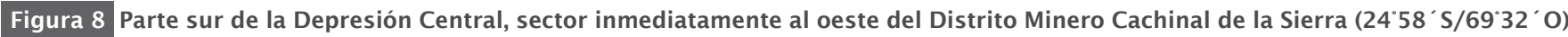
Región de Antofagasta. Se observan relieves islas controlados estructuralmente. Esto contrasta notablemente con la misma unidad morfológica de la Depresión Central en su parte norte. 


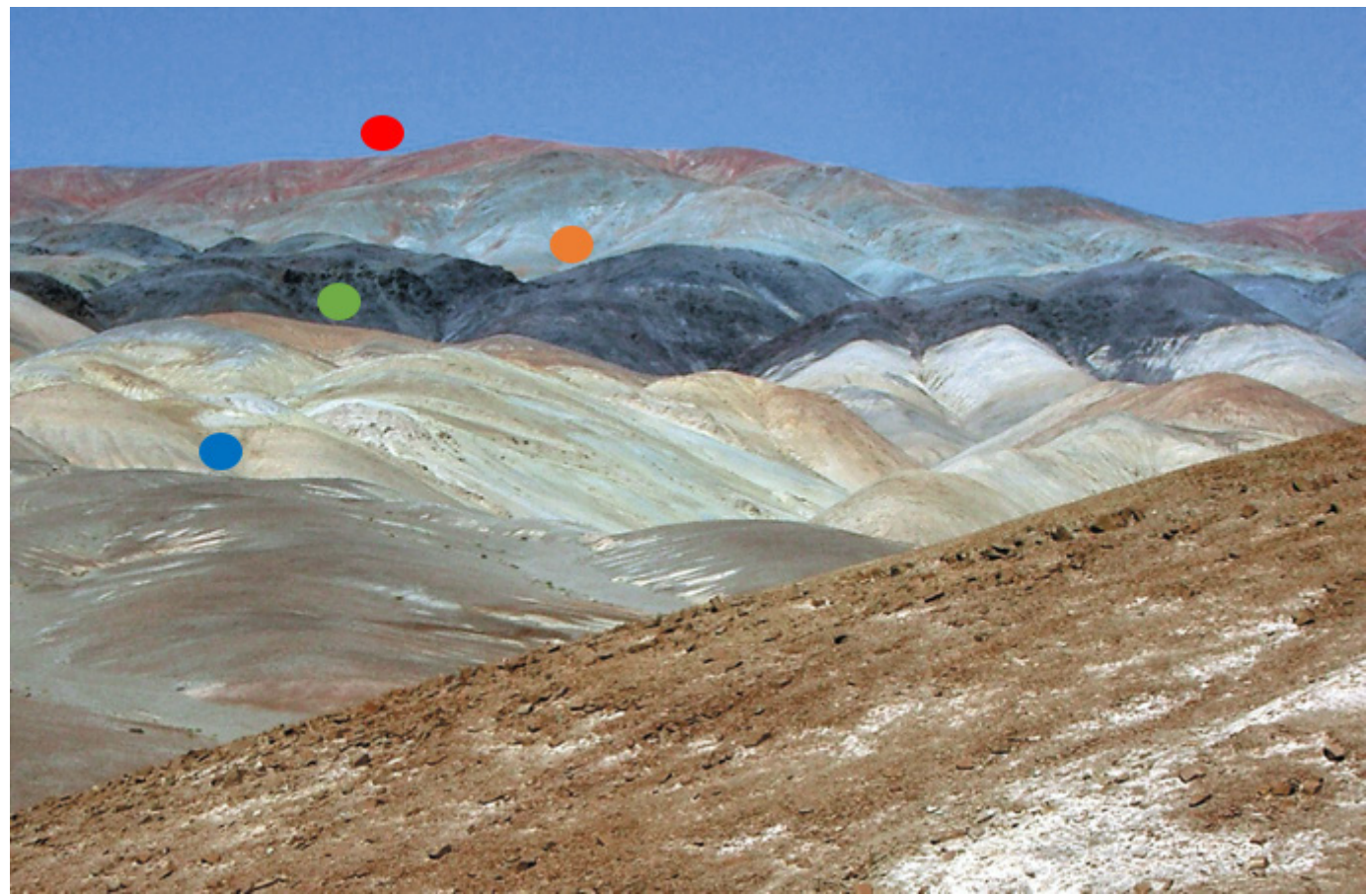

Figura 9 Aspecto de la Precordillera, en este caso la Cordillera de Domeyko, sector de Sierra de Varas (24⒋ 'S/69'09'O), Región de Antofagasta. Se observa la variedad de unidades geológicas y el intenso tectonismo que las afecta. Se trata del flanco oeste de un anticlinorium volcado que, desde arriba muestra granitos paleozoicos (círculo rojo), siguen secuencias marino continentales del Triásico (círculo naranja). luego rocas volcánicas del Triásico (círculo verde) y debajo el Jurásico marino (círculo azul).

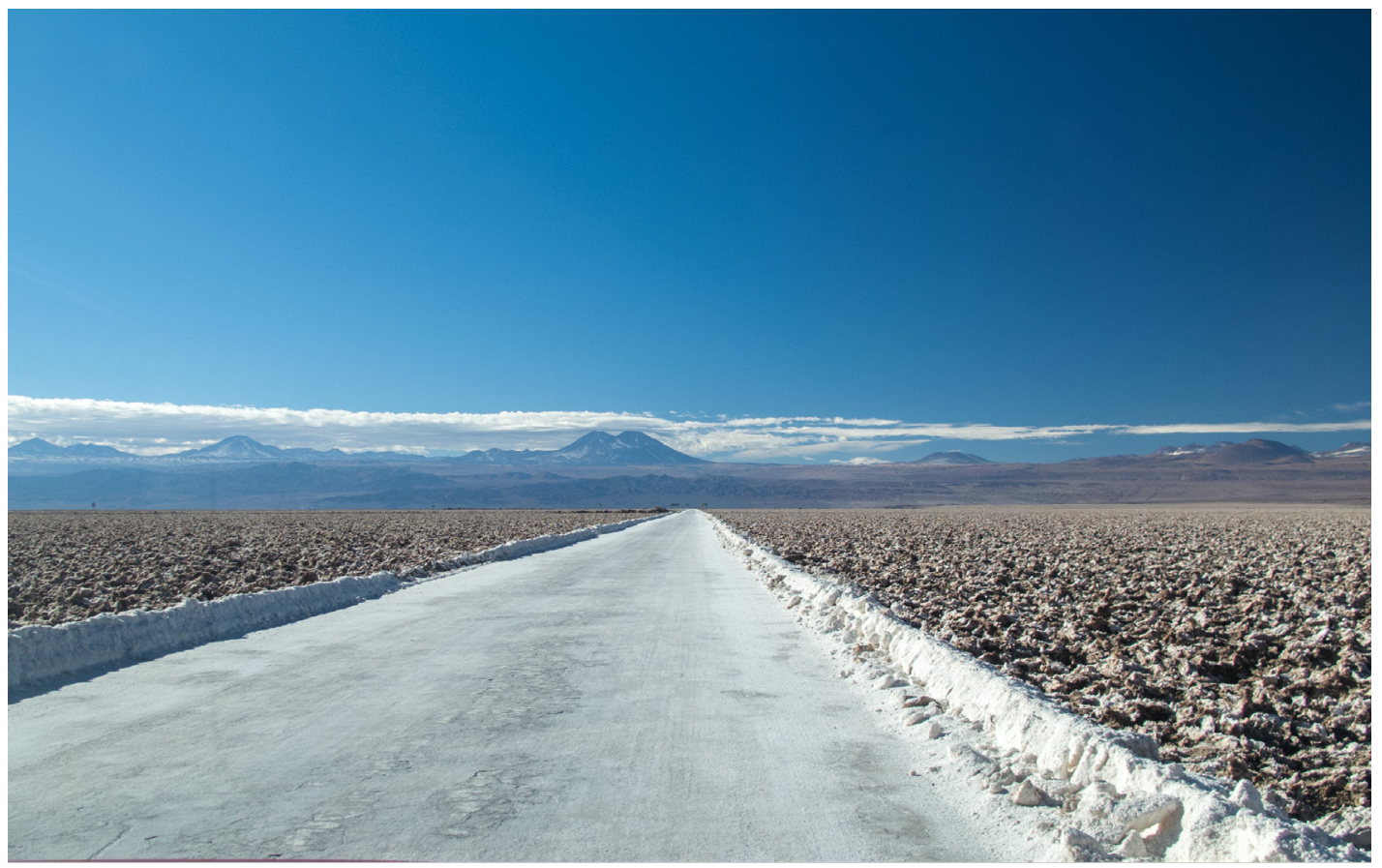

Figura 10 La cuenca Preandina del Salar de Atacama, $\left(23^{\circ} 23^{\prime} \mathrm{S} / 68^{\circ} 21^{\prime}\right.$ O) entre la Alta Cordillera y la Precordillera. Vista hacia el este desde el Núcleo del Salar. 


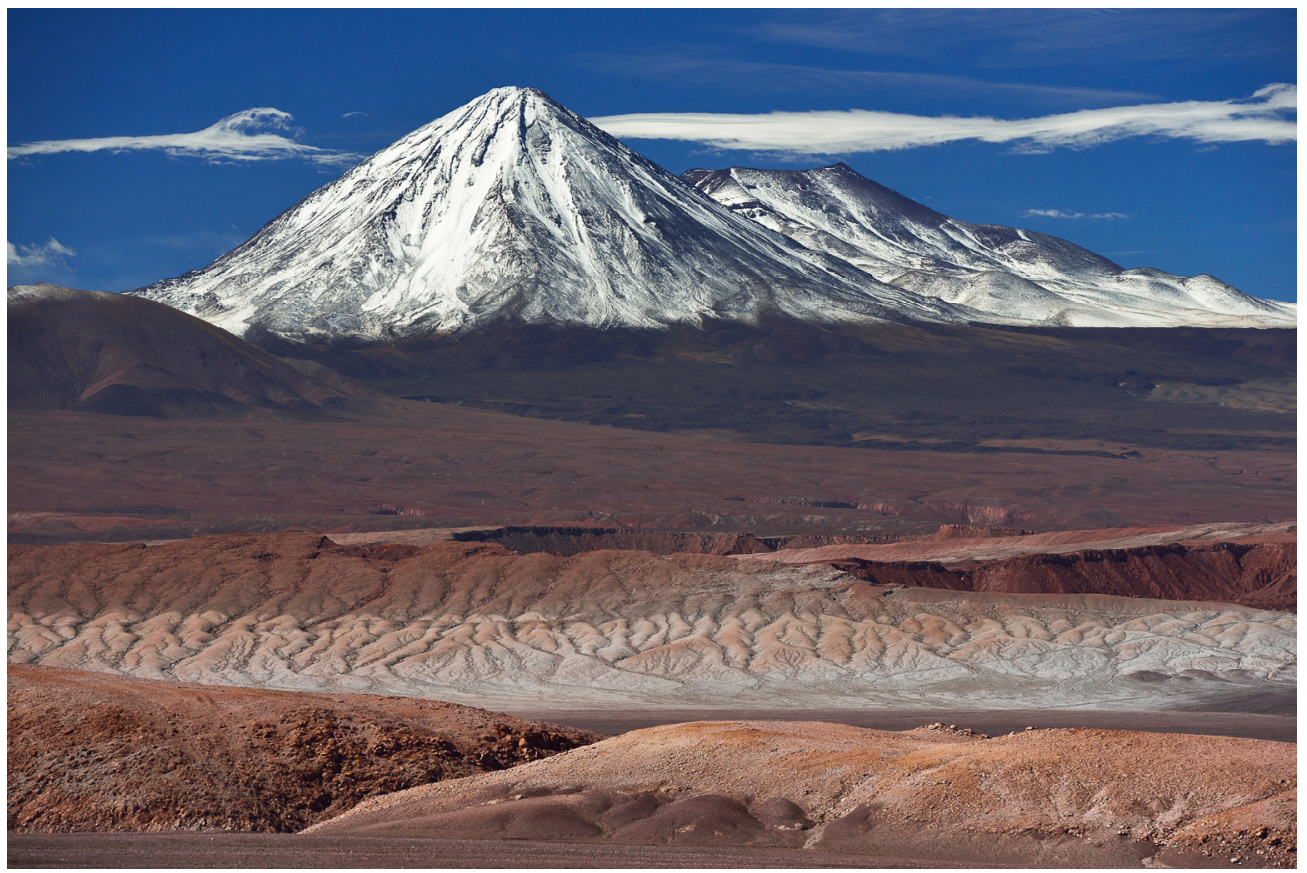

Figura 11 Vista del Altiplano, desde el oeste. Está compuesto por rocas volcánicas ácidas y se le sobreimponen aparatos volcánicos y salares. En este caso se trata del Volcán Licancabur $\left(22^{\circ} 50^{\prime} \mathrm{S} / 67^{\circ} 53^{\circ} \mathrm{O}\right)$.

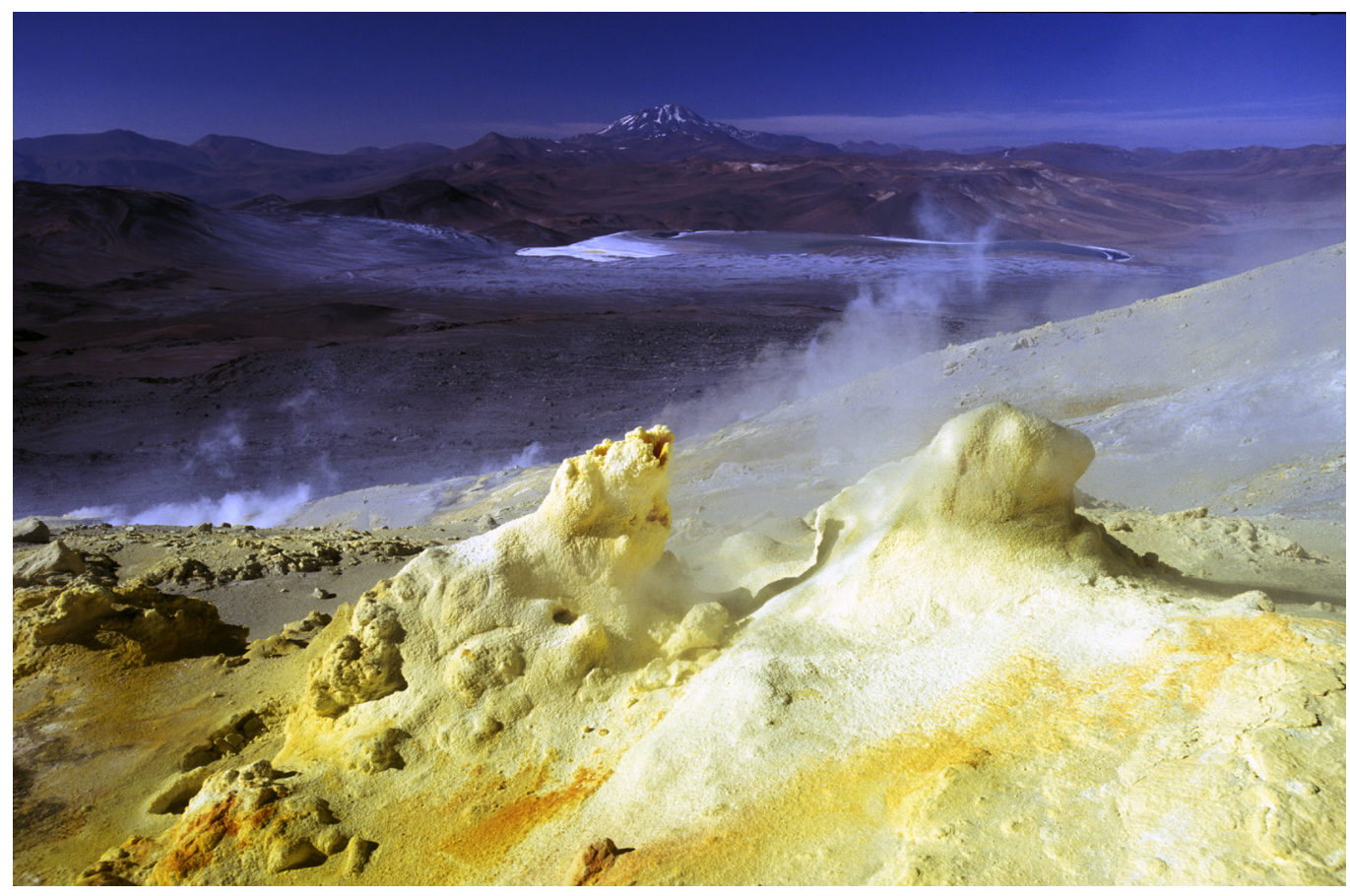

Figura 12 Volcán Lastarria $\left(25^{\circ} 09^{\prime} \mathrm{S} / 68^{\circ} 31^{\circ} \mathrm{O}\right)$. Un volcán activo con fumarolas y sulfataras cuyos productos Ilegan directamente a la cuenca del Salar de Aguas Calientes Sur, un salar tipo Andino que se observa al fondo de la imagen. Estos aportes se transportan por aguas superficiales y subterráneas y tienen como nivel de base el salar. 


\subsection{GLIMA Y PALEOGLIMA}

En la parte oeste de esta macroregión, identificada con el núcleo del Desierto de Atacama, el clima es hiperárido, mientras que hacia el este y sobre los 3000 m s.n.m. es árido (Garreaud et al., 2003; Scanlon et al., 2006). Las precipitaciones varían en forma estacional, interanual e inter-década y se generan en tres fuentes (Garreaud et al., 2009), formando tres zonas climáticas (Houston, 2006): i) la del Océano Pacífico origina precipitaciones, con predominio de nevadas, en invierno (junio a agosto; ii) la que se reconoce en la Cordillera de la Costa, donde nubes bajas, sometidas a la inversión térmica producto del Anticiclón del Pacífico, generan nieblas dinámicas, principalmente en invierno (Cereceda et al., 2002); y iii) la del Atlántico, que origina precipitaciones en el Altiplano predominantemente en verano (Garreaud et al., 2003, 2009). Una cuarta es descrita por Vuille y Keiming,
(2004) y proviene del Gran Chaco, en Argentina, con una zona continental de baja presión que hace que en verano los vientos del este amazónico cambien su dirección hacia el sur, transportando humedad a los sub-trópicos.

En relación a las nieblas dinámicas (también conocidas como "dripping fogs" o "Camanchaca"), son típicas del norte de Chile. Se originan en la liberación del calor absorbido durante el día por el mar, en forma de vapor. Este queda retenido en la costa por el Anticliclón del Pacífico, que le impide subir hasta que es calentado al progresar el día, durante la mañana, Estas nieblas penetran profundamente en el continente durante la mañana y, al aumentar la temperatura, desaparecen rápidamente (Cereceda, 2002) (Figuras 13A y $13 \mathrm{~B})$.

La Camanchaca, formada por minúsculas gotas de agua en suspensión, al tomar contacto con cuerpos que interceptan su paso, se condensan
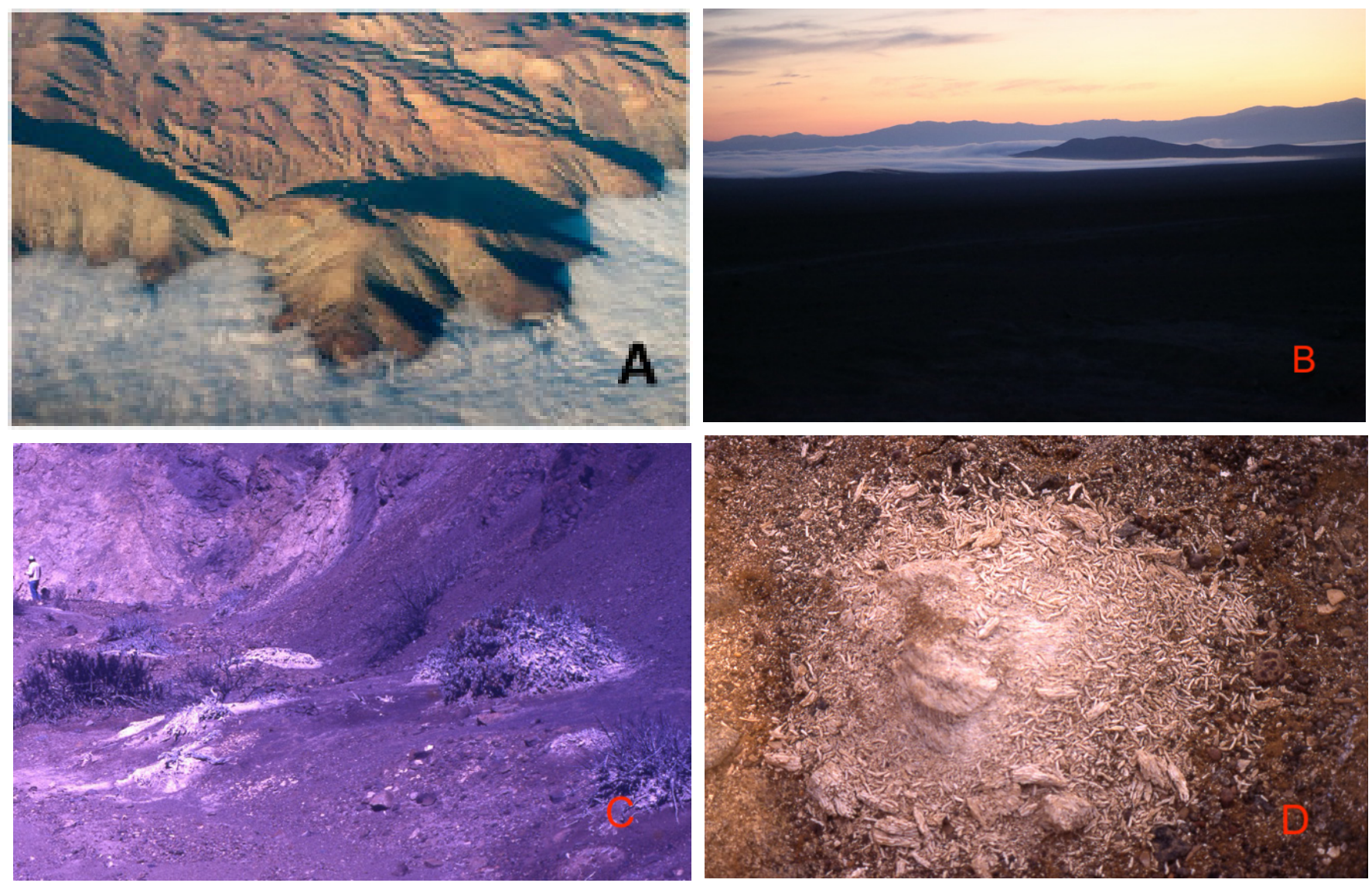

Figura 13 A) Aspecto típico de la Camanchaca en la costa, adosada al acantilado costero, parte occidental de la Cordillera de la Costa. Sector de Paposo ( $25^{\circ} 01^{\prime} \mathrm{S} / 70^{\circ} 28^{\prime}$ O) B) Camanchaca al interior del Desierto cubriendo la localidad de Aguas Blancas - Yungay (24 $10^{\circ}$ 'S/ $69^{\circ} 51^{\prime}$ O). C, D) Vegetacion destruida por el exceso de sal de la Camanchaca. Costa de Taltal. 
y crean comunidades biológicas costeras (Cereceda, 2002). Formada sobre el mar, la Camanchaca se mueve por advección hacia las montañas costeras, estacionándose a lo largo del acantilado costero (Cereceda, 2002) (Figura 13A). Su expansión espacial máxima ocurre en invierno y la mínima, en verano (Cereceda et al., 2008). Sträter et al., (2010) describen el alto contenido de sulfatos muy menor de nitratos y cloruros y con un $\mathrm{pH}$ ácido $(2,5-3,5)$ del agua contenida en estas nieblas, atribuyéndolo a contaminación con el spray marino. Nuestras observaciones corroboran esta contaminación con el reconocimiento de la destrucción de vegetación por exceso de sal en sectores costeros de la Cordillera de la Costa en Taltal $\left(25^{\circ} 24^{\prime} \mathrm{S} / 70^{\circ} 29^{\prime} \mathrm{O}\right)$. (Figuras $13 \mathrm{C}$ y 13D). Este tipo de niebla es responsable de diversos procesos y estructuras asociados a sales en el ambiente desértico.

Desde el punto de vista paleoclimático, numerosos trabajos en las últimas dos décadas se refieren a la evolución climática a lo largo del Cenozoico, (Lamb y Davis, 2003; Geyh et al., 1999; Betancourt et al., 2000; Gregory-Wodzicki, 2000; Grosjean et al., 2001; Rech et al., 2002; Hartley y Chong, 2002; Farías et al., 2005; Garzione et al., 2008; Sáez et al., 2016). Por su parte, Evenstar et al., (2015) hacen una revisión de numerosas publicaciones referidas al tema y resumen conclusiones de estos sobre cambios climáticos durante el Cenozoico desde el Oligoceno. Los trabajos se basan en el solevantamiento de los Andes, en estudios geoquímicos, mineralógicos y de enriquecimiento de yacimientos o en cambios geomorfológicos y biológicos. Hay coincidencia en que el Desierto de Atacama actual es, sino el más seco, uno de los más secos del planeta (Camara et al., 2014). No hay consenso en los criterios para establecer los límites entre el núcleo desértico hiperárido del oeste con la zona árida de mayor altitud, como tampoco sobre las razones de la transición de condiciones áridas a hiperáridas.

Considerando la estabilidad latitudinal de esta macroregión durante los últimos $150 \mathrm{Ma}$ (Hartley y Chong, 2002; Keller et al., 1997), se postula, como hipótesis de trabajo, que las condiciones áridas/semiáridas han prevalecido en el Desierto de Atacama, al menos desde el Oligoceno temprano (Hartley, 2003), e incluso desde el Cretácico tardío
(Hartley et al., 2005). Estudios de la mineralización supérgena, procesos de erosión y pedogénesis (Alpers y Brimhall, 1988; Sillitoe y McKee, 1996; Rech et al., 2006), sugieren que el Desierto de Atacama experimentó una marcada disminución de las precipitaciones entre 19 y $13 \mathrm{Ma}$. Tosdal et al. (1984), García y Herail (2005), Farías et al. (2005) y Riquelme et al. (2007) mencionan que la sedimentación, en diferentes lugares del piedemonte del Desierto de Atacama, disminuyó fuertemente a los $8 \mathrm{Ma}$, lo que marcaría reducción de la lluvia. Hartley y Chong (2002) y Hartley (2003) analizaron los sedimentos y la estratigrafía neógena en la Depresión Central para inferir un inicio mucho más reciente de hiperaridez, entre 6 y 3 Ma. Reich et al. (2009) analizaron el enriquecimiento supergénico de los depósitos de cobre en la Precordillera y en la costa $\left(23^{\circ} \mathrm{S}\right)$, y sugieren un inicio de la hiperaridez aproximadamente hace 1.5 Ma. Se propone un enfriamiento de la superficie del mar durante el Plioceno en la costa del Norte de Chile y sur del Perú conectada con una tendencia de enfriamiento global, desde el Mioceno medio hasta el Presente (Kennett, 1977; Zachos et al., 2001). Federov et al. (2006) y Ravelo et al. (2004) consideran condiciones cálidas permanentes por la acción de El Niño en el Pacífico tropical hace unos 3 Ma. Valero et al. (1996, 1999, 2003) reconocen ciclos de mayor humedad en la formación de la sedimentación lacustre del Holoceno en la Alta Cordillera en las lagunas de Miscanti $\left(23^{\circ} \mathrm{S}\right)$ y Negro Francisco $\left(27^{\circ} \mathrm{S}\right)$. Latorre et al. (2006) y Sáez et al. (2016) evidencian al menos tres períodos regionales de mayor humedad durante la parte más tardía del Pleistoceno.

Considerando las conclusiones descritas y observaciones propias del registro estratigráfico, en este trabajo se considera la hipótesis de que, durante el Cenozoico, el Norte de Chile ha mantenido condiciones climáticas similares a las actuales, con ciclos continuos de hiperaridez/aridez intercalados con otros de períodos más húmedos. Estos ciclos incluirían microciclos (miles de años) que incluso pueden comprobarse por sus efectos sobre antiguas poblaciones humanas. Algunos de los argumentos que manejamos es la presencia, en el registro estratigráfico, de numerosos paleo- 
lagos y sistemas fluviales presentes desde el límite Cretácico Paleoceno hasta hoy en el Desierto de Atacama (Figura 14), algunos de los cuales incluyen cambios de facies desde lagos a salares (Figura 15). También se reconocen: i) paleosistemas fluviales de alta energía; ii) discordancias producto del arrasamiento de sistemas volcánicos del Paleógeno por avenidas torrenciales; iii) suelos "activos" por la acción combinada de agua y sales; iv) sistemas de fallas que transportaron agua y salmueras; y v) conservación de algunos rasgos geomorfológicos y de rocas por decenas de millones de años como calderas, cráteres, vidrios volcánicos y campos geotermales del Paleógeno.

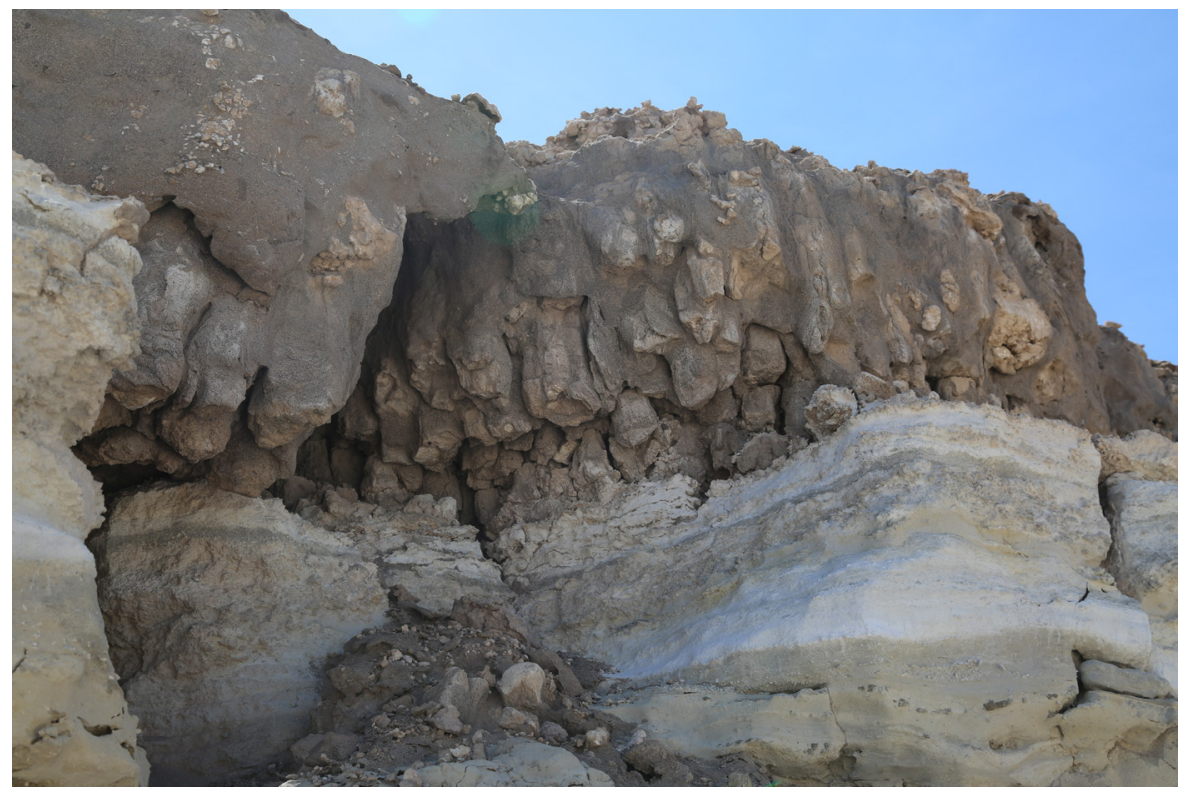

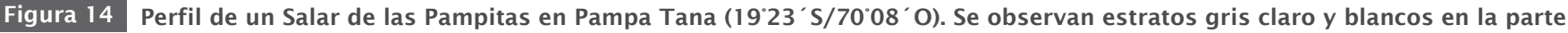
inferior que corresponden a margas y diatomitas que evidencian la presencia de un paleolago. Sobreyacen costras de yeso/cloruro de sodio con profundas grietas de desecamiento con un límite muy bien definido que marca el desecamiento y transición de lago a salar.

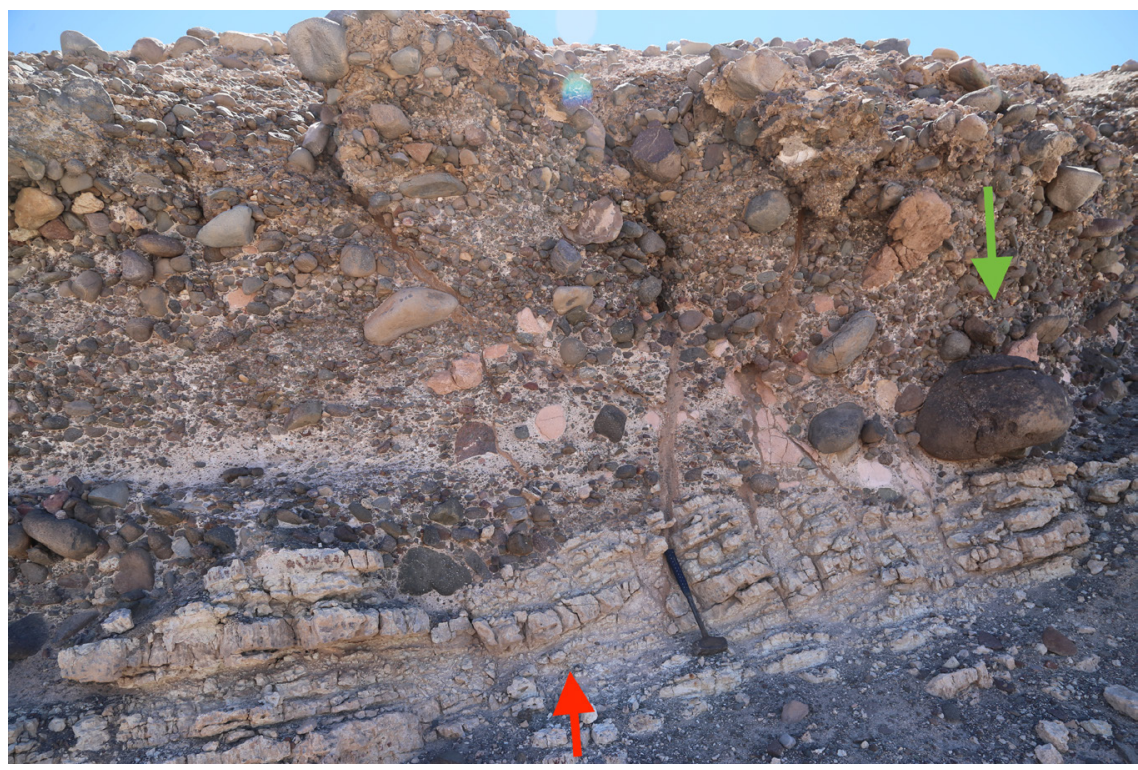

Figura 15 Perfil en un sector al oeste de Cerro Birrete $\left(23^{\circ} 01^{\prime} \mathrm{S} / 69^{\circ} 40^{\prime} \mathrm{O}\right)$. En la base se reconoce una caliza lacustre blanca con ostrácodos (flecha roja) evidenciando el desarrollo de un paleolago. Sobreyacen sedimentitas de un ambiente fluvial de alta energía con clastos imbricados (flecha verde). La edad de esta secuencia se ubica prácticamente en el límite Cretácico - Paleógeno. 


\section{La presencia de las sales en el Dominio Salino}

\subsection{GENERALIDADES}

El "Dominio Salino del Norte de Chile" incluye la presencia de una variedad de sales en la superficie y subsuperficie del ambiente hiperárido del Desierto de Atacama y la región árida a semi-árida de la Precordillera y Alta Cordillera. El concepto también se refiere a la formación de estructuras salinas. Parte de lo que se describe no aparece registrado en la literatura geológica y, consecuentemente, algunos de los nombres asignados son tentativos, provisorios y discutibles.

Las sales en esta región presentan un alto dinamismo. Se transportan por la acción del viento o en solución, ya sea superficialmente en ríos o en avenidas ocasionales de ambientes desérticos, en aguas subterráneas, o a lo largo de fallas. Se condensan a partir de la Camanchaca, cristalizan y recristalizan en fracturas, o se depositan por capilaridad y evaporación (Figuras 16A a 16C). En el largo plazo su estabilidad depende de los cambios climáticos.

Risacher y Fritz (2009) mencionan la posibilidad de removilización de sales del Cenozoico provenientes de salares sepultados por actividad volcánica. Rech et al., (2006) agregan datos isotópicos para el origen del Ca y S del yeso, la sal más abundante en estos ambientes, que comprobarían localmente la movilidad del spray marino. Spiro y Chong (1996) aportan datos isotópicos que prueban un origen volcánico para los sulfatos del Salar de Atacama y de la Cordillera de la Sal. Carmona et al., (2000) estudiaron la composición isotópica de sulfatos en sondajes del Salar de Atacama y analizaron los aportes hídricos superficiales. Además, establecieron que las razones de ${ }^{87} \mathrm{Sr} /{ }^{86} \mathrm{Sr}$ y las composiciones de $\mathrm{S}$
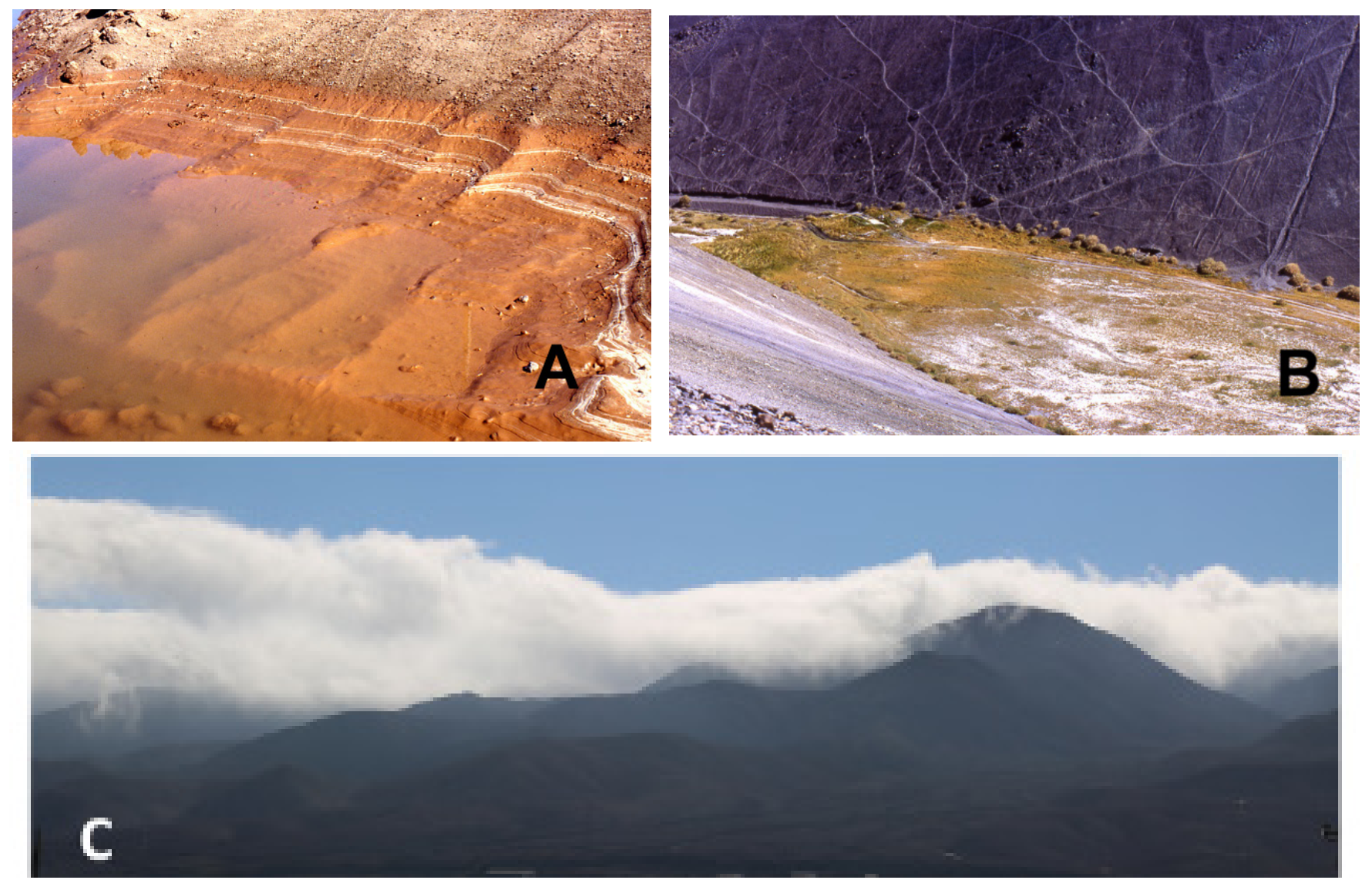

Figura 16 A) Horizontes salinos depositándose en aguas de lluvias en el Desierto de Atacama. (Aluvión de 1991 en la Región de Antofagasta). B) "Vega" en la Precordllera cuya recarga proviene de la zona volcánica de la Alta Cordillera. Las sales, que afloran destruyendo la vegetación, provienen por capilaridad del nivel freático somero. C) Nieblas dinámicas incluyendo contaminación con el spray marino sobrepasando la Cordillera de la Costa e internándose en el desierto. 
y O de los sulfatos sugieren una fuente volcánica e hidrotermal desde el norte y este, y otra diferente para los aportes del sur y oeste.

Todos estos procesos concentran sales en los suelos, en cuencas endorreicas como los salares y lagos salinos, en las aguas subterráneas, en secuencias sedimentarias y yacimientos, y generan distintas estructuras salinas. También se asume que la ausencia significativa de dunas en el Desierto de Atacama obedece al hecho de que una cantidad importante de los sedimentos finos están cementados por sal.

\subsection{SUELOS SALINOS}

Un suelo ampliamente distribuido en el ambiente hiperárido del Desierto de Atacama y en parte del sector Precordillera/Alta Cordillera es el "panqueque" o "chuca", nombres locales de la nomenclatura artesanal usada en la Industria del Salitre. Este suelo se ajusta adecuadamente a la descripción de un gypsisol: "cualquier paleosuelo enterrado que tiene, como su característica más prominente, yeso o anhidrita pedogénica como un horizonte superficial o subsuperficial"; (Glossary of Geology, 2011). Corresponde a capas compactas localmente friables o extremadamente compactas, de potencias que varían desde 0.5 hasta cerca de $2.0 \mathrm{~m}$, formadas por material detrítico fino con cemento salino compuesto mayoritariamente por yeso/anhidrita y subordinadamente cloruro de sodio. Como minerales de presencia muy secundaria se reconocen glauberita, ulexita y alunita, así como trazas de mirabilita, basanita, kieserita, starkeyita, loweita, bloedita, probertita, darapskita y humberstonita. En su zona de eluviación, se puede transformar, por meteorización, en un polvo muy fino que es descrito como "chuca".

En el caso del Desierto de Atacama, este tipo de suelos se distribuyen prácticamente en toda su extensión independiente de la topografía, toda vez que se forman sobre la totalidad del relieve. incluyendo cumbres y laderas de los cerros (Figura 17). Se presenta de varias maneras, Aflora como un horizonte superficial homogéneo, ocasionalmente con grietas de desecación y pequeñas cuencas donde se forman costras de cloruro de sodio (Figura18). En otros casos

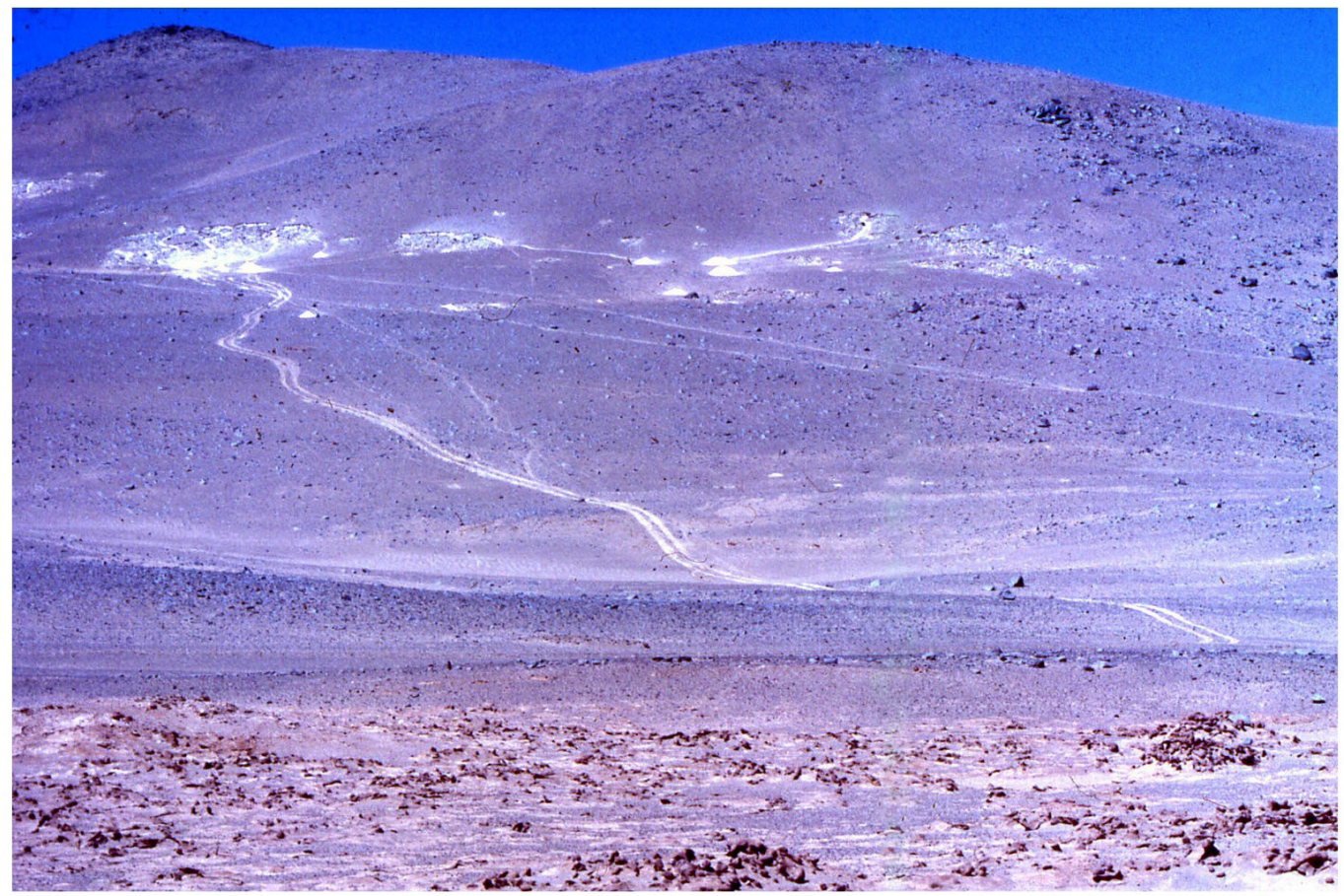


corresponde a un horizonte subsuperficial, duro y compacto, cubierto solo por centímetros de sedimentos aluviales (Figura 19). En estos casos, el gypsisol suele presentar, en su base horizontes de sales como tenardita y mirabilita con espesores de hasta $30 \mathrm{~cm}$, distribución lateral de cientos de $\mathrm{m}^{2}$ y estructuras de tepee (Figura 20). En un solo caso, Cerros de la Joya $\left(21^{\circ} 51^{\prime} \mathrm{S}-69^{\circ} 23^{\prime} \mathrm{W}\right)$, con características idénticas, estos horizontes son exclusivamente de ulexita pura.

Lo más común que se observa es que, desde la superficie, aparece un regolito de litología homogénea, que corresponde a la roca del basamento subyacente. Solo algunos centímetros por debajo de este regolito aparece el gypsisol, localmente friable, que penetra la roca del basamento hasta varios metros de profundidad, destruyéndola físicamente y se desconoce si está asociada a alguna actividad química. Esto hace que los clastos de la roca del basamento aparezcan como flotando sobre el horizonte salino (Figuras 21 y 22). Finalmente, en los cerros de la costa y en quebradas que desembocan en el mar, se reconoce una cubierta sedimentaria, también como un gypsisol, como por ejemplo, en los casos de Coloso $\left(23^{\circ} 45^{\prime} \mathrm{S} / 70^{\circ} 27^{\prime} \mathrm{O}\right)$ y Patache $\left(20^{\circ} 48^{\prime} \mathrm{S} / 70^{\circ} 11^{\prime} \mathrm{O}\right)$ (Figura 23). En este caso se asume un origen marino de las sales y datos isotópicos de $\mathrm{S}$ y $\mathrm{O}$, como lo comprueban Rech et al., (2006). A su vez, la isotopía de $\mathrm{S}$ y $\mathrm{O}$ indica un origen volcánico para sulfatos descritos de la base de los gypsisols (Barraza, 2006). No se conoce información sobre la edad de los gypsisols y se les asume una edad pliocena-pleistocena

Tenardita y mirabilita asociadas a estos suelos fueron explotadas intensamente hasta hace unos 25-30 años atrás. La actividad se abandonó por falta de demanda y debido al antieconómico método de extracción, toda vez que éste era manual. Los boratos de Cerro de La Joya también fueron abandonados por razones similares.

Otras manifestaciones salinas superficiales en el núcleo hiperárido del Desierto de Atacama corresponden a concentraciones de sulfatos en la base de clastos en la superficie, asociaciones de sales y material eólico meteorizando clastos superficiales, sales en grietas destruyendo afloramientos en superficie y remanentes del basamento intensamente meteorizados por sales.

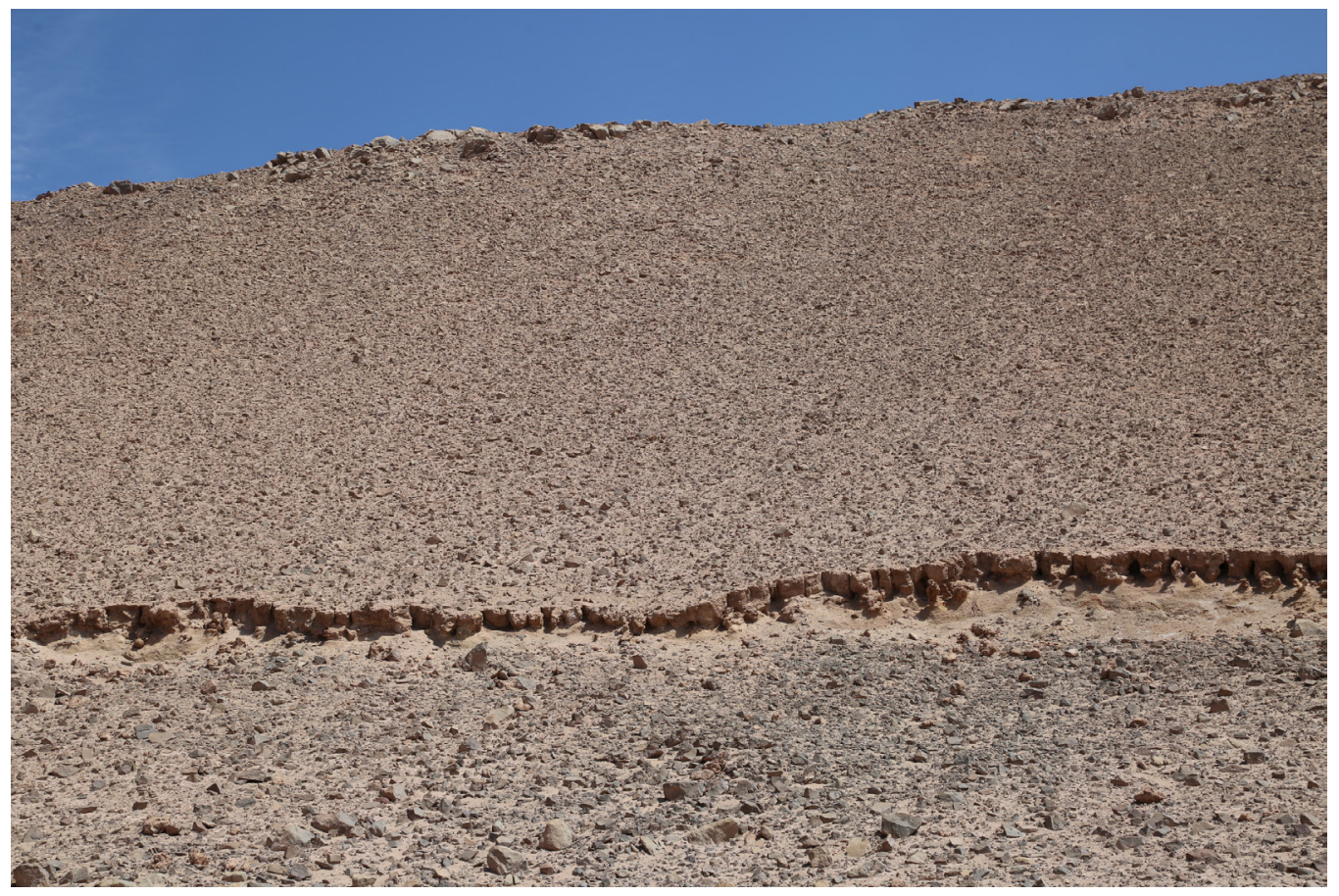




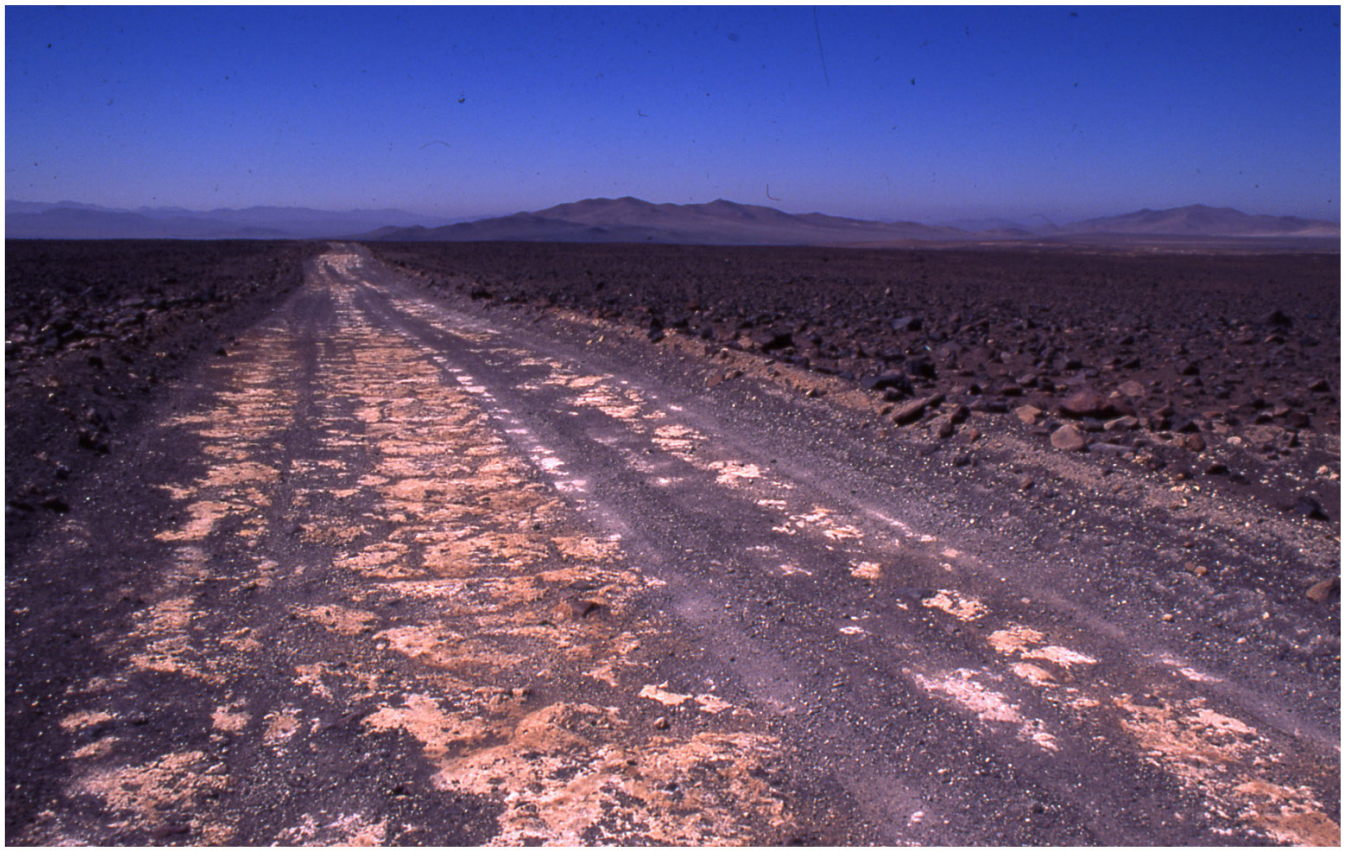

Figura 19 Cubierta de material detrítico e inmediatamente debajo el gypsisol muy compacto y duro.

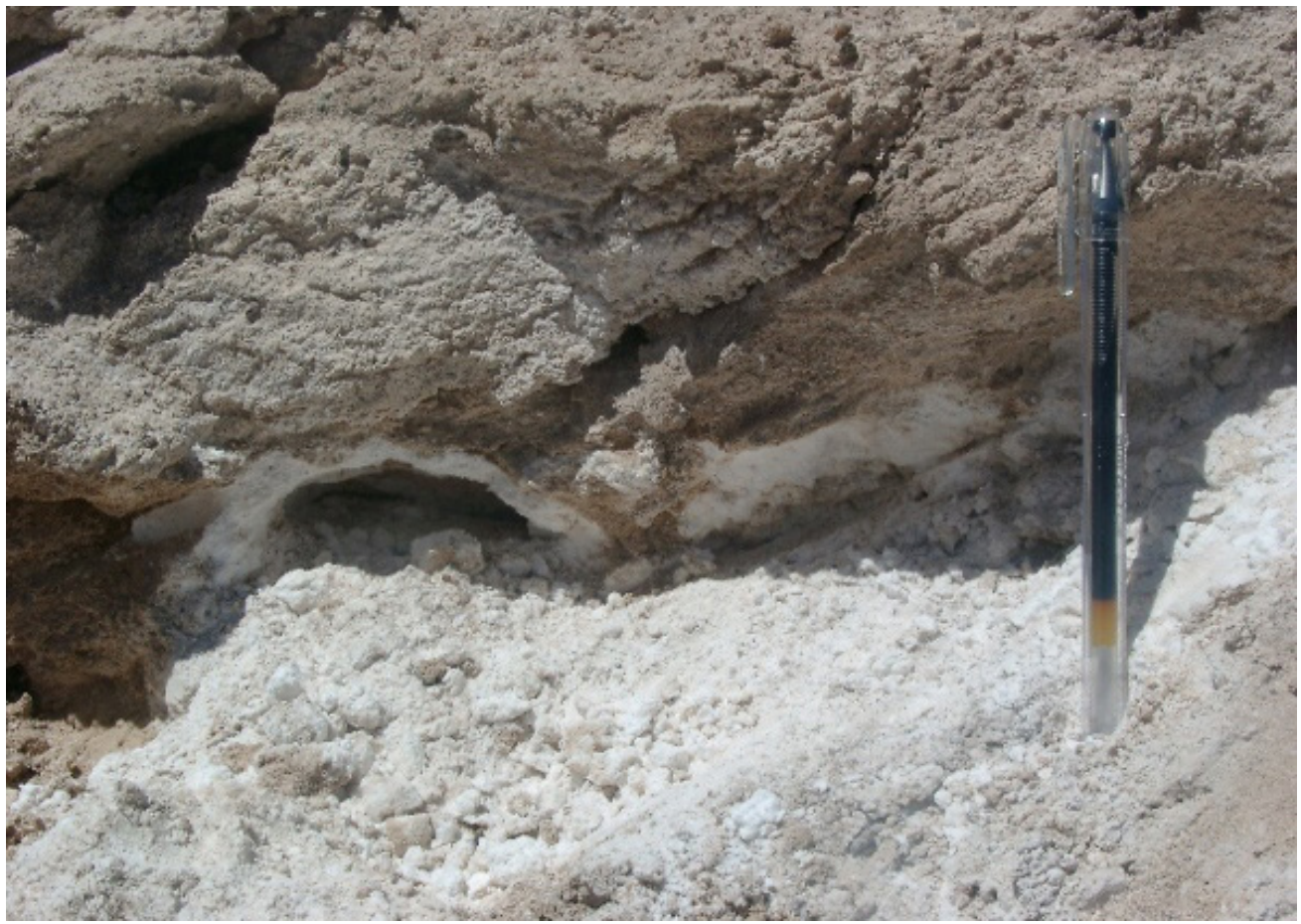




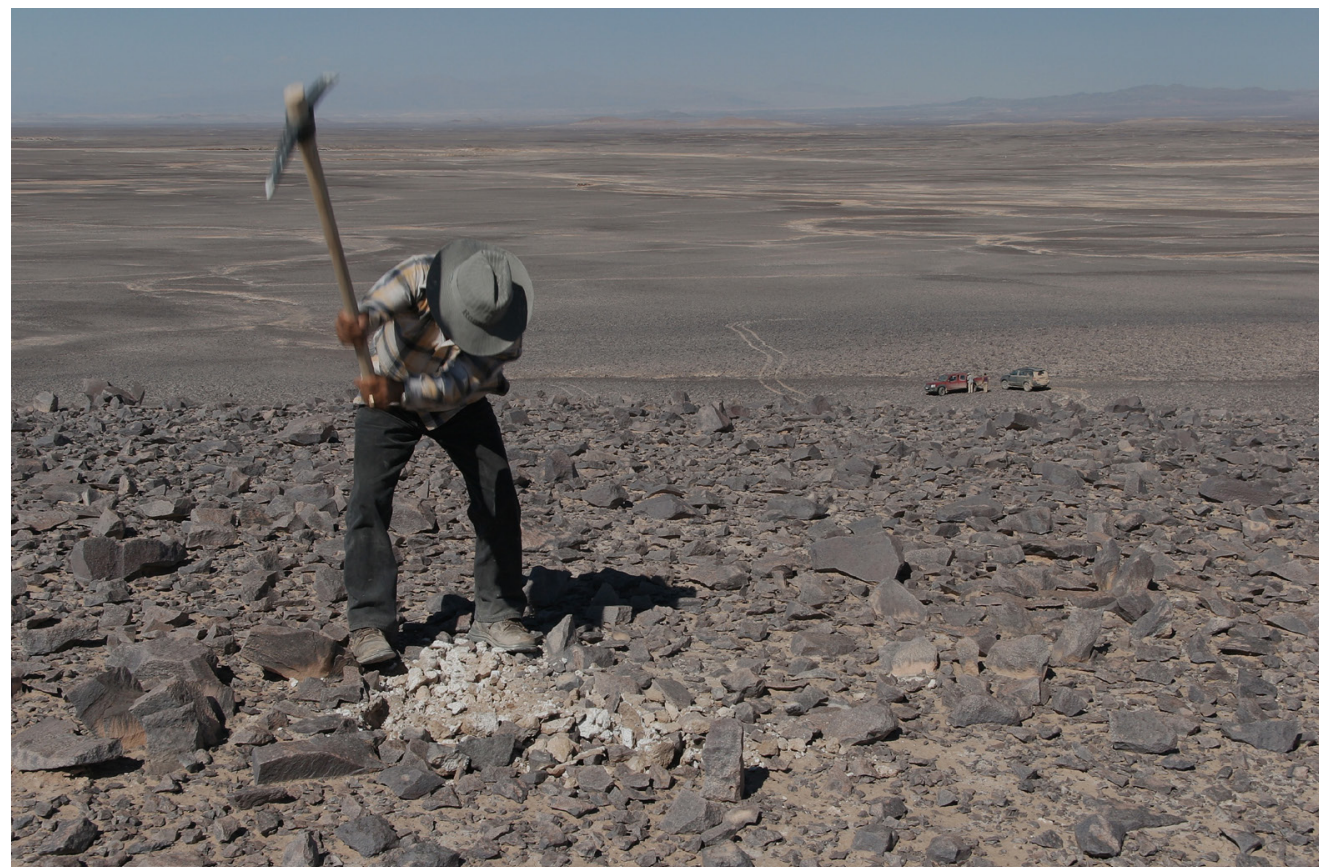

Figura 21 Zona superficial en un suelo gypsisol del Desierto de Atacama. Es una cubierta homogénea de clastos del basamento, pero se observa que, inmediatamente debajo, aparece el gypsisol.

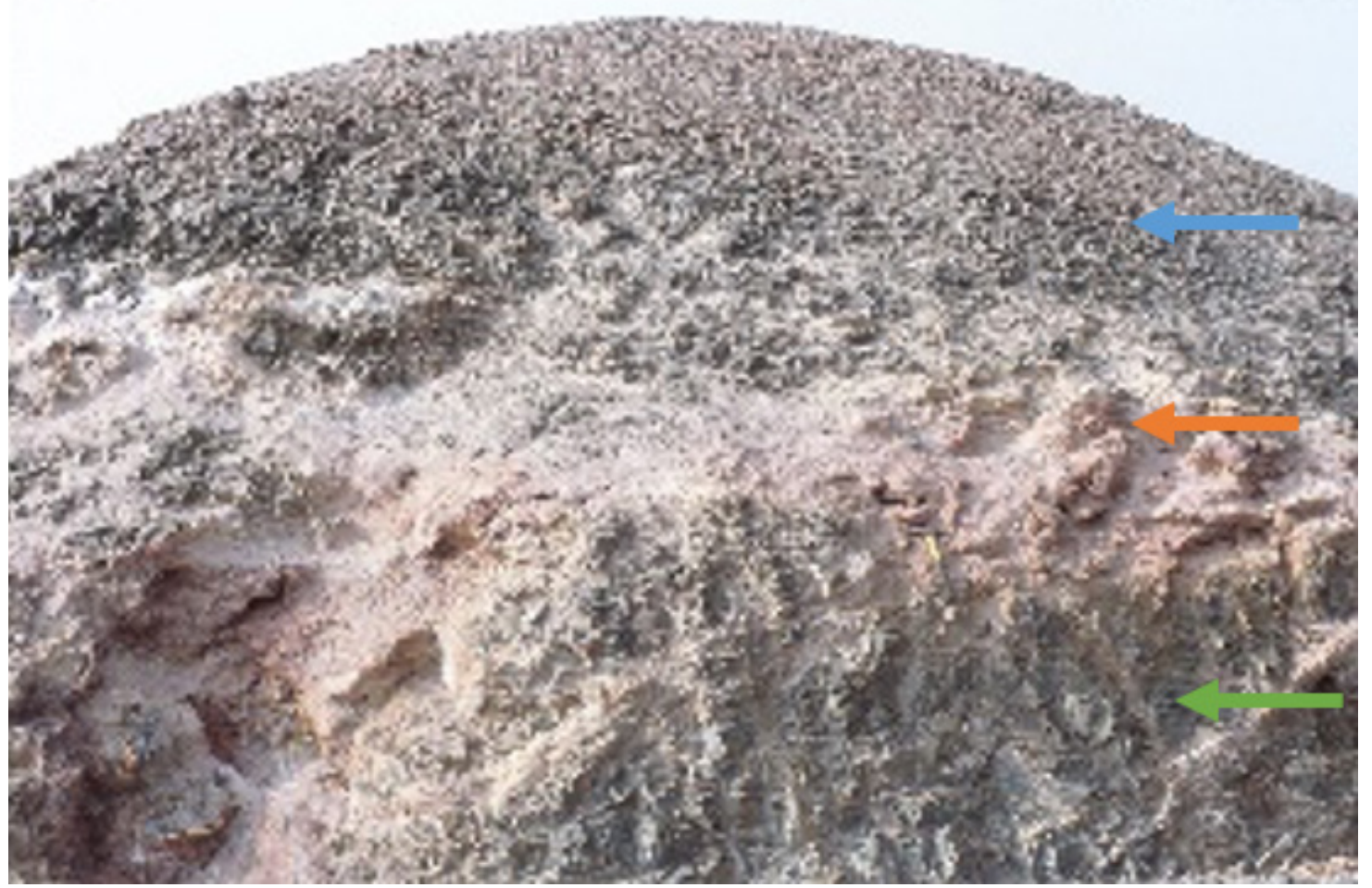

Figura 22 Perfil que muestra la zona superficial homogénea de clastos del basamento. Inmediatamente debajo un horizonte irregular de yeso/anhidrita que penetra y destruye varios metros de la roca del basamento. Los clastos superficiales aparecen "flotando" encima del gypsisol. 


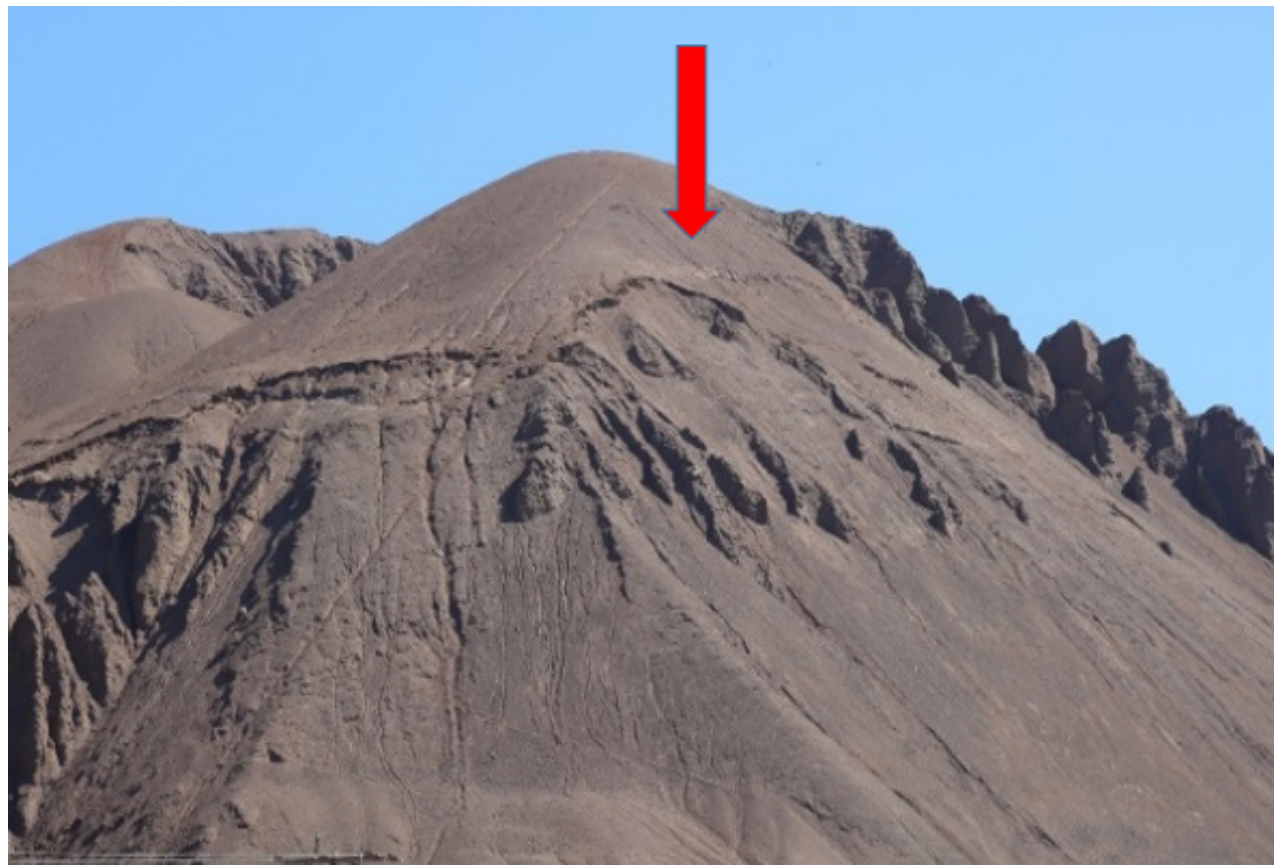

Figura 23 Cubierta sedimentaria con abundante yeso en los cerros próximos a la costa inmediata en la vertiente oeste de la Cordillera de la Costa. Sector de Coloso ( $\left.23^{\circ} 45^{\prime} \mathrm{S} / 70^{\circ} 27^{\prime} \mathrm{O}\right)$.
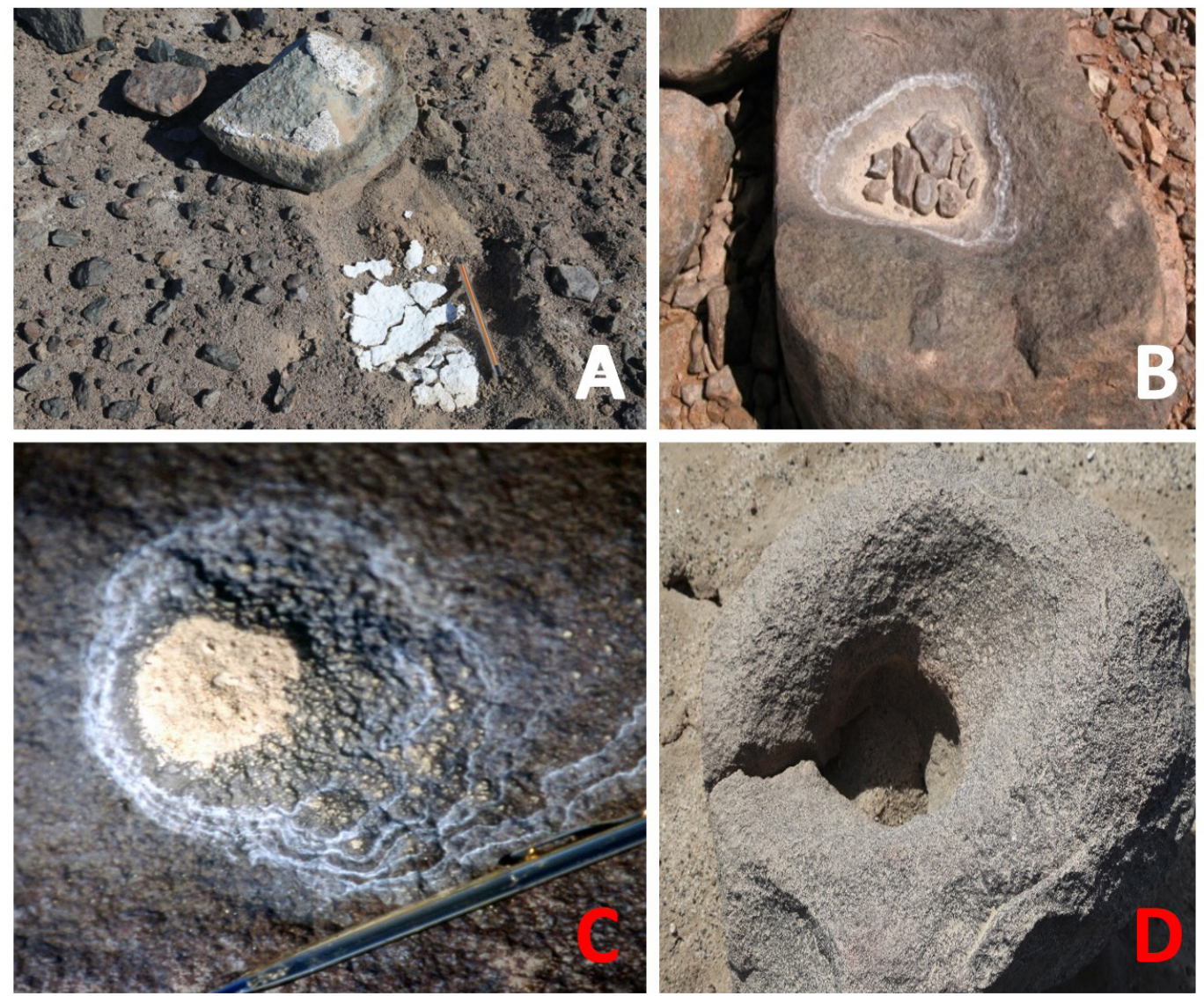

Figura 24 A) Clastos parcialmente cubiertos por sales. Debajo de ellos concentración de sales acumuladas por gravedad, transportada por aguas de Camanchaca. B, C,D) Sulfatos depositados en cavidad de una roca por acción de la Camanchaca. Las aureolas blancas muestran el nivel que ocuparon soluciones sucesivas. En la cavidad, material detrítico derivado de la destrucción de la misma roca y otros acumulados por el viento. Se asume que el viento hace girar estos detritos y produce un efecto mecánico abrasivo que sigue perforando la roca hasta atravesarla totalmente. 
En el caso de acumulación de sulfatos en la base de clastos en la superficie, se interpreta que estos se depositan por acción del viento y de la Camanchaca, condensándose sobre los clastos calentados durante el día. Los pequeños flujos de agua salina los disolverían y, por gravedad, se desplazarían por los bordes de los clastos y concentrarían, por evaporación, las sales bajo ellos (Figura 24A).

En otros casos, las sales se acumulan en las irregularidades de la superficie de las rocas y, por efectos combinados de la acción del viento, agua de las camanchacas redepositada a través del tiempo y probables reacciones químicas, como la acción de ácidos débiles u otras sales, por ejemplo $\mathrm{H}_{2} \mathrm{CO}_{3}$ generado en lluvias esporádicas, ejercen actividad química meteórica sobre la roca. Paralelamente, el viento actúa sobre el material detrítico en las cavidades, el cual, al girar produce una erosión abrasiva mecánica en la roca. Debido a estos procesos, las cavidades se profundizan hasta perforar totalmente la roca (Figuras 24A a 24D).

Otro caso es el conocido mecanismo de cristalización y recristalización de sales por la acción del agua y por los cambios de temperatura en las grietas de las rocas, lo que las fragmenta y destruye (Figuras 25A a la 25C). Finalmente, como se ha descrito, la acción de los gypsisols genera la destrucción mecánica de rocas del basamento. Cuando el viento va denudando los gypsysols, quedan expuestas estas rocas destruidas. (Figuras $26 \mathrm{~A}$ y $26 \mathrm{~B})$.
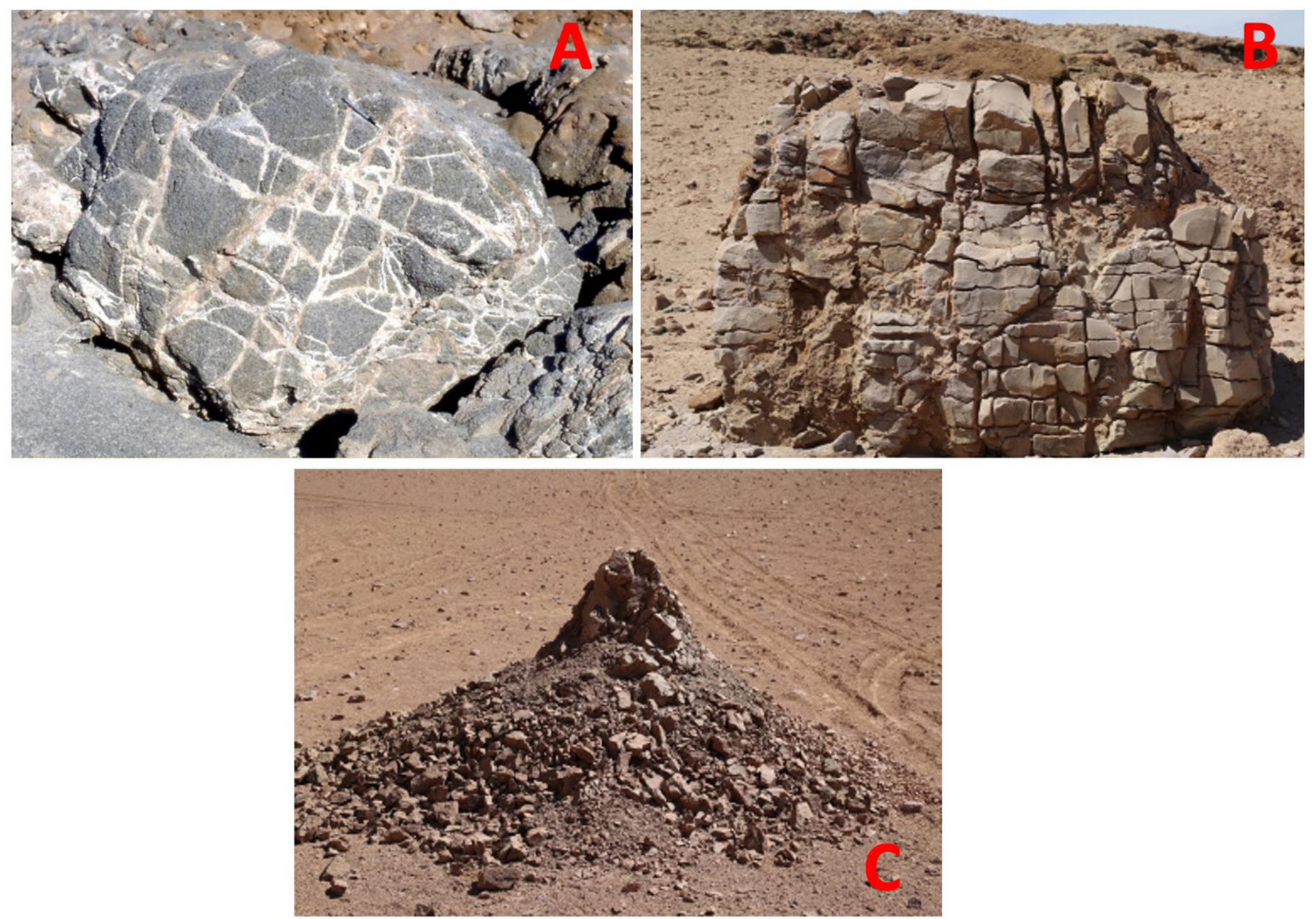

Figura 25 Rocas destruidas por sales introducidas en sus fracturas. Las sales cristalizan y recristalizan por la acción del agua con sales y los cambios de temperatura. 

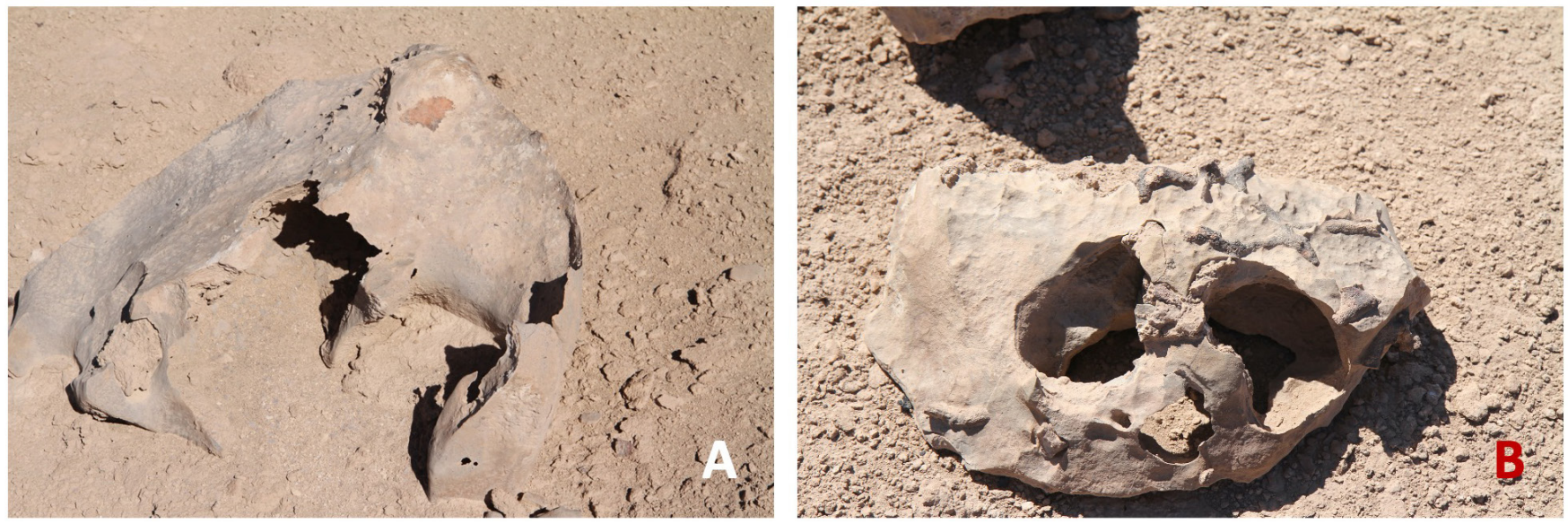

Figura 26 Rocas del basamento destruidas mecánicamente por la actividad del gypsisol.

\subsection{ESTRUCTURAS SALINAS}

\subsubsection{DIQUES NEPTÚNICOS}

En los yacimientos de nitratos y en otros sectores del desierto se observan los llamados diques de inyección o neptúnicos. Consisten en material detrítico y salino inyectado, en condiciones de presión, desde fluidos superficiales. Su color es pardo en distintos tonos. Algunos de ellos muestran zonación indicando procesos repetidos de inyección, otros tienen una composición homogénea de materiales detríticos finos cementados por sales. Fueron descritos originalmente como "diques de barro" por Ericksen (1983). El más característico es el que se presenta en los yacimientos de nitratos con alta concentración de esa mena y hay sectores en los que la explotación se concentró casi exclusivamente en estos cuerpos (Figura 27).

\subsubsection{ESTRUCTURAS DE DISOLUCIÓN ("SINK HOLES')}

Las estructuras más características de este tipo son las del Salar de Atacama, donde actualmente están en desarrollo (Figura 28A) o han formado lagunas(Tebenquiche, $23^{\circ} 08^{\prime} \mathrm{S} / 68^{\circ} 15^{\prime} \mathrm{O}$ )(Figura 28D), y las del "Ojo de Agua" o Laguna de Chiu Chiu (22 $\left.{ }^{\circ} 0^{\prime} \mathrm{S} / 68^{\circ} 39^{\prime} \mathrm{O}\right)$. En el área de Quillagua (21⒊' $\left.\mathrm{S} / 69^{\circ} 32^{\prime} \mathrm{O}\right)$ se conocen varias estructuras fósiles de este tipo que alcanzan diámetros de más de 200 m (Figura 28B). También se observan en evaporitas jurásicas en la Cordillera de Domeyko, en el Salar de Llamará (Figura 28C), en el Salar Grande asociadas a sistemas de fallas y en la Cordillera de la Sal $\left(22^{\circ} 57^{\prime} \mathrm{S} / 68^{\circ} 18^{\prime} \mathrm{W}\right)$ donde forman un complejo sistema de cavernas en el subsuelo.

\subsubsection{CONDUCTOS SUBSUPERFICIALES DE SALMUERAS}

En diferentes lugares del desierto hiperárido se observan, aisladas o en conjunto, cavidades circulares de 40-50 cm y hasta ca. $1.5 \mathrm{~m}$ de diámetro, con profundidades no mayores a $1.0 \mathrm{~m}$, que muestran surgencias de salmueras. Esto queda evidenciado por pequeños drenajes que irradian desde ellos o por estar rodeados de aureolas salinas. En algunos casos, están a menos de un metro de distancia entre ellos y se puede observar su comunicación subterránea y sus paredes recubiertas de sales como residuos de la circulación de salmueras en su interior. La interpretación que se les ha dado es que se forman a partir de la circulación de aguas subterráneas salinas a profundidades someras o a través de fallas. Estas constituirían niveles artesianos ocasionales, incluyendo conductos que les permitirían formar vertientes efímeras (Figuras 29 y 30$)$. 


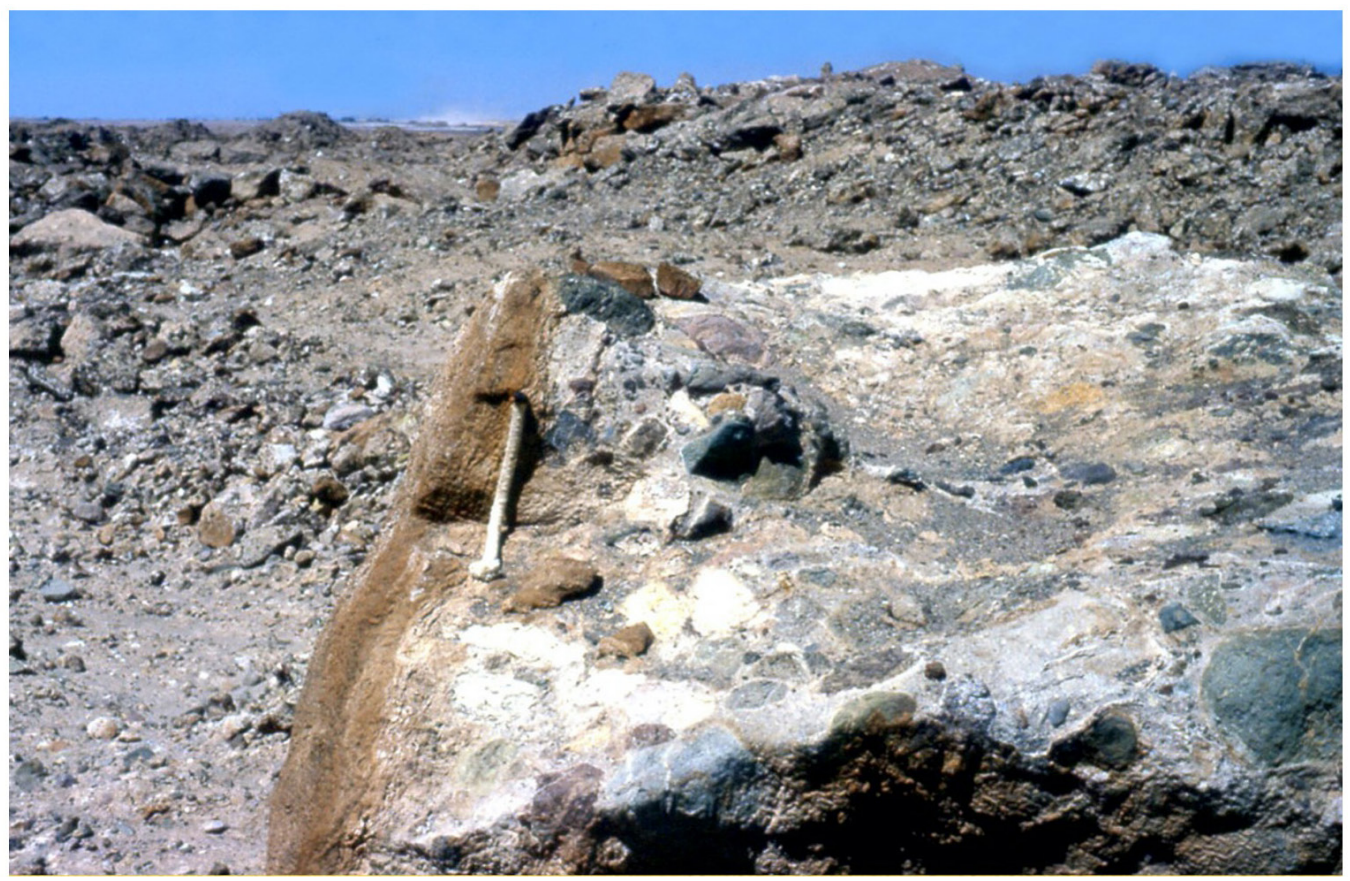

Figura 27 Dique de inyección en yacimientos de nitratos. Su concentración en nitratos suele ser alta y, en casos, fueron explotados sistemáticamente.
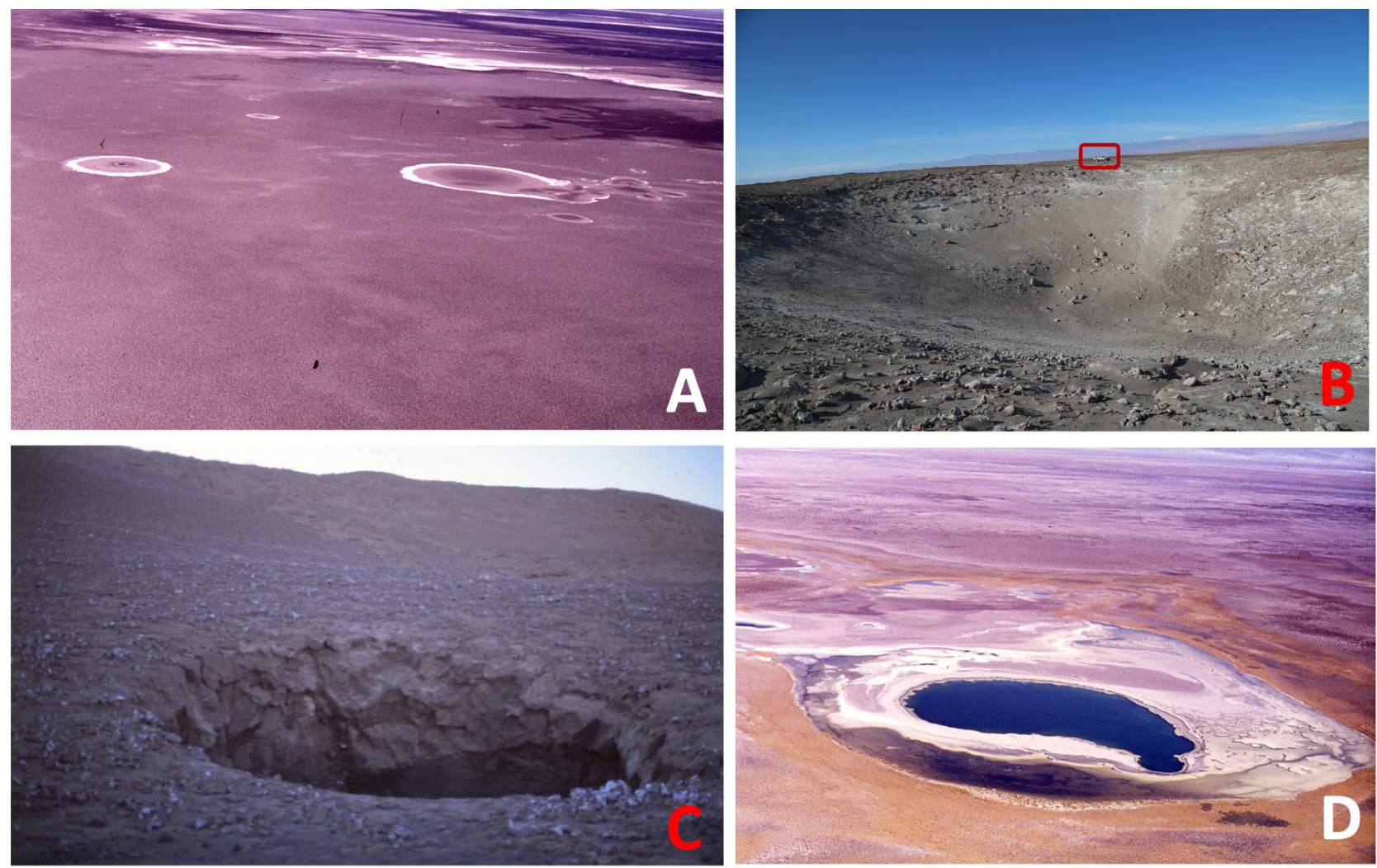

Figura 28 A) Estructuras de disolución en formación en el Salar de Atacama. B) Sink hole en Quillagua (21 $39^{\prime}$ S $/ 69^{\circ} 32^{\prime}$ O), asimismo en el cuadro rojo se observa un automóvil como referencia de escala; C) Sink hole en el Salar de Llamará. D) Laguna de Tebenquiche en el Salar de Atacama $\left(23^{\circ} 08^{\prime} \mathrm{S} / 68^{\circ} 15^{\prime} \mathrm{O}\right)$ formada por un conjunto de estas estructuras de disolución. 


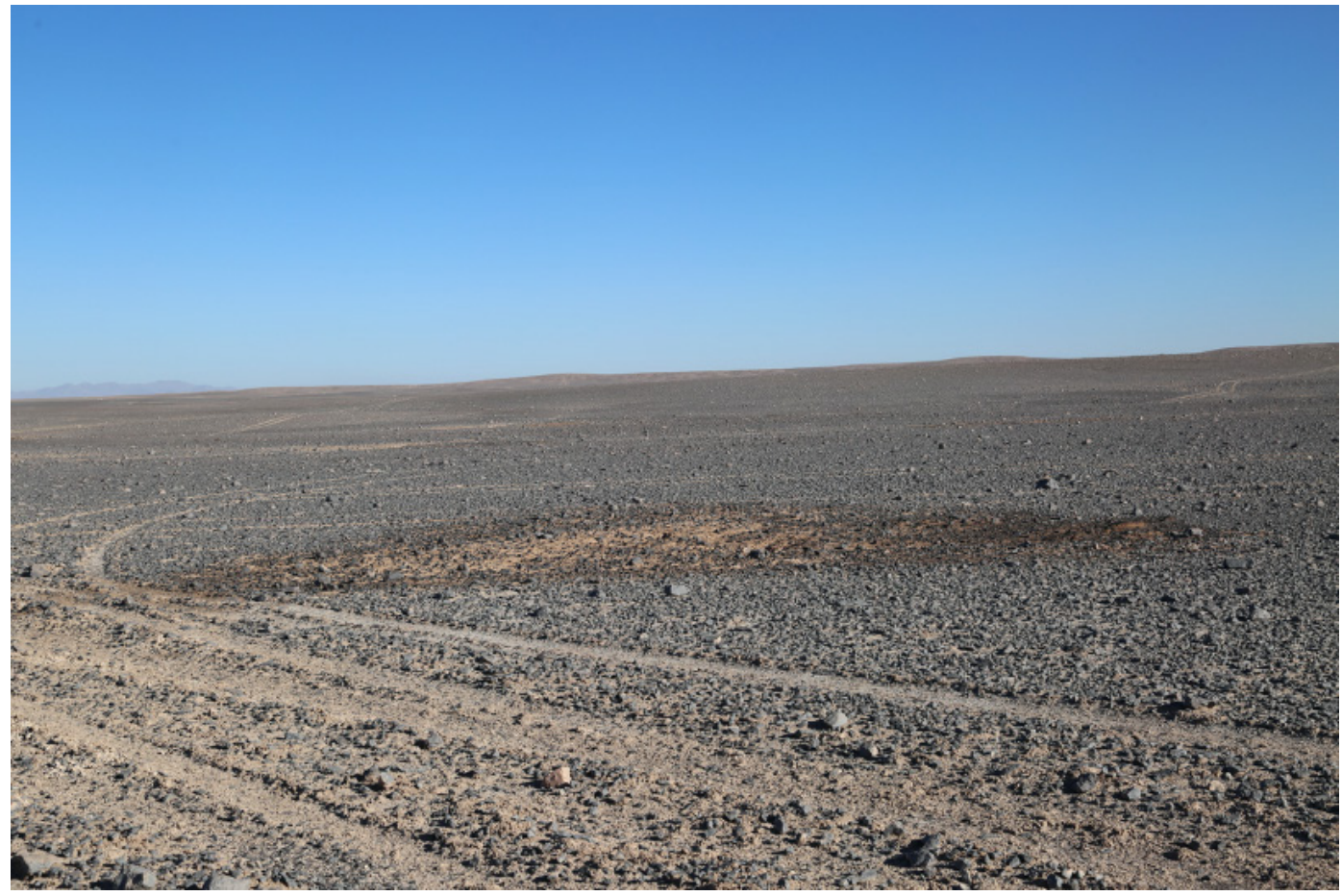

Figura 29 Cavidad circular con alrededor de $1.5 \mathrm{~m}$ de diámetro. La rodea una aureola más obscura con sedimentos y sales demostrando que corresponden a salmueras que surgieron de esta especie de cráter.

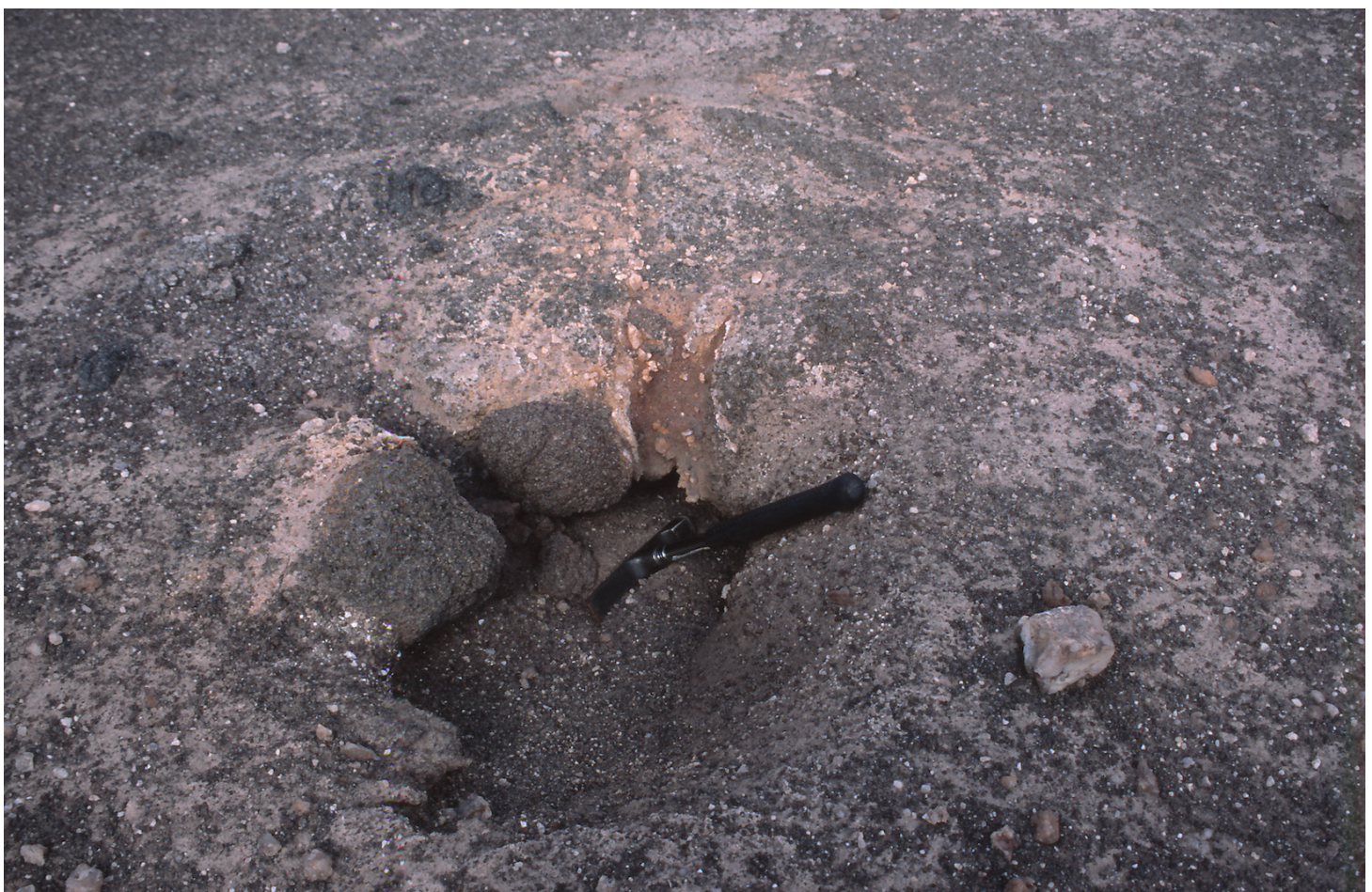

Figura 30 Una cavidad del mismo tipo que la que se muestra en la Figura 29, pero que, en este caso, es irregular y se prolonga horizontalmente en el subsuelo. 


\subsubsection{FALLAS QUE TRANSPORTAN SOLUCIONES}

En la Depresión Central se reconocen fallas de diversa extensión a través de las que circularon salmueras. Algunas se extienden por kilómetros y sus escarpes en superficie pueden ser solo de algunos decímetros. En casos está expuesto el plano de falla, mostrando costras salinas adosadas a éste, formadas por la evaporación de los fluidos salinos que circularon a través de la estructura. El ejemplo más claro está en el área de Cerro Birrete $\left(23^{\circ} 01^{\prime} \mathrm{S} / 69^{\circ} 40^{\prime} \mathrm{W}\right)$, donde una falla pone en contacto una secuencia de basaltos y sedimentitas lacustres del Cretácico Superior $(71+2.4 \mathrm{Ma}, \mathrm{K}-\mathrm{Ar}$ en roca total, este trabajo) con una secuencia de conglomerados. En el plano de esta falla se reconocen conductos que aún muestran sales fósiles y, al pie del mismo, depósitos de costras salinas formadas a partir de los fluidos provenientes de la falla. Estas sales tienen altas concentraciones de nitratos (hasta $28 \%$ ) y yodo (1200 ppm). (Figuras 31 A- 31E). En otros lugares se observan alineamientos topográficos, similares a escarpes de fallas, de hasta algunos metros de longitud, de los cuales han fluido soluciones que depositaron sales que forman costras salinas con grietas de desecación de dimensiones métricas que demuestran una rápida evaporación (Figuras 32 y 33).

Además de las estructuras descritas, existen otras que no se muestran en este trabajo. Por nombrar algunas, están todas aquellas que se producen en salares como grietas de desecamiento rellenas por sales, las burbujas conocidas como salt-cups o los plegamientos y destrucción de rocas por la acción de sales (Figura 34). También deben mencionarse las estructuras diapíricas de las evaporitas marinas jurásicas.
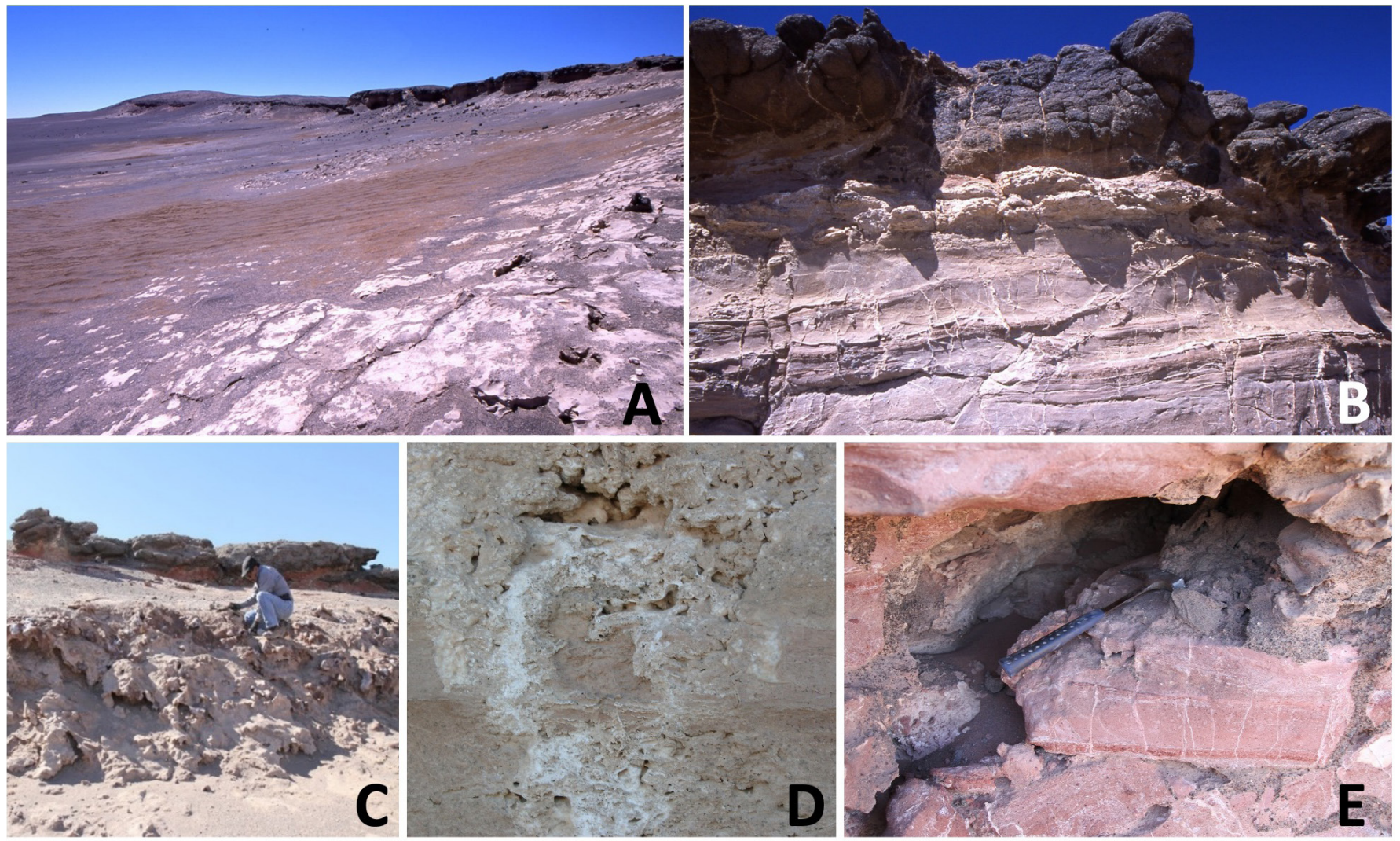

Figura 31 A) Vista general del escarpe de falla de Cerro Birrete al fondo y, en el primer plano, las costras salinas que se disponen adosadas a éste. B) Detalle del plano de falla. La parte superior corresponde a una lava andesítico-basáltica y la inferior a una secuencia sedimentaria lacustre asociada a un sistema hidrotermal. C) Se muestra la potencia de las sales acumuladas al pie del plano de falla. D) E: Cavidades en el plano de falla que corresponden a los conductos por donde han circulado las soluciones salinas. 


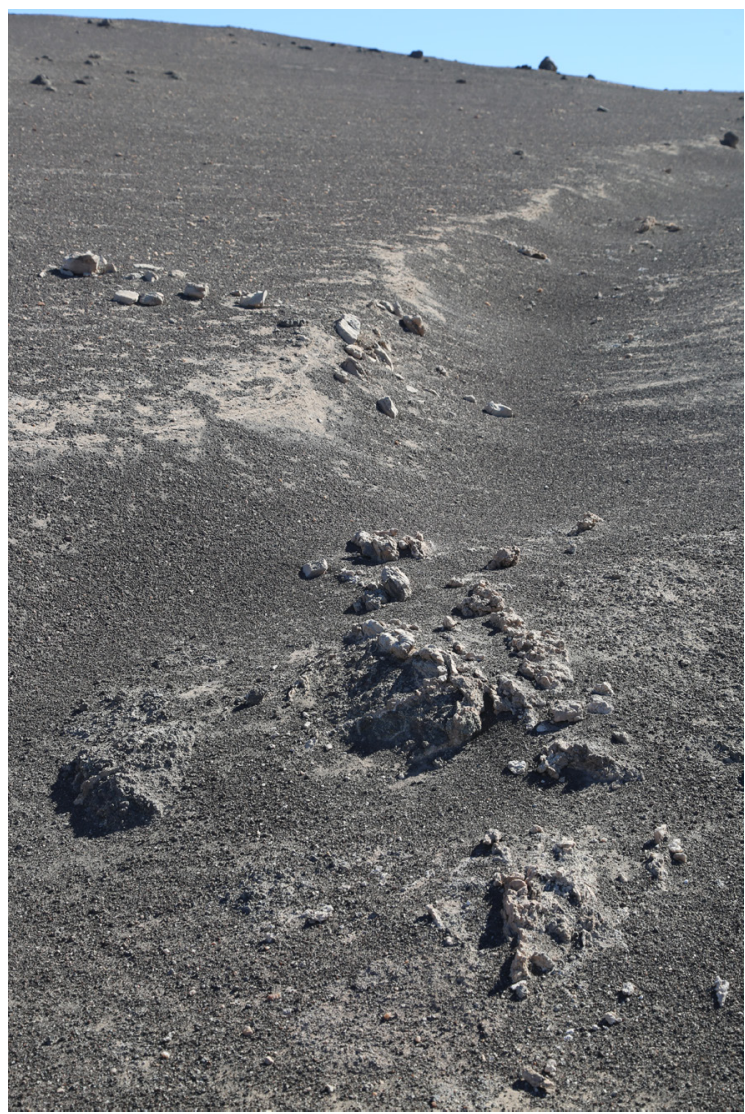

Figura 32 Una falla que se reconoce a lo largo de cientos de metros, pero cuyo escarpe aflora con una altura menor a $1 \mathrm{~m}$. Se observan las costras salinas adosadas al plano de falla.

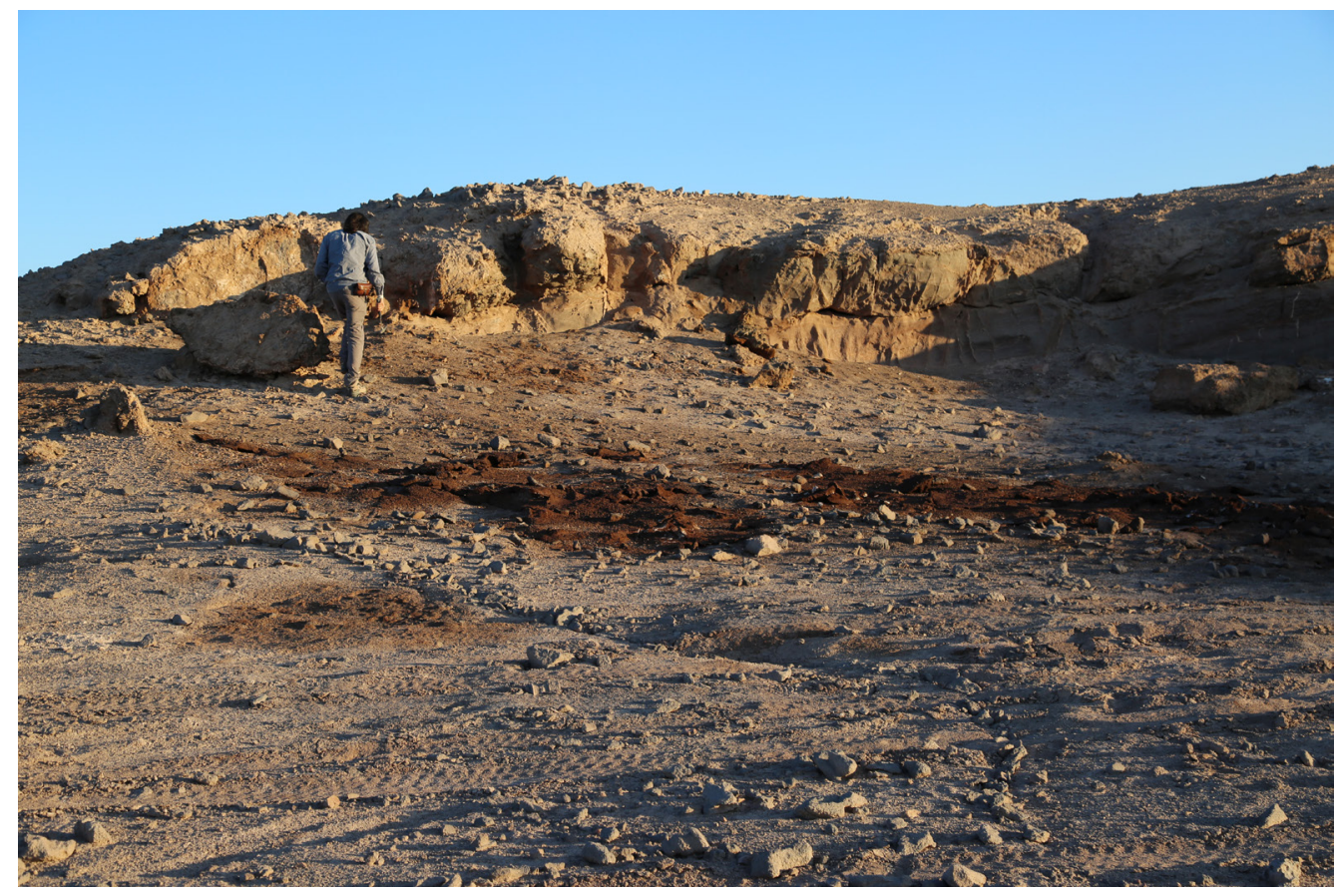

Figura 33 Plano de falla que, en su bloque deprimido, muestra una cubierta de sales (color más obscuro) adosada a este con grietas de desecamiento métricas en las costras salinas. Las salmueras emergieron de la falla y se depositaron de acuerdo a la pendiente, en flujos laminares similares a los que se generan en los fenómenos de liquefacción. El tamaño de las grietas de desecación indica una evaporación rápida. 


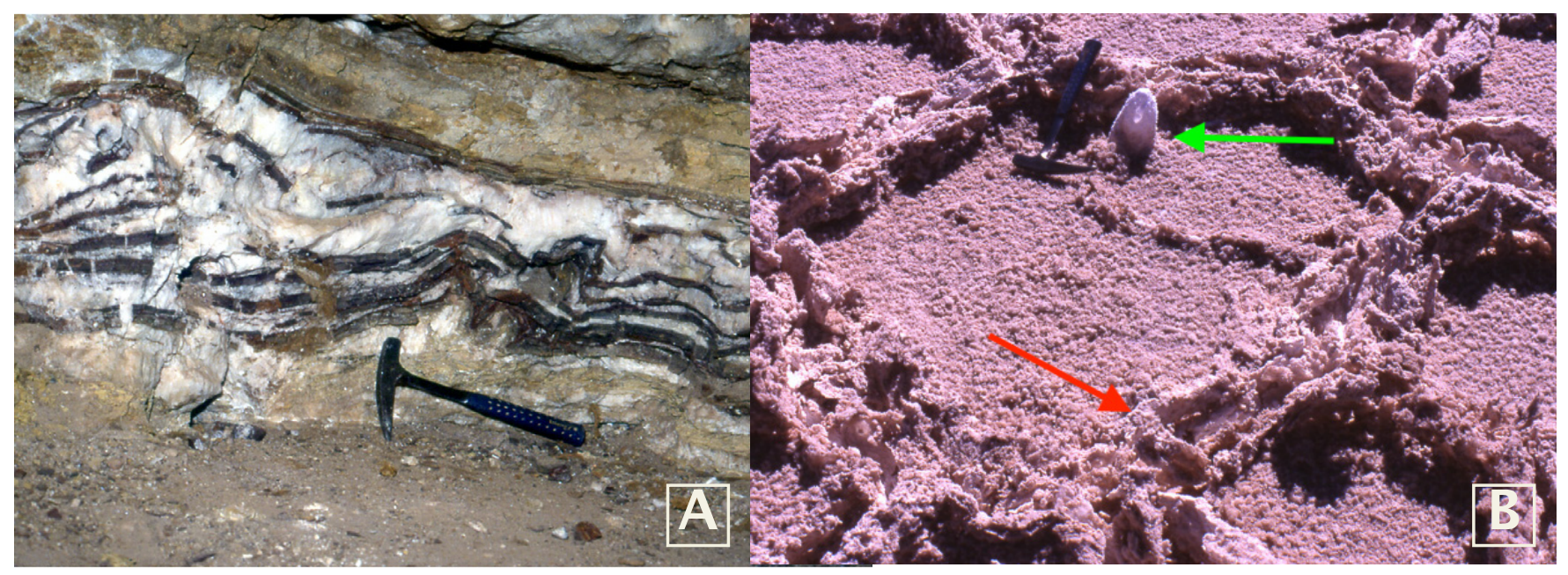

Figura 34 A) En la izquierda aparece un estrato de rocas destruido y plegado por la acción de sales. En este caso se puede hablar de halokinesis considerando que las sales incluyen abundante halita. B) En la derecha grietas de desecamiento rellenas de sal (Flecha roja) y una Burbuja salina o Salt cup (Flecha verde).

\subsection{SALARES}

\subsubsection{GENERALIDADES}

Los salares son cuencas sedimentarias endorreicas de ambientes hiperáridos a áridos, rellenas de rocas sedimentarias detríticas y evaporitas y, eventualmente, con intercalaciones de rocas volcánicas. El principal agente de transporte y sedimentación es el agua, tanto superficial como subterránea. El agua evoluciona a salmueras en las cuencas, se distribuye en cuerpos abiertos como lagunas, sistemas de drenajes, o como niveles subterráneos, mientras que en la superficie se forman costras salinas producto de la evaporación. Originalmente, los salares se forman a partir de lagos o lagunas salinas en ambientes desérticos, donde las salmueras, por procesos de evaporación y evapotranspiración, evolucionan a evaporitas. Si la recarga se termina o disminuye por cambios climáticos, tectonismo $\mathrm{u}$ otras razones, la cuenca queda rellena exclusivamente de los sedimentos lacustres originales y evaporitas, y se habla de salares fósiles.

Los factores que definen la formación de las cuencas endorreicas que albergan los salares tienen diferentes orígenes. Pueden ser tectónicas controladas por sistemas de fallas como en el caso de los salares de Atacama y Punta Negra $\left(24^{\circ} 28^{\prime} \mathrm{S} / 68^{\circ} 54^{\prime} \mathrm{O}\right)$ y Salar Grande $\left(20^{\circ} 57^{\prime} \mathrm{S} / 69^{\circ} 58^{\prime} \mathrm{O}\right)$. Otras se forman por la acu- mulación de productos de la actividad volcánica, como sucede en gran parte de la Alta Cordillera. Algunas están asociadas a playa lakes y se forman en la parte distal de conos aluviales coalescentes. Este último es el caso de los salares de la Pampa del Tamarugal, asi como el del Salar de Llamará, formado en la parte distal del gran Cono Aluvial de Arcas $\left(21^{\circ} 43^{\prime} \mathrm{S} / 69^{\circ} 08^{\prime} \mathrm{O}\right)$.

Las cuencas hidrológicas superan arealmente, en varios órdenes de magnitud, a los salares que albergan. Por ejemplo, la cuenca hidrológica del Salar de Atacama se estima en unos 30,000 $\mathrm{km}^{2}$, mientras que la superficie de su salar es diez veces menor (Moraga et al., 1974). En el caso de los salares asociados a conos aluviales, las cuencas hidrológicas pueden estar lejanas a los cuerpos evaporíticos. Los procesos cíclicos de aportes y evaporación generan la formación de costras salinas de diferente composición que se distribuyen de acuerdo a los productos de solubilidad de las sales y con características variadas según su contenido de agua, edad, grado de erosión y o meteorización, acción del viento, nieblas dinámicas y otros factores. Lo general es una zonación con sedimentos detríticos en la parte externa y costras salinas en las partes interiores topográficamente más bajas.

Los salares, en general, poseen un medio ambiente frágil con actividad salina muy dinámica, donde las costras pueden disolverse con inundaciones laminares, saturarse de salmueras, 
desecarse por la evaporación y formar numerosas estructuras como "sink holes", "salt cups", grietas de desecación además de lagunas, vertientes y drenajes internos (Moraga et al.,1974).

El clima en el norte de Chile ha ido variando en su aridez desde el oeste hacia el este. Como consecuencia, los salares de la Cordillera de la Costa, de la Depresión Central, de las Cuencas Preandinas y de la Alta Cordillera, son diferentes. Los de más al oeste están fosilizados como el Salar Grande, que ya no recibe recarga o están en proceso de fosilización como Pintados $\left(20^{\circ} 33^{\prime} \mathrm{S} / 69^{\circ} 38^{\prime} \mathrm{O}\right)$ y Bellavista $\left(20^{\circ} 46^{\prime} \mathrm{S} / 69^{\circ} 37^{\prime} \mathrm{O}\right)$ con una recarga ocasional o limitada. Los salares de la Alta Cordillera y de las Cuencas Preandinas están activos al día de hoy, aunque severamente afectados por efectos del cambio climático y por sobreconsumo de sus recursos hídricos. Las paleocostas de lagunas y salares andinos indican una batimetría hasta 10 o más metros más profunda que la actual y una extensión areal que supera en cientos de metros a la que se observa hoy.

Los salares del Norte de Chile, especialmente los andinos y preandinos, son oasis en zonas desérticas con fauna y flora, en parte endémicas. Hoy se atribuye gran importancia a su microbiota, que muestra una amplia variedad, novedad y potencialidad en la generación de nuevo conocimiento y en Biotecnología.

En este marco de ambientes desérticos, depósitos salinos y actividad volcánica, subsisten microorganismos considerados extremófilos, no sólo por su capacidad de vivir en condiciones extremas de temperatura, salinidad, desecación, radiación UV y $\mathrm{pH}$, sino también por sobrevivir en presencia de nutrientes que no son compatibles con los organismos eucariotas (Nealson y Conrad 1999; Azua- Bustos et al., 2014, 2015).

La microbiota de los diferentes salares es controlada por la salinidad (Chong et al., 2004, 2005, 2006; Demergasso et al., 2004, 2008, 2010; Meneses et al., 2008) y por factores como la altitud y el tipo de iones disueltos; por ejemplo, el contenido de sulfato y el pH (Escudero et al., 2018). Las comunidades microbianas se estructuran, además, diferencialmente en los hábitats que componen el ecosistema: i) las salmueras, ii) sedimentos y estruc- turas subacuosas como los tapetes microbianos y iii) evaporitas o bioevaporitas incluyendo estromatolitos. En estos hábitats se observan diferencias en la distribución de microorganismos fototróficos oxigénicos y anoxigénicos, de respiración aeróbica y anaeróbica, entre otros (Demergasso et al., 2003, 2007; Gutiérrez-Preciado et al., 2018). En los últimos años se ha avanzado en el estudio de comunidades endolíticas resistentes a la desecación, asociadas a sales delicuescentes en el Salar Grande (Parro et al., 2011) y en costras de halita (Finstad et al., 2017), en evaporitas (Rasuk et al., 2014) y en comunidades que participan en los procesos de formación de minerales (Farías et al., 2014).

Desde estos ambientes se han aislado microorganismos de interés biotecnológico y científico por sus mecanismos de resistencia y la producción de compuestos bioactivos como prodigiosin (Gallardo et al., 2016). En el marco del estudio de metabolismos extremos especializados para usar pares redox presentes en estos ambientes, como los involucrados en el ciclo biogeoquímico del arsénico (Lara, et al., 2012; Escudero et al., 2013b, Lee et al., 2018) se han obtenido cultivos capaces de formar biominerales con potencial uso en tratamiento del cáncer y en la industria optoelectrónica (Serrano et al., 2017). Desde las comunidades microbianas de salares ácidos soportadas por azufre de origen volcánico (Escudero et al., 2018) se han aislado también microorganismos con potencial uso en procesos de lixiviación en presencia de cloruro y en el tratamiento de soluciones industriales ácidas (Rautenbach et al. 2011). Algunos de estos salares se han estudiado también por su analogía con Marte (Davila et al., 2013; Escudero et al. 2013a;Wierzchos et al., 2013; Ziolkowski et al. 2013; Chong et al. 2015, Escudero et al. 2015, Hinman et al., 2017, Benison 2019).

\subsubsection{SALARES DE LA CORDILLERA DE LA COSTA}

En la Cordillera de la Costa se ubican salares fósiles que no reciben recarga, como el Salar Grande, el Salar La Gloria (20³2’S $69^{\circ}$ 59`W) y la yesera Loco Feliz (Vásquez y Sepúlveda, 2013), remanente de un salar $\left(20^{\circ} 26^{\prime} \mathrm{S} / 70^{\circ} 03^{\prime} \mathrm{W}\right)$. 
El Salar Grande es un gran yacimiento de sal en una cuenca tectónica endorreica que forma parte de un sistema de cuencas asociado a la Depresión Central y a la Cordillera de la Costa. Su eje mayor tiene más de $30 \mathrm{~km}$, un ancho promedio del orden de 4 a $5 \mathrm{~km}$ y una profundidad que, en partes, supera los $100 \mathrm{~m}$. Está relleno exclusivamente de cloruro de sodio con pureza que, en amplios sectores, supera el 99\% promedio (Figura 35). Es la única cuenca evaporítica de importancia en la Cordillera de la Costa del Norte de Chile y tiene un marcado control estructural tipo pull apart, definido por el sistema de la Falla de Atacama (Figura 9). Este salar sería la etapa final de la evolución de un lago salino de poca profundidad, de acuerdo a la presencia de estructuras chevron en la sal. Esto es coherente con la ausencia de aporte terrígeno, lo que, a su vez, documenta la aridez climática. Un único horizonte de ca. $1.0 \mathrm{~m}$ en $80 \mathrm{~m}$ de sal, que incluye cristales de thenardita, demuestra un capítulo de menor temperatura ambiental durante la sedimentación. Se reconoce un capítulo de desagüe del lago, probablemente asociado al sistema de drenaje del rio Loa o a la acción de fallas, que llevó a su rápido drenaje representado por grandes grietas de desecamiento. Hoy el salar es fósil, la sal es masiva, ha perdido toda su porosidad, no recibe recarga y fallas del basamento reactivadas afectan el cuerpo salino (Chong et al., 1999).

La sal que se explota en este salar cubre la totalidad de la demanda doméstica de Chile y, entre 2009 y 2018, se han exportado de sus minas del orden de 8.9 millones de toneladas anuales de sal, tanto del tipo caminos como de calidad química.

En estas cuencas evaporíticas de la Cordillera de la Costa se incluyen los depósitos de yeso marino del Plioceno, formados en sebhkas de la Península de Mejillones. Corresponden a cuerpos evaporíticos asociados a solevantamientos tectónicos que formaron terrazas en la parte sur de la Península de Mejillones (2309'S/70³2’O). Las evaporitas son de yeso, mayoritariamente del tipo macla "tail fish" y de alta pureza, distribuidas en cuerpos lenticulares de varios cientos de metros cuadrados y con potencias que pueden superar los $20 \mathrm{~m}$. El yeso se explota, muy irregularmente, para ser usado en la fabricación de cemento.

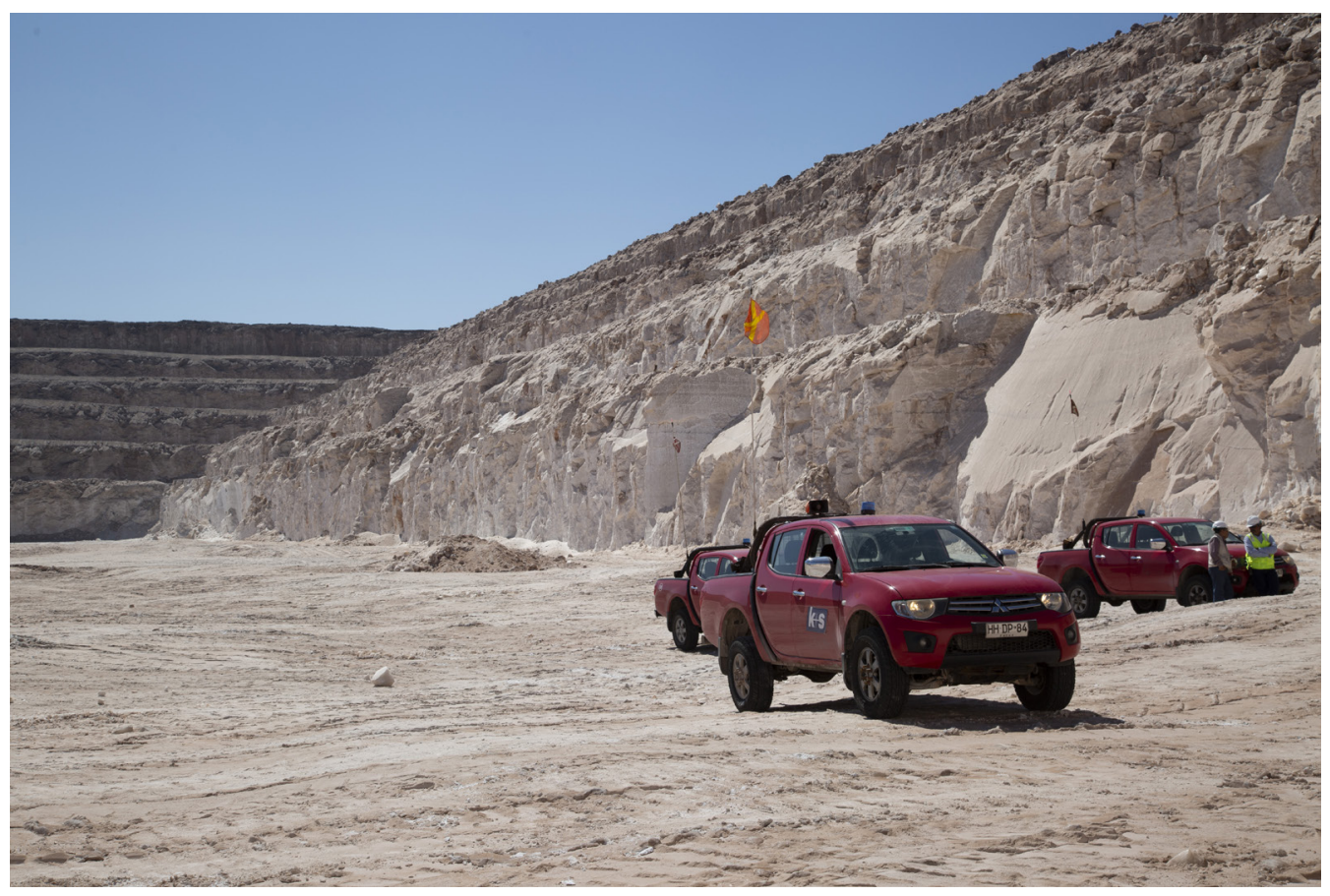

Figura 35 Frente de explotación en la mina principal de Salinas de Punta de Lobos que muestra la pureza de la sal que se explota en el Salar Grande. 


\subsubsection{SALARES DE LA DEPRESIÓN CENTRAL}

Estos cuerpos evaporíticos se han formado en la parte distal de sistemas aluviales provenientes de la Precordillera y la Alta Cordillera que tienen, como nivel de base, la Depresión Central, mayoritariamente en la Pampa del Tamarugal. Su límite occidental es el borde de la Cordillera de la Costa, en la parte más baja de la Depresión Central. Su recarga es ocasional e irregular y el recurso hídrico ha sido explotado intensamente. En el presente están en plena etapa de fosilización (Figuras 36 y 37). Ejemplos son los salares de Llamará, Pintados (20³3’S/69³8’W), Bellavista $\left(20^{\circ} 46^{\prime} \mathrm{S} / 69^{\circ} 37^{\prime} \mathrm{O}\right)$ (Figuras 36 y $37)$, Obispito $\left(19^{\circ} 38^{\prime} \mathrm{S} / 69^{\circ} 57^{\prime} \mathrm{O}\right)$ y Sur Viejo (205' S/69³3'O) en la Pampa del Tamarugal, y los salares del Carmen $\left(23^{\circ} 39^{\prime} \mathrm{S} / 70^{\circ} 17^{\prime} \mathrm{O}\right)$, Navidad $\left(23^{\circ} 44^{\prime} \mathrm{S} / 69^{\circ} 55^{\prime} \mathrm{O}\right)$ más al sur. Los salares de ubicación más septentrional de este tipo, entre Arica y Quebrada Tiliviche $\left(19^{\circ} 29^{\prime} \mathrm{S} / 70^{\circ} 06^{\prime} \mathrm{O}\right)$, están cortados por profundas quebradas y se han denominado "Salares de las Pampitas" (Chong, 1984, 1988) (Figura 38).
Los salares de Pintados y Bellavista se ubican en una sola cuenca, por ello Vásquez y Sepúlveda (2013) describen en ellos la presencia, en trazas, de los boratos hexahidroboracita, ulexita, probertita, los sulfatos goergeyita, hexahidrita, anhidrita, y nitratos. Los autores Basadre (1884), Casamiquela (1972) y Casamiquela y Sepúlveda (1974) citados en Vasquez y Sepúlveda (2013) señalan la presencia, en estos depósitos, de restos fósiles de Megatherium medinae indicando para ellos una edad máxima pleistocena. Los mismos autores citan varias caracteristicas destacando que:

- Según Vila (1975) existe una zonación de cloruros, sulfatos y carbonatos con distintas proporciones de materiales detríticos y otra de carbonatos - sulfatos - cloruros. También destaca que en las costras superiores predominan halita, thenardita y glauberita.

- Sayes (1978) describe una zonación con distintas facies salinas y trazas de Li, Cs y Rb.

- Stoertz y Ericksen (1974) indican que los salares de Pintados y Bellavista se habrían formado a partir de lagos efímeros. En cambio

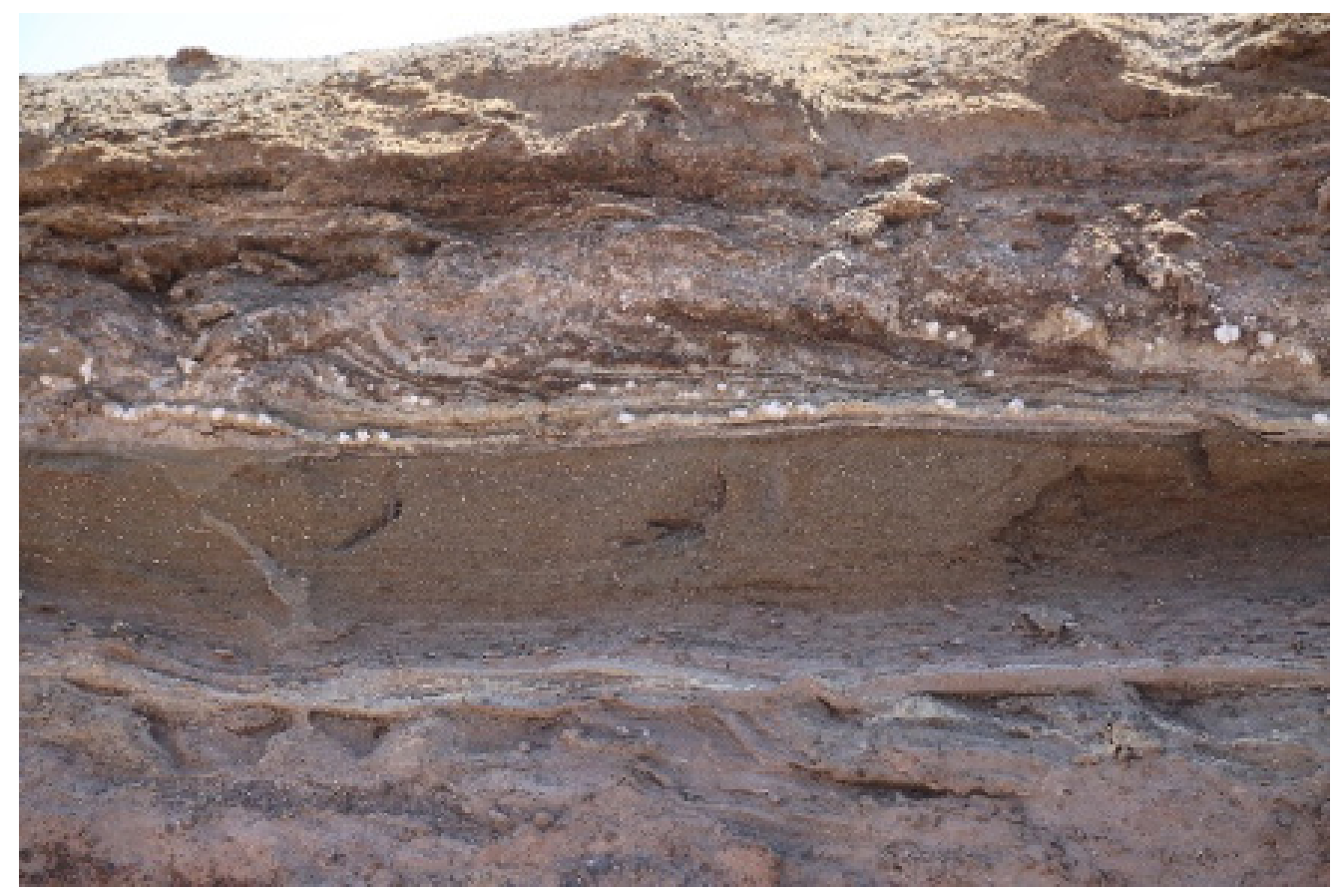

Figura 36 Perfil del Salar de Bellavista donde se observan los sedimentos lacustres originales que incluyen pequeños núcleos esféricos que corresponden a boratos (ulexita) que demuestran el origen volcánogénico desde el este de los aportes. 


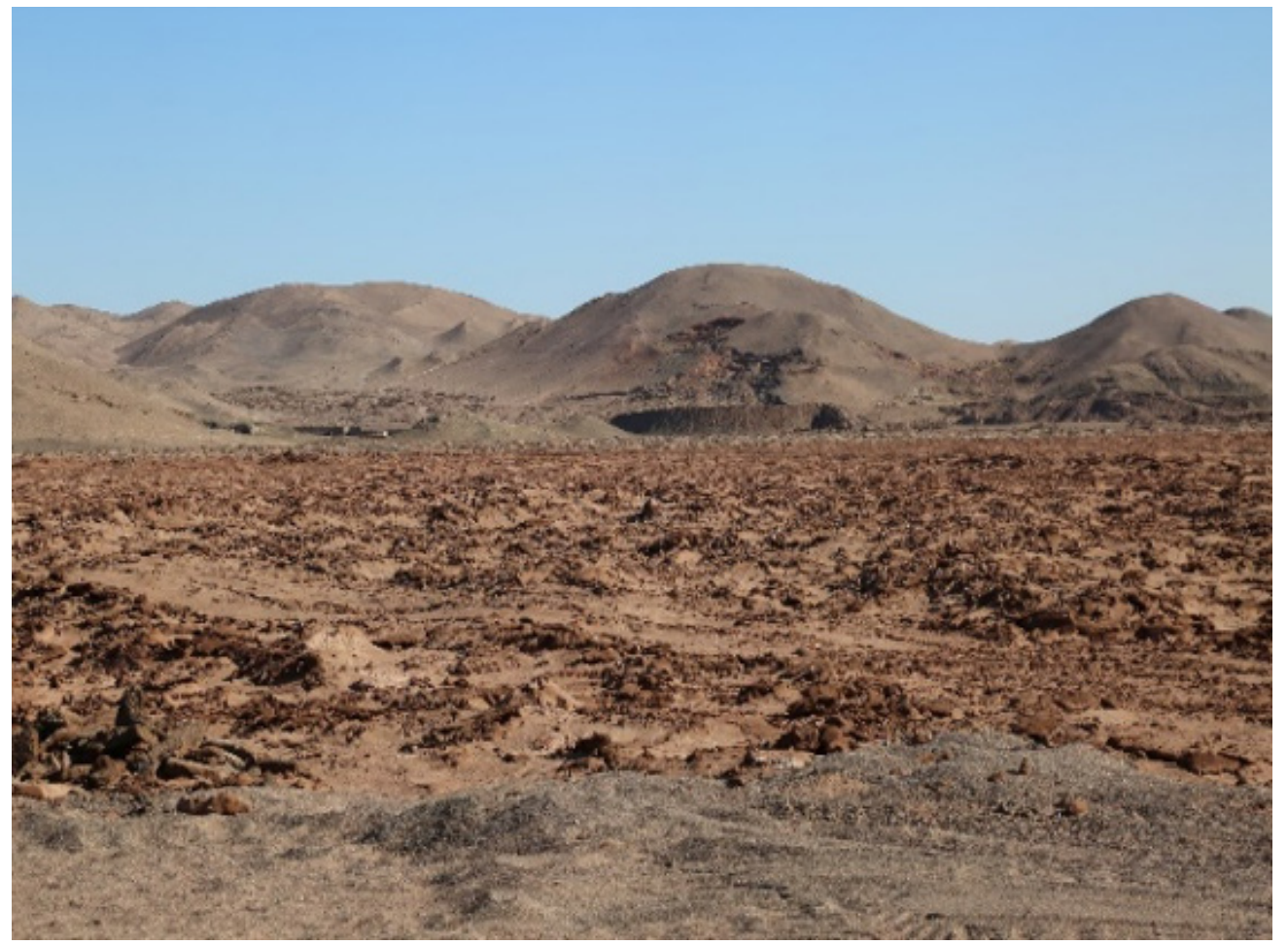

Figura 37 Aspecto general de la superficie del Salar de Bellavista. En sus bordes se observan "calicheras" de la explotación de nitratos.

Vila (1975) y Sayes (1978) apoyan un origen a partir de acuíferos salinos libres con sales concentrándose por capilaridad.

- Risacher et al., (2003) estiman que estas cuencas tendrían una recarga subterránea continua.

La cuenca más antigua de este grupo es la de Llamará, descrita originalmente por Brüggen (1950), quien la asoció al dominio de un gran lago que denominó Lago Salado de Soledad, y cuya extensión areal incluiría los actuales salares Llamará, Salar Grande y parte de la cuenca de Quillagua. Esto corresponde a una superficie de miles de kilómetros cuadrados, con una distribución relativamente ambigua de cuencas mayores y secundarias. De acuerdo al mismo autor, este lago se habría formado por la acumulación de agua debido a desniveles regionales en la Pampa del Tamarugal y, posteriormente, habría sido drenado al mar cuando aportes, desde la Alta Cordillera, habrían aumentado su volumen superando los límites de la cuenca.
Posteriormente, Hofstetter (1957) en Skarmeta y Marinovic (1981) denominó como Formación Lago Soledad a los depósitos salinos distribuídos en todas las cuencas evaporíticas del sector. Finalmente, Bobenrieth (1979) en Skarmeta y Marinovic (1981) propone el nombre de Formación Soledad, mantenida a la fecha y descrita como costras de yeso y anhidrita, cubiertas por otra de sal. Se le asigna una edad pliocena-pleistocena (Skarmeta y Marinovic, 1981). Bao et al., (1999) hacen una descripción de la evolución del paleolago ubicado en esta cuenca, a la que asignaron una edad de 5.8 + 0.4 Ma, sobre la base del estudio de diatomeas. Quezada et al., (2012) hicieron una recopilación de distintos trabajos de esta área y describiron depósitos salinos, eólicos, de piedemonte y aluviales que indicaron edades del Plioceno-Pleistoceno.

La interpretación que se asume en este trabajo, de acuerdo a trabajos de terreno, es la siguiente: La Pampa del Tamarugal, desde el Mioceno más tardío, habría incluido una serie de lagos a lo largo de toda su extensión, con una recarga proveniente desde el este y asociada al solevantamiento andino. 


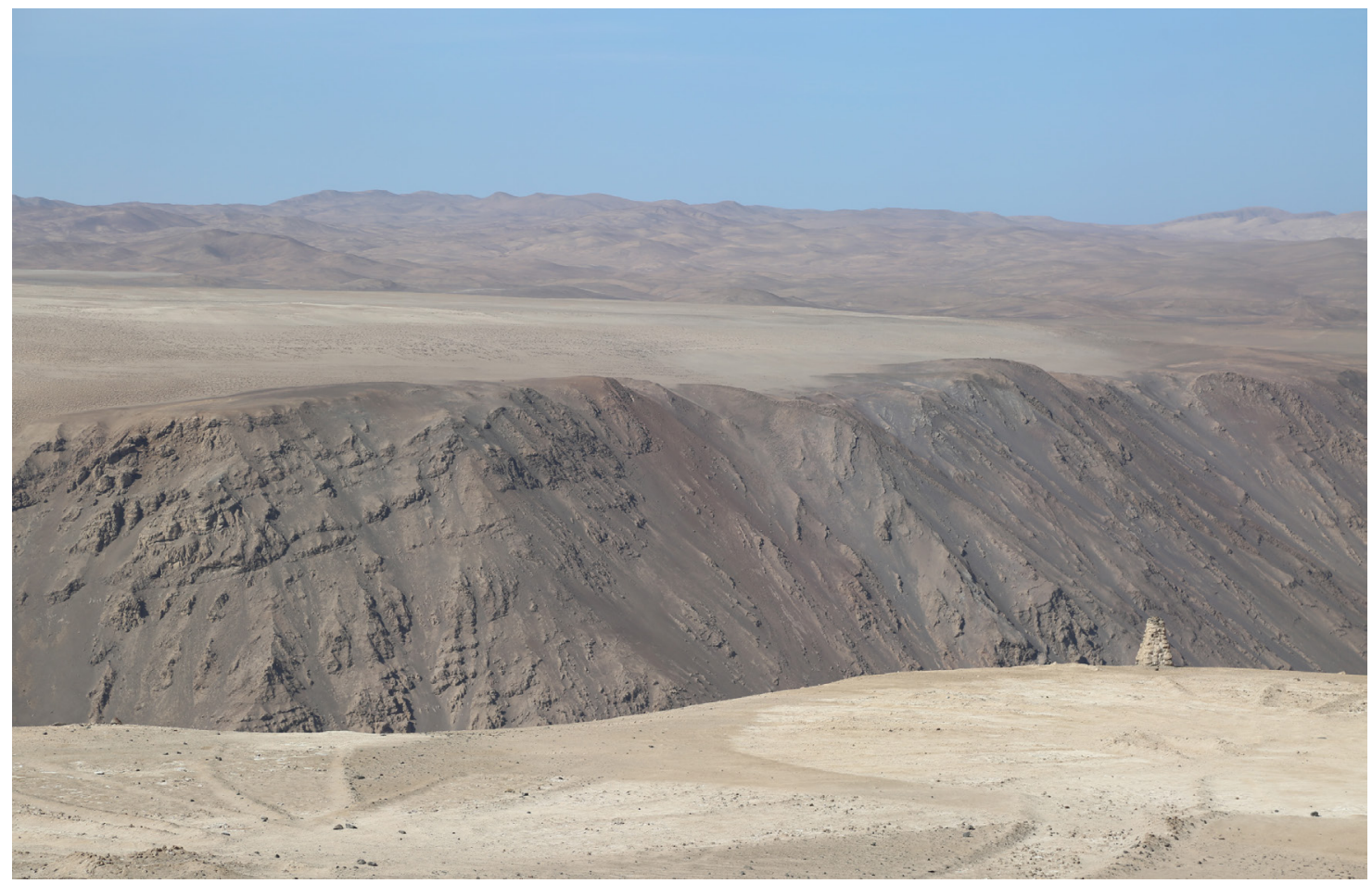

Salar de las Pampitas cortado por la Quebrada de Chaca (18 $\left.49^{\prime} \mathrm{S} / 70^{\circ} 08^{\prime} \mathrm{O}\right)$.

En partes, estos lagos estarían alimentados con importantes sistemas de conos aluviales coalescentes que fueron canales principales de aportes, como el caso de Chacarillas $\left(18^{\circ} 48^{\prime} \mathrm{S} / 70^{\circ} 10^{\prime} \mathrm{O}\right)$ y Arcas. Estos lagos están hoy representados por sus secuencias de sedimentitas lacustres, que tienen, como característica principal, la inclusión de abundantes diatomitas que aparecen desde los salares más septentrionales hasta aproximadamente la cuenca de Quillagua y, en forma muy irregular, hasta los $22^{\circ} \mathrm{S}$. Un ciclo de cambio climático que impuso una mayor aridez, cambió las condiciones y provocó que estos lagos comenzaron a evolucionar a salares en las cuencas más profundas.

Una segunda interpretación es que el sistema del Río Loa comenzó a drenar el Lago Soledad a través de Quebrada Amarga (2125'S/6945’O), lo que habría disminuido el volumen de aportes. Esto tendría una clara evidencia en el cambio del perfil del Río Loa entre Quillagua y la cuenca de Llamará, y entre ésta y el mar. En el primer caso es un valle bajo, ancho y plano, donde el río se ha desplazado formando meandros. En cambio, desde su conexión con Quebrada Amarga, es un cañón estrecho en forma de $\mathrm{V}$ y varios cientos de metros de profundidad que se habría formado por el mayor aporte desde el Lago Soledad. Como resultado se formaron cubiertas de costras de sal y yeso que hoy se distribuyen en la cuenca. Su parte sureste fue posiblemente la más baja y conservó salmueras hasta el desecamiento total, y está representada por las actuales Lomas de la Sal $\left(21^{\circ} 34^{\prime} \mathrm{S} / 69^{\circ} 31^{\prime} \mathrm{O}\right)$ un cuerpo macizo de sal de más de $20 \mathrm{~km}$ de largo, un ancho de unos $4 \mathrm{~km}$ y una potencia que supera los $80 \mathrm{~m}$. Esto permite plantear la hipótesis que las salmueras alcanzaron un alto grado de evolución y es posible que parte de éstas se hayan desplazado por estructuras, aprovechando la pendiente regional hacia el oeste, hasta la cuenca del Salar Grande formando su actual cuerpo de halita pura. Costras actuales de yeso/anhidrita, que se acuñan hacia el norte y hacia el este, representan una zonación incluyendo las partes marginales y bordes del antiguo lago. Posteriormente, la cuenca ha continuado, hasta hoy, recibiendo aportes desde el este a través 
del Cono Aluvial de Arcas y en forma subterránea formando cuerpos salinos más jóvenes, incluyendo la redepositación de sales antiguas. El volumen de los aportes no permite formar lagos y la recarga se acumula subterráneamente y en pequeñas lagunas (Puquios). La edad asignada por Bao et al. (1999) se ajusta a este esquema. Ritter et al.,(2018) describen la evolución de esta cuenca y estudian en detalle sus paleocostas, usando núcleos cosmogéncos ${ }^{10} \mathrm{Be}$ $\mathrm{y}^{21} \mathrm{Ne}$ derivado. Sus resultados revelan períodos de hiperaridez durante el lapso Plioceno-Pleistoceno y confitman la presencia de un gran lago en la cuenca Quillagua-Llamará.

En Bellavista y Pintados se ha explotado sulfato de sodio; en la cuenca del Salar de Llamará sal para uso industrial en el sector de Lomas de la Sal, diatomitas en Cerro Soledad $\left(21^{\circ} 15^{\prime} \mathrm{S} / 69^{\circ} 33^{\prime} \mathrm{O}\right)$ y yeso en Loco Feliz, todo ello a pequeña escala. Todas estas actividades se paralizaron hace más de veinte años. Actualmente se explotan diatomitas en los Salares de las Pampitas con una producción promedio entre 2007-2016 del orden de 26,200 ton/año (SERNAGEOMIN, 2018). En el Salar de Llamará se explotan actualmente los yacimientos de nitratos subyacentes a sus costras salinas.

\subsubsection{SALARES DE LAS GUENGAS PREANDINAS}

Son los más antiguos y de mayor tamaño del Norte de Chile. Reciben recarga de la Alta Cordillera y, muy subordinadamente, de la Precordillera y corresponden al Salar de Atacama y al de Punta Negra. Las salmueras enriquecidas del primero constituyen los yacimientos de litio más importantes del mundo, además de concentraciones económicas de potasio, magnesio y boro como subproductos y trazas de cesio y rubidio.

El Salar de Atacama, con $3000 \mathrm{~km}^{2}$ de superficie y una profundidad reconocida de casi 1.0 $\mathrm{km}$, es el de mayor tamaño e importancia económica del Norte de Chile (Figura10). Se ubica unos $200 \mathrm{~km}$ al este de la ciudad de Antofagasta $\left(23^{\circ} 23^{\prime} \mathrm{S} / 68^{\circ} 21^{\prime} \mathrm{O}\right)$, en una cuenca tectónica entre la Cordillera de Domeyko y la Alta Cordillera. Su principal recarga, estimada en $6000 \mathrm{l} / \mathrm{seg}$, pro- viene desde el este, es menor desde sus partes sur y norte y muy subordinada desde el oeste. Su marco geológico es esencialmente de rocas volcánicas del Cenozoico que se disponen sobre un basamento Mesozoico/Paleozoico. Hacia el oeste, la Cordillera de Domeyko tiene un variado registro estratigráfico y magmático, que incluye rocas sedimentarias e intrusivas del Paleozoico, Mesozoico y Cenozoico (Bevacqua, 1992).

La superficie del Salar está formada por unidades salinas hacia el centro y detríticas en los bordes con límites variables, cuando la cuenca es parcialmente inundada por flujos laminares. Las costras pueden estar secas o saturadas de salmueras. Las sales, mayoritariamente halita, se ordenan en forma concéntrica, de acuerdo a su producto de solubilidad, agrupándose escasos carbonatos y boratos en los bordes; en seguida sulfatos y en el centro se dispone el Núcleo del Salar, formado exclusivamente por cloruros (Moraga et al., 1974). En toda la cuenca se forman variados tipos de estructuras, como "sink holes", burbujas salinas ("salt cups") o diferentes tipos de grietas de desecamiento rellenas de sal. De acuerdo a Bevacqua (1992) son características generales del Salar:

- Alberga variedades de aguas superficiales con su recarga de sólidos disueltos estimadas de 2 a $325 \mathrm{~g} / \mathrm{l}$, que forman acuíferos confinados, freáticos y artesianos a distintas profundidades.

- El Núcleo clorurado es la parte más estable y homogénea del Salar e incluye un nivel de agua subterránea somero con las mayores concentraciones salinas con promedios cercanos a los $340 \mathrm{~g} / \mathrm{t}$.

- A través de magnetometría, sísmica y estudios estratigráficos, se han detectado importantes estructuras, tanto en el cuerpo salino - detrítico, como en su basamento, que incluyen la formación de subcuencas.

- Hacia el oeste, fallas inversas han generado el cabalgamiento de secuencias de la Cordillera de la Sal, concordantes con aquellas del Salar. Se asume una sedimentación constante desde el Oligoceno, con una escasa variación de las condiciones de depositación, subsidencia con- 


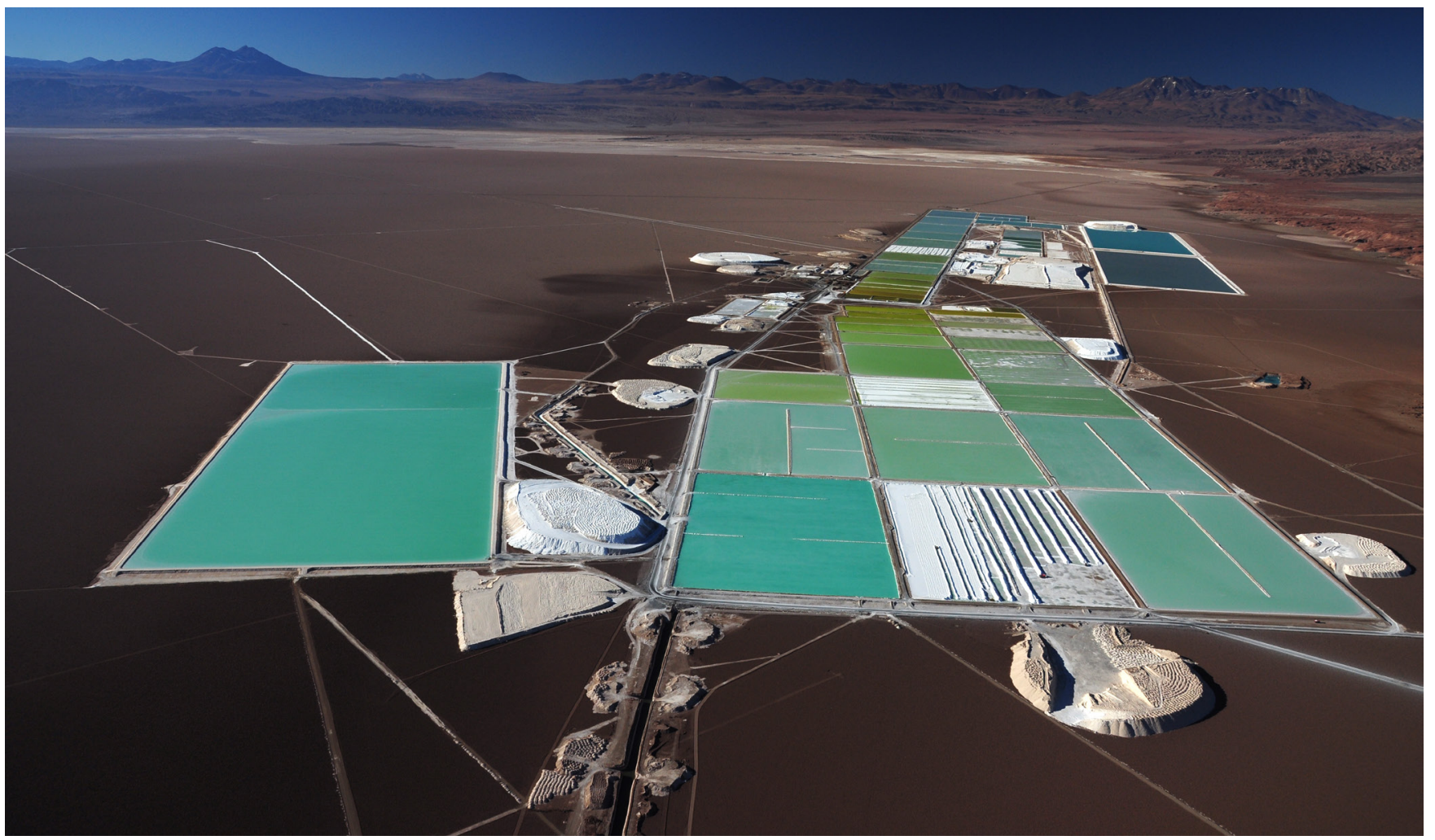

tinua y la inclusión de capítulos volcánicos con una ignimbrita de 3,1+0,3 Ma intercalada en la parte superior de la secuencia sedimentaria salina.

La información del Anuario 2018 del SERNAGEOMIN indica:

- La importancia económica del Salar se basa en los elementos que enriquecen sus salmueras, como litio $(0.14 \%)$, potasio, boro y magnesio en sus partes central y sur. Las concentraciones de litio estimadas en 6.3-6.5 millones de toneladas, son las mayores conocidas en un yacimiento de salmueras en el planeta, y constituyen cerca de un $22 \%$ de las reservas mundiales que actualmente abastecen aproximadamente el $40 \%$ de la demanda global.

- Los productos que se exportan de este salar son carbonato, cloruro e hidróxido de litio, con un promedio anual, entre 2007 y 2016, de 65.110 ton/año de carbonato de litio, 3360 ton/año de cloruro de litio y 4540 ton/año de hidróxido de litio. A esto se agrega, para el mismo lapso, un promedio de 106,850 ton/ año de sulfato de potasio y 1,410,000 ton/año de cloruro de potasio. Se estima que la producción de litio en el 2021 será del orden de 150,000 ton de litio equivalente (Figura 39).

Entre el 2007 y 2013 la producción de ácido bórico total en la Región de Antofagasta fue de 4,900 ton/año promedio, y parte de ella provino del Salar de Atacama, donde la explotación de boratos de salmueras cesó el 2013.

En el futuro próximo, el Salar de Atacama se convertirá en un centro de atención en la minería de Chile, toda vez que se deberá decidir una serie de factores que hoy están en discusión. Es el caso de la solución de acuerdos entre empresa y comunidades, la decisión sobre la concesión del Gobierno a las empresas (el litio es considerado un mineral estratégico), el acuerdo en las cuotas de producción y la sustentabilidad del Salar en 
aspectos como la preservación de la microbiota, protección del medio ambiente y explotación del recurso hídrico.

\subsubsection{SALARES ANDINOS DE LA ALTA CORDILLERA}

Corresponden a las cuencas evaporíticas más jóvenes y numerosas del Norte de Chile y se ubican en la Alta Cordillera. Constituyen salares activos y lagos en evolución a salares (Figuras 40 y 41). Toda su recarga proviene del ambiente volcánico de la Alta Cordillera y varios de ellos poseen fuentes termales en el interior de sus cuencas. Incluyen yacimientos de boratos y su importancia económica relacionada a litio y potasio, es subordinada y poco conocida públicamente, pero es cuantitativa y cualitativamente menor a la del Salar de Atacama. La mineralogía de este tipo de salares puede ser muy variada en el detalle, pero siempre se encuentra el predominio de minerales en los cuales el aporte volcánico es notorio, como en el caso del azufre. Esto queda reflejado, por ejemplo, en el caso del Salar de Gorbea $\left(25^{\circ} 24^{\prime} \mathrm{S} / 68^{\circ} 40^{\prime} \mathrm{O}\right)$ en el cual las especies minerales detectadas corresponden a yeso, halita, thenardita, hexahedritay epsodimita. Siguen en abundancia relativa bloedita y carnalita; como menores, aubertita, kainita y starkeyita y, como trazas, loewita, steklita y humberstonita (Cortez, 2014). Más del 80\% de estos minerales corresponde a sulfatos, siendo siempre mayoritario el yeso.

Algunos ejemplos representativos, en el marco de unos 60 salares de este tipo, son Quisquiro o Loyoques $\left(23^{\circ} 13^{\prime} \mathrm{S} / 67^{\circ} 14^{\prime} \mathrm{O}\right)$, Laguna de Tara $\left(22^{\circ} 59^{\prime} \mathrm{S} / 67^{\circ} 17^{\prime} \mathrm{O}\right)$, Salar de Tara $\left(23^{\circ} 01^{\prime} \mathrm{S} / 67^{\circ} 18^{\prime} \mathrm{O}\right)$, Salar Aguas Calientes $\left(23^{\circ} 07^{\prime} \mathrm{S} / 67^{\circ} 24^{\prime} \mathrm{O}\right)$, Salar de Pajonales $\left(25^{\circ} 08^{\prime} \mathrm{S} / 68^{\circ} 49^{\prime} \mathrm{O}\right)$, Gorbea $\left(25^{\circ} 24^{\prime} \mathrm{S} / 68^{\circ} 40^{\prime} \mathrm{O}\right)$ e Ignorado $\left(25^{\circ} 29^{\prime} \mathrm{S} / 68^{\circ} 37^{\prime} \mathrm{O}\right)$.

El volcanismo Mioceno-Presente tiene una relación directa con todas estas cuencas endorreicas salinas formadas en la Alta Cordillera, tanto en lo que se refiere a la formación de las cuencas como al aporte de sales solubles que ingresan a éstas. Se trata de las cuencas evaporíticas más jóvenes de Chile. De acuerdo a Risacher y Fritz
(2009) y Risacher et al., (2003), las salmueras de los salares andinos en general son alcalinas, enriquecidas en sulfatos y carbonatos. Los mismos autores indican que los aportes de las salmueras estarían condicionados por la presencia de evaporitas fósiles, ahora bajo las rocas volcánicas, que aportarían sus iones. $\mathrm{El} \mathrm{pH}$ de las salmueras es normalmente neutro, pero en función de los aportes, en una minoría es ácido, por ejemplo, Salar de Gorbea, $\left(25^{\circ} 24^{\prime} \mathrm{S} / 68^{\circ} 40^{\prime} \mathrm{O}\right)$.

Los principales solutos que aporta el volcanismo son sulfatos (principalmente yeso) cloruros (mayoritariamente halita), carbonatos asociados a fuentes termales y boratos que, en el caso de Chile, son exclusivamente boratos dobles de Na y Ca (Chong, 2000)

Estos salares, asociados a sus cuencas hidrográficas, constituyen reservas de agua importantes del norte de Chile. Son el recurso único para la flora, fauna y microbiota existentes y son usados en la agricultura por los pueblos originarios. Flora, fauna, microbiota e hidrogeología de estas cuencas no son ampliamente conocidas y estudiadas, aunque en los últimos 20 años se ha intensificado la investigación de la microbiota con resultados que demuestran su gran variedad e importante potencial biotecnológico. En los últimos años, los recursos hídricos han sido explotados sistemáticamente en actividades industriales. La explotación minera única es la de boratos (Chong et al.,2000), aunque se considera que algunos de ellos poseen salmueras que pueden ser beneficiadas por litio. Los boratos aparecen en distintas concentraciones en todos los salares andinos, sin embargo, por su volumen de reservas, accesibilidad y costos de explotación, sólo algunos resultan explotables.

Adicionalmente, estos salares constituyen, en muchos casos, un paisaje único a nivel mundial. $\mathrm{Su}$ potencial para aplicar servicios ecosistémicos, especialmente en los aspectos de turismo, es una posibilidad no desarrollada y que contribuiría, en forma muy potente, a la sustentabilidad de este tipo de depósitos y al desarrollo regional.

Los yacimientos chilenos de boratos se encuentran exclusivamente en este tipo de salares y su edad se considera pleistocena/holocena. A su vez, los depósitos similares argentinos tienen edades 
que van desde el Mioceno al Pleistoceno, con una edad más antigua acotada en el orden de $6 \mathrm{Ma}$, y se reconocen tres ciclos de mineralización (Alonso, 1986).

Los factores descritos marcan la clara diferencia entre los yacimientos argentinos y chilenos que, aunque están ubicados en el mismo ambiente geológico, en los primeros se trata de reservas enormes, menas de mayor demanda comercial y una marcada variedad de yacimientos.

En los depósitos argentinos se encuentran las reservas de mayor volumen, calidad y variedad de boratos en el Hemisferio Sur (Alonso, 1986). En el caso de la mineralogía, desde el punto de vista comercial, los boratos mantienen una escala de valor económico de acuerdo a su composición, siendo los más valiosos los de Na y Ca. En Argentina están presentes prácticamente la totalidad de los boratos económicos de mayor valor; mientras que en Chile sólo se reconoce y explota la ulexita o natroboratocalcita $\left(\mathrm{NaCaB}_{5} \mathrm{O}_{9} \cdot 8 \mathrm{H}_{2} \mathrm{O}\right)$ un borato doble de $\mathrm{Na}$ y $\mathrm{Ca}$, asociado a halita, yeso y thenardita. Además, hay una presencia ocasional y no econó- mica de kaliborita $\left(\mathrm{KMg}_{9} \mathrm{~B}_{11} \mathrm{BO}_{9} \cdot 9 \mathrm{H}_{2} \mathrm{O}\right)$, inyoita $\left(\mathrm{Ca}_{2} \mathrm{~B}_{6} \mathrm{~B} \mathrm{O}_{11} \cdot 13 \mathrm{H}_{2} \mathrm{O}\right)$, bórax $\left(\mathrm{Na}_{2} \mathrm{~B}_{4} \mathrm{BO}_{7} 10 \mathrm{H}_{2} \mathrm{O}\right)$ y gowerita $\left(\mathrm{Na}_{2} \mathrm{~B}_{6} \mathrm{O}_{7}(\mathrm{OH})_{6} \cdot 2 \mathrm{H}_{2} \mathrm{O}\right)$ y trazas de otros minerales. Esta situación podría explicarse por el hecho de que estos cuerpos salinos son dinámicos, especialmente en su parte más superficial, por anegamientos, altas tasas de evaporación/evapotranspiración, gradiente geotermal, presencia de fuentes termales en las cuencas e intercambio iónico. Estos factores hacen que la condición de equilibrio de algunos minerales no se alcance. Por ejemplo, la ausencia de calcita/dolomita que presentan estos salares podría deberse a que esos minerales, al estar en solución y por efectos de la temperatura, generan inestabilidad en los boratos, transformando boratos de calcio en ulexita por el exceso de calcio. Sin embargo, probablemente la verdadera razón de las diferencias que se describen entre los yacimientos argentinos y chilenos, es que estos últimos son geológicamente más jóvenes, mientras que los argentinos muestran un mayor desarrollo a través de lapsos de edad geológica más amplios, resultando en diferentes tipos de depó-

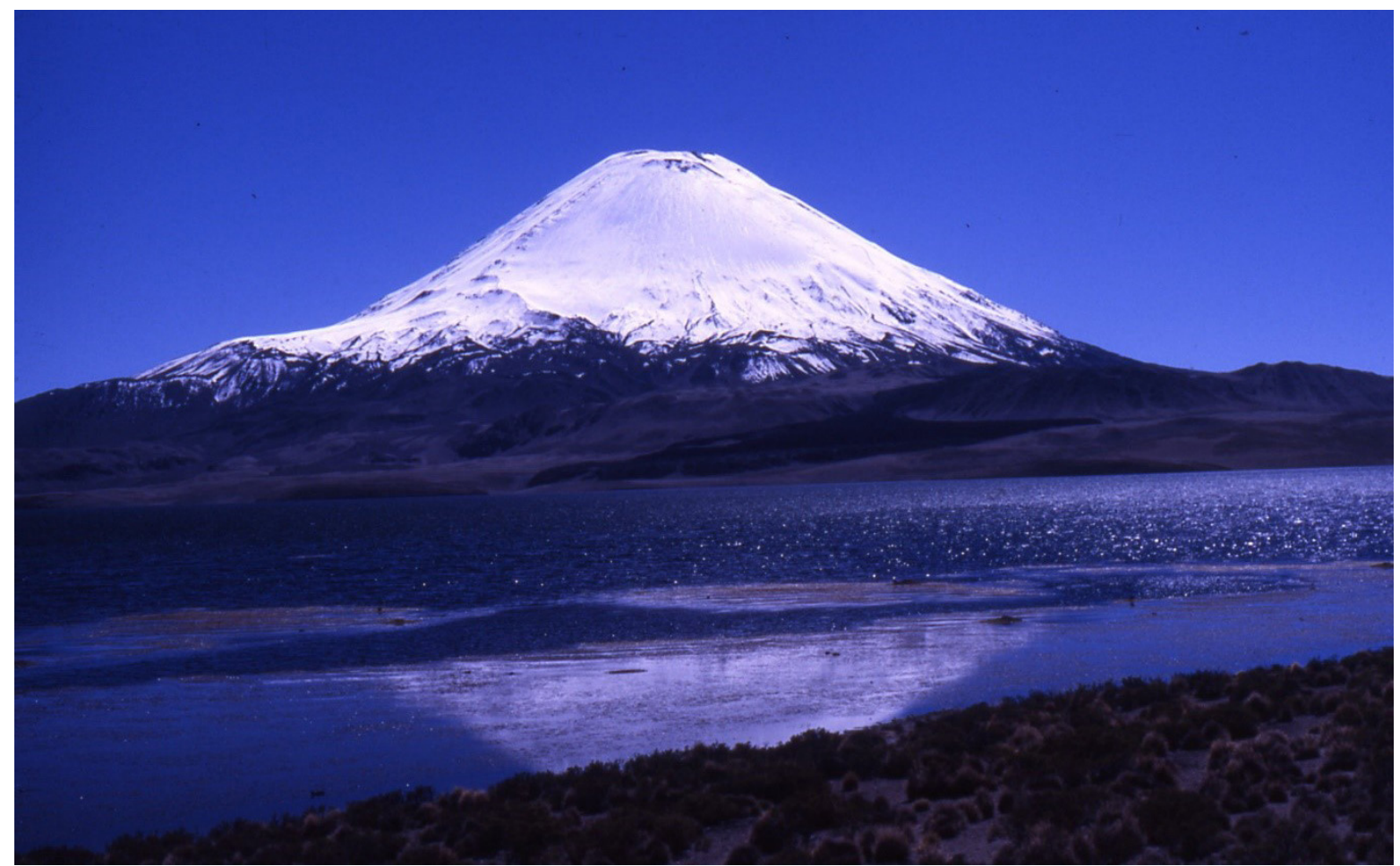

Figura 40 Lago Chungará ( $\left.18^{\circ} 14^{\prime} \mathrm{S} / 69^{\circ} 09^{\prime} \mathrm{O}\right)$. Una clásica cuenca endorreica andina que evoluciona a salar. Es el lago con mayor altitud del planeta. 


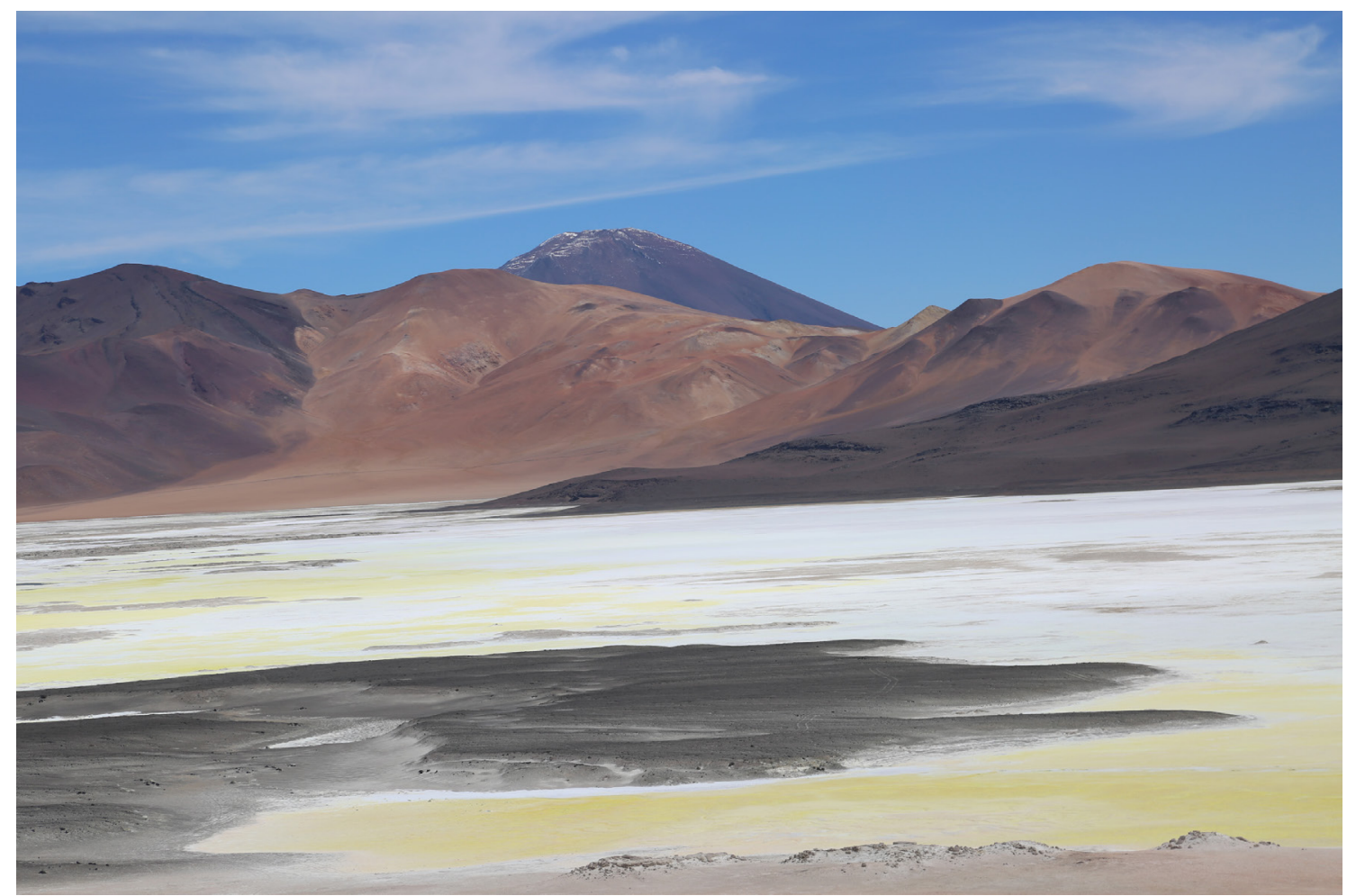

sitos. Esta situación abre la expectativa geológica de considerar que en Chile se podrían encontrar yacimientos similares a los argentinos.

De acuerdo a Chong et al., (2000), los yacimientos de boratos de los salares andinos son los únicos conocidos en Chile, y son explotados entre los 4,000 y los 4,500 m s.n.m. Sus cuencas son someras, aunque en el Salar de Surire $\left(18^{\circ} 50^{\prime} \mathrm{S} / 69^{\circ} 06^{\prime} \mathrm{O}\right)$ se reconocen más de $100 \mathrm{~m}$ de profundidad. Los aportes a las cuencas se relacionan directamente con la actividad volcánica que, incluso puede estar en el interior de éstas, como en el caso de Surire. Las salmueras pueden alcanzar hasta $50,000 \mathrm{mg} / \mathrm{l}$ de sólidos disueltos, llegando a valores 100 veces mayores que en las aguas meteóricas, y 10 veces mayores que los de las aguas termales. Los principales aportes se relacionan con las rocas volcánicas cenozoicas. Las salmueras son principalmente cloruradas, con iones principales como $\mathrm{Na}_{+}, \mathrm{Ca}^{2+}, \mathrm{Li}^{+}$, $\mathrm{Mg}^{2+}$ asociados a cloruros, sulfatos, boratos y carbonatos. Existen cantidades significativas de $\mathrm{As}$ y $\mathrm{Hg}$ y anomalías de $\mathrm{Sr}$, Cs y Rb. Yacimientos importan-

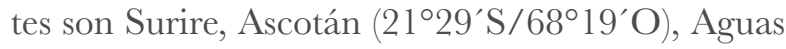

Calientes Norte $\left(23^{\circ} 07^{\prime} \mathrm{S} / 67^{\circ} 24^{\prime} \mathrm{O}\right)$, Quisquiro o Loyoques $\left(23^{\circ} 13^{\prime} \mathrm{S} / 67^{\circ} 14^{\prime} \mathrm{O}\right)$ y Aguas Calientes Sur $\left(23^{\circ} 31^{\prime} \mathrm{S} / 67^{\circ} 34^{\prime} \mathrm{O}\right)$. Los minerales explotados y explorados se encuentran aflorando o a profundididades de alrededor de un metro. Se presentan en forma de lentes desde centimétricos hasta $0.5 \mathrm{~m}$ o más de potencia (barras). que pueden distribuirse, en forma continua, en centenares o miles de metros cuadrados. La ulexita incluye abundante agua intersticial y la sobrecarga de yeso, halita y materiales volcánigénicos detríticos varía desde algunos $\mathrm{cm}$ hasta $1.0 \mathrm{~m}$ o puede no estar presente. Por debajo de los boratos se presentan arcillas saturadas de salmueras, a veces con horizontes centimétricos de rejalgar. La ulexita también se presenta en las arcillas superficiales como nódulos aislados (papas) desde $\mathrm{cm}$ a dm, con altas leyes de $\mathrm{B}_{2} \mathrm{O}_{3}$. Inmediatamente debajo de los horizontes económicos, sigue un nivel de agua subterránea. No existen antecedentes en relación a la presencia de ulexita por debajo del nivel de agua subterránea. Las anomalías de boro en las salmueras no son económicamente atractivas. 
En un solo caso, en el Desierto de Atacama, en Cerro de la Joya $\left(21^{\circ} 51^{\prime} \mathrm{S} / 69^{\circ} 23^{\prime} \mathrm{O}\right)$, se han reconocido boratos (ulexita) en horizontes centimétricos inmediatmente por debajo de la cubierta aluvial. Éstos fueron explotados por un corto lapso y la explotación se abandonó por lo exiguo de sus reservas (Chong et al.,2000).

Entre los años 2009 a 2018, Chile exportó, desde los salares, un promedio de 101,000 ton de ácido bórico y un promedio de 520.352 ton de ulexita (SERNAGEOMIN, 2018).

\section{Los Yacimientos de Nitratos y Yodo del Norte de Chile (YNY)}

\subsection{INTRODUGGIÓN}

Los YNY son los depósitos de Minerales Industriales más importantes del país y de ellos se obtienen nitratos de sodio y potasio con el nombre genérico de salitre, yodo como subproducto y existió una producción irregular de sulfato de sodio. En el pasado se experimentó, con resultados negativos, la posibilidad de recuperar boratos. Hoy se debería llamar la industria del Yodo con el subproducto nitratos toda vez que la casi totalidad de las empresas activas del rubro producen exclusivamente yodo.

La industria floreció a inicios del siglo 19 y decayó con la invención del "Salitre Sintético", durante la Primera Guerra Mundial. Sus establecimientos mineros, las Oficinas Salitreras y Campamentos, originalmente agrupados en Cantones, fueron apagando sus fuegos en forma progresiva y, con la Gran Depresión Económica de 1930, prácticamente desaparecieron como una actividad económica principal. Algunas oficinas siguieron produciendo, beneficiadas por el alto costo del producto sintético y apoyadas en subvenciones del Gobierno. En esta iniciativa incluso se crearon algunas nuevas oficinas (Chacabuco, 1922; María Elena, 1926; Pedro de Valdivia, 1931; Victoria, 1944). Hoy, funcionando como una oficina completa, produciendo nitratos y yodo, solo sobrevive María Elena (22²0’S/6940’O). En la década de 1980, la industria experimentó un giro positivo con el aumento de la demanda y precio internacional del yodo. Desde entonces, y hasta hoy, el principal producto de esta industria es el yodo, mismo con el cual Chile ha liderado la producción mundial compitiendo con Japón. La principal empresa del rubro es la Sociedad Química y Minera de Chile (SQM) que, además, produce nitratos de sodio y potasio en forma subordinada.

La producción promedio de nitratos entre los años 2009-2018 ha sido del orden de 875,000 ton/año y la de yodo, en el mismo lapso, del orden de 18,400 ton/año (SERNAGEOMIN, 2018).

Estos yacimientos presentan algunas características exclusivas, como son sus reservas de cientos de millones de toneladas. Existen yacimientos relativamente similares en el NW de China, en la localidad de Xiao Lao Hu, Desierto de Taklamakan, a unos $70 \mathrm{~km}$ de la ciudad de Thurpan, pero estos no incluyen yodo y sus reservas no son comparables a las de Chile. También es conocida la existencia de nitratos en ambientes desérticos de Namibia (Ericksen, 1983) y Estados Unidos (Mansfield y Boardman,1932), pero éstas no constituyen yacimientos, se asemejan lejanamente a los chilenos solo por sus ambientes desérticos. De hecho, los intentos de poner en producción los depósitos norteamericanos durante la Primera Guerra Mundial e iniciativas posteriores, fracasaron por la calidad de los depósitos.

Otro factor relevante y distintivo de los yacimientos chilenos es que su mena, el "caliche", incluye un ensamble de minerales solubles en agua que difícilmente se encuentra en la Naturaleza. Por otra parte, la solubilidad de estas sales no las hace compatibles con su estabilidad natural durante millones de años mientras que aquí se conservan debido al marco climático/paleoclimático y geomorfológico del territorio, donde están emplazadas. Se debe aclarar que el término caliche en Chile se usa exclusivamente para denominar a la mena de nitratos.

En lo que se refiere al origen de las sales y a los procesos de formación de los yacimientos, persisten dudas razonables sin respuestas aceptadas unánimamente. Recién en la década de 1990 
comenzaron a aplicarse estudios de láminas delgadas, inclusiones fluidas y microscopía electrónica a sus minerales. Se observa un claro divorcio entre el conocimiento de estos depósitos en el campo con algunos resultados y conclusiones obtenidos en laboratorios. También son argumentos lógicos que las empresas que explotan y han explotado estos yacimientos asuman que el enorme volumen de reservas no hace necesario su conocimiento geológico. A esto se agrega que el objetivo prioritario de esta industria, por más de 70 años, ha sido sobrevivir. Hoy las empresas cuentan con escasos geólogos asociados a su producción y ninguno relacionado con la investigación.

\subsection{UBICACIÓN DE LOS YNY}

Los depósitos se pueden ubicar con criterios geográficos, geomorfológicos y geológicos. Geográficamente se ha decidido ubicar las Oficinas Salitreras porque éstas incluyen los yacimientos (pampas), las instalaciones de beneficio, los campamentos, las áreas de relaves (tortas) y las minas (calicheras) (Figuras 49,50 y 52). Los yacimientos se extienden a lo largo de una franja de unos $700 \mathrm{~km}$, entre Pampa Tana por el norte $\left(19^{\circ} 23^{\prime} \mathrm{S} / 70^{\circ} 08^{\prime} \mathrm{O}\right)$ hasta aproximadamente Cerro La Peineta $\left(25^{\circ} 00^{\prime} \mathrm{S} / 70^{\circ} 08^{\prime} \mathrm{O}\right)$, por el sur. Si se considera que en el pasado no se explotaban leyes inferiores a $14-15 \%$ de nitratos y se conocen yacimientos cubiertos por sedimentos, esta franja debe estimarse continua. El límite septentrional es tentativo toda vez que algunos Salares de las Pampitas en la Depresión Central $\left(25^{\circ} 24^{\prime} \mathrm{S} / 68^{\circ} 40^{\prime} \mathrm{O}\right)$ contienen anomalías significativas de nitratos y yodo. La principal discontinuidad N-S de esta franja se debe a una estructura continental probablemente asociada al Lineamiento Calama -Olacapato- Toro (Salfity, 1985), que crea un segmento separado de yacimientos (Figuras 2 y 53).

Desde el punto de vista geomorfológico, los yacimientos se disponen, en su totalidad, entre el borde oeste de la Precordillera y la Cordillera de la Costa. Su mayor concentración se ubica entre la parte oeste de la Depresión Central y este de la Cordillera de la Costa. No existe ningún yacimiento al oriente de la Precordillera (Figura 53).

En lo que se refiere al marco geológico, los yacimientos, en su mayoría, se ubican entre los principales sistemas estructurales del Norte de Chile, el Sistema de la Falla de Atacama (Jurásico), al oeste, y el Sistema de la Falla Domeyko o "West Fissure" (Terciario), al este. Aunque no parecen guardar relación con algún tipo de unidad estratigráfica o intrusiva, todos los yacimientos se ubican al oeste de la franja volcánica del Paleógeno, o están incluidos en ésta. Se menciona un yacimiento único en las cercanías del Volcán Maricunga $\left(32^{\circ} 21^{\prime} \mathrm{S} / 71^{\circ} 15^{\prime} \mathrm{O}\right)$, pero no se han encontrado antecedentes al respecto. No se cuenta con información de la edad de los yacimientos; sin embargo, considerando que se disponen debajo de las secuencias salinas de Llamará con una edad cercana a los $6 \mathrm{Ma}$ (Bao et al., 1999), se puede especular una edad tentativa Plioceno-Mioceno.

\subsection{MARCO GEOLÓGICO DE LOS YNY}

Salvo Whitehead (1920), la literatura no relaciona los YNY con un entorno geológico específico $y$, en este trabajo, tenemos la hipótesis de que esa relación existe como describimos más adelante. El marco geológico general, de acuerdo a Chong (1994), tiene las siguientes características principales:

- Las rocas del Paleozoico tienen una escasa presencia. Se trata de secuencias marinas y continentales afectadas por metamorfismo e intrusivos plutónicos que se asignan al Devónico, Carbonífero y Pérmico.

- En el Triásico se reconocen secuencias marinas y continentales intercaladas con series volcánicas e intrusivos hipabisales.

- El Jurásico está representado por formaciones marinas, continentales, evaporíticas y volcánicas de composición intermedia e intrusivos intermedios a básicos.

- $\mathrm{Al}$ Cretácico inferior corresponden rocas volcánicas y continentales y escasos afloramientos de secuencias marinas, además de intrusivos de composición intermedia. A su 
vez, el Cretácico superior incluye rocas volcánicas de composición ácida a intermedia, sedimentitas continentales y rocas intrusivas plutónicas.

Las rocas que se observan más relacionadas con los YNY pertenecen al Cretácico SuperiorPaleógeno. Sus secuencias se emplazan en la parte oriental y central de la Depresión Central, especialmente en su parte sur; mientras que, hacia el norte, están cubiertas, como sucede en la Pampa del Tamarugal. Su litología incluye riolitas, dacitas, andesitas y basaltos, asociados a intrusivos hipabisales ácidos, emplazados como diques, mantos o domos y apófisis de dioritas. Se reconocen, además, paleocampos termales y secuencias lacustres. Constituyen las rocas encajadoras de numerosos YNY y tienen una disposición espacial que podría relacionarse con el eventual origen de éstos. La hipótesis de trabajo que se establece entre estas rocas volcánicas paleógenas y los YNY se basa en los siguientes antecedentes:

- La gran mayoría de los YNY se ubican hacia el oeste o en el interior del área de afloramientos del dominio volcánico Cretácico
Superior-Paleógeno y de los productos de su erosión.

- Las rocas volcánicas paleógenas se asocian, espacial y genéticamente, a numerosos yacimientos epitermales y pórfidos cupríferos. La movilización y concentración del volumen de iones metálicos de esos depósitos necesitó, originalmente, una cantidad importante de iones salinos en los magmas originales.

- Los YNY del tipo en roca que se emplazan en algunas de las rocas volcánicas paleógenas no guardan ninguna relación con algún proceso de sedimentación asociado, Están exclusivamente en estas rocas como vetas, mantos y cuerpos irregulares (Figura 55A).

- La columna estratigráfica de las rocas volcánicas del Paleógeno incluye la presencia de paleocampos termales y secuencias lacustres y fluviales (Figura 54). Algunos de esos lagos incluyen YNY y los paleocampos termales están estrechamente relacionados con horizontes salinos.

- En yacimientos epitermales de Au paleógenos se han encontrado núcleos salinos, totalmente aislados, de sulfatos cloruros y nitratos (darapskita, humberstonita), asociados a los cuerpos metálicos y sus zonas de alteración.

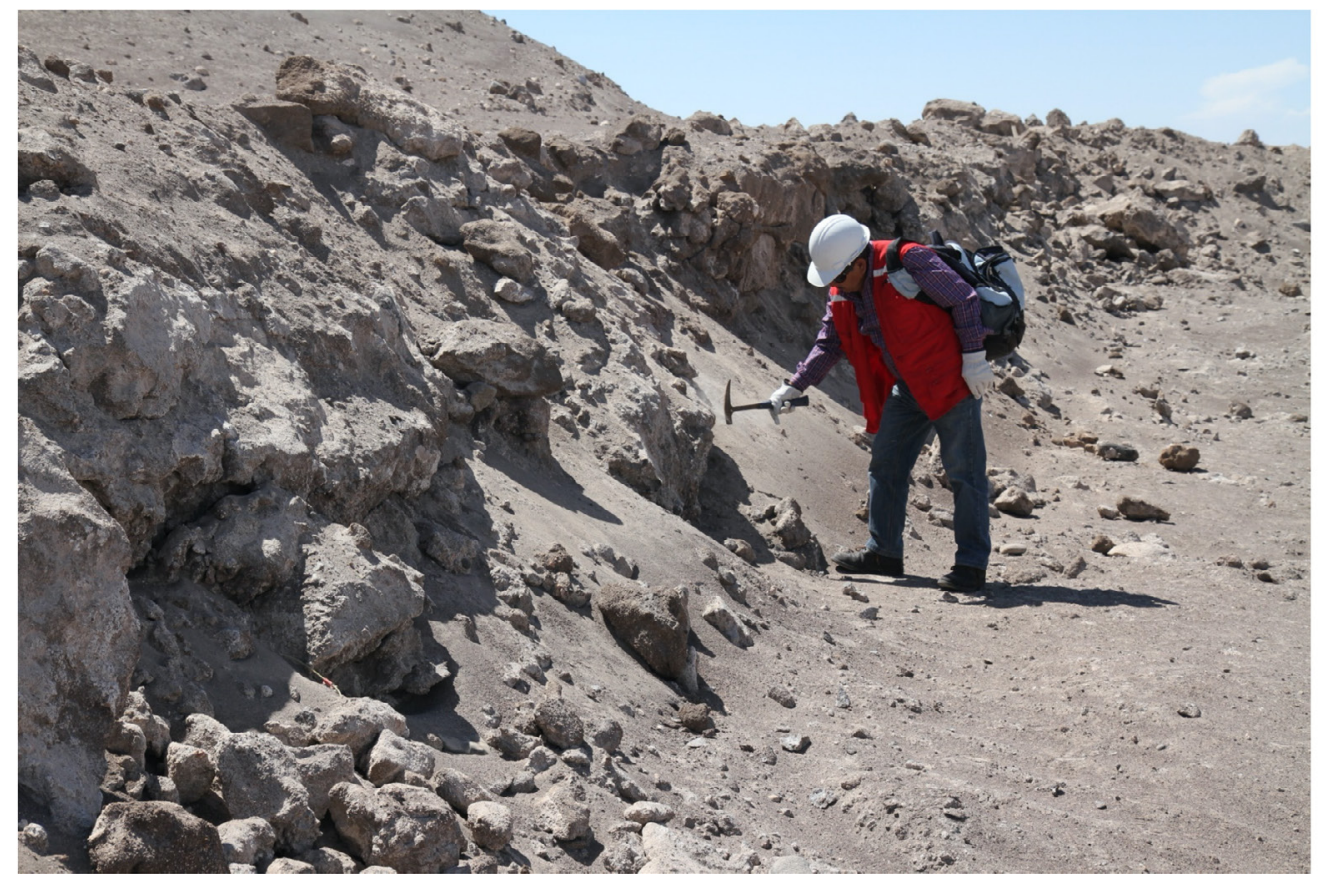




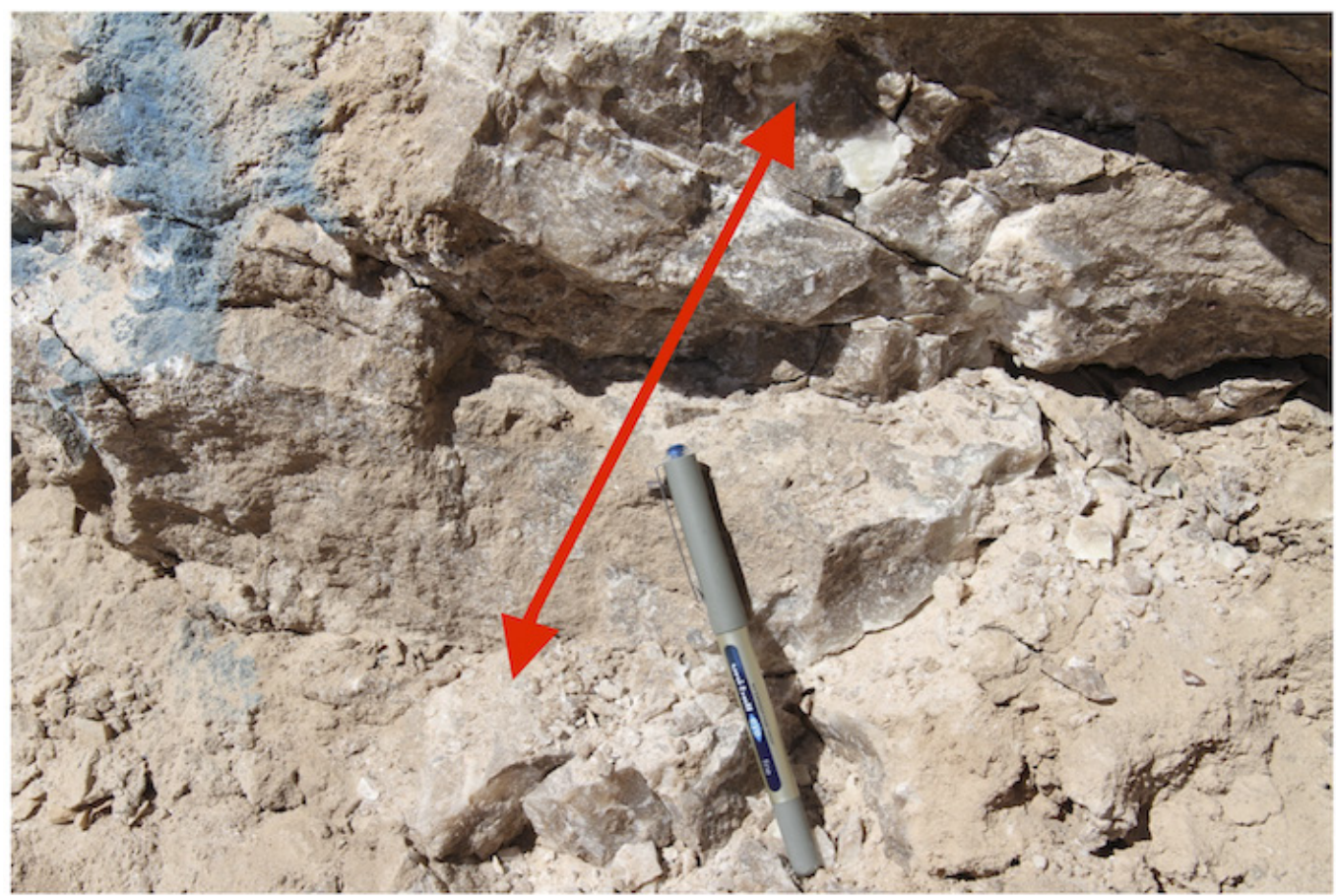

Figura 43 Aspecto del caliche negro en un yacimiento sedimentario. El caliche es todo el ancho que aparece marcado con la doble flecha roja. Distrito de Aguas Blancas (2406 'S/6948'O).

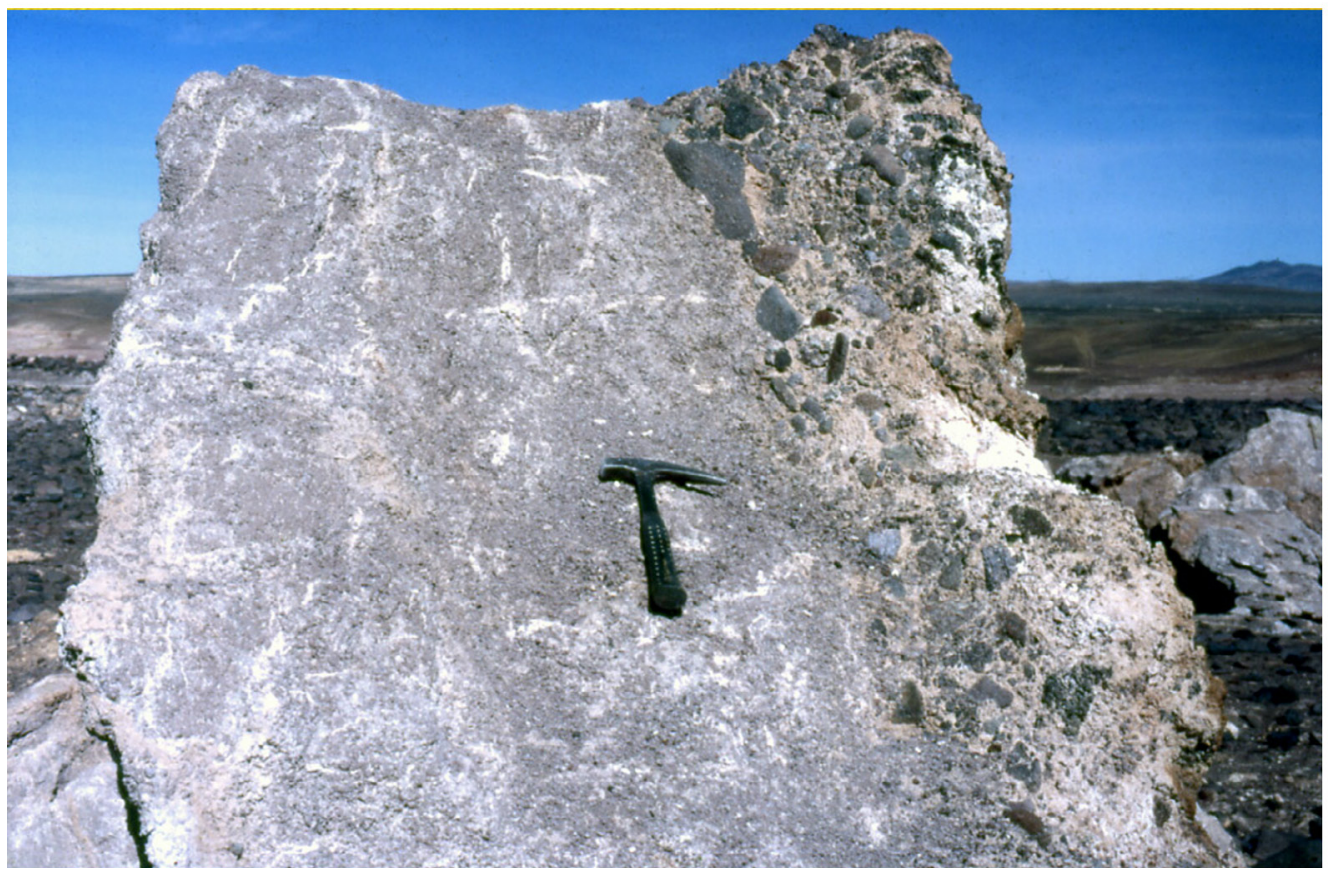

Figura 44 Un bloque no explotado en un laboreo de la secuencia sedimentaria descrita para los yacimientos: Costra (conglomerado con sales) y Caliche (la unidad sobre la cual está el martillo). 


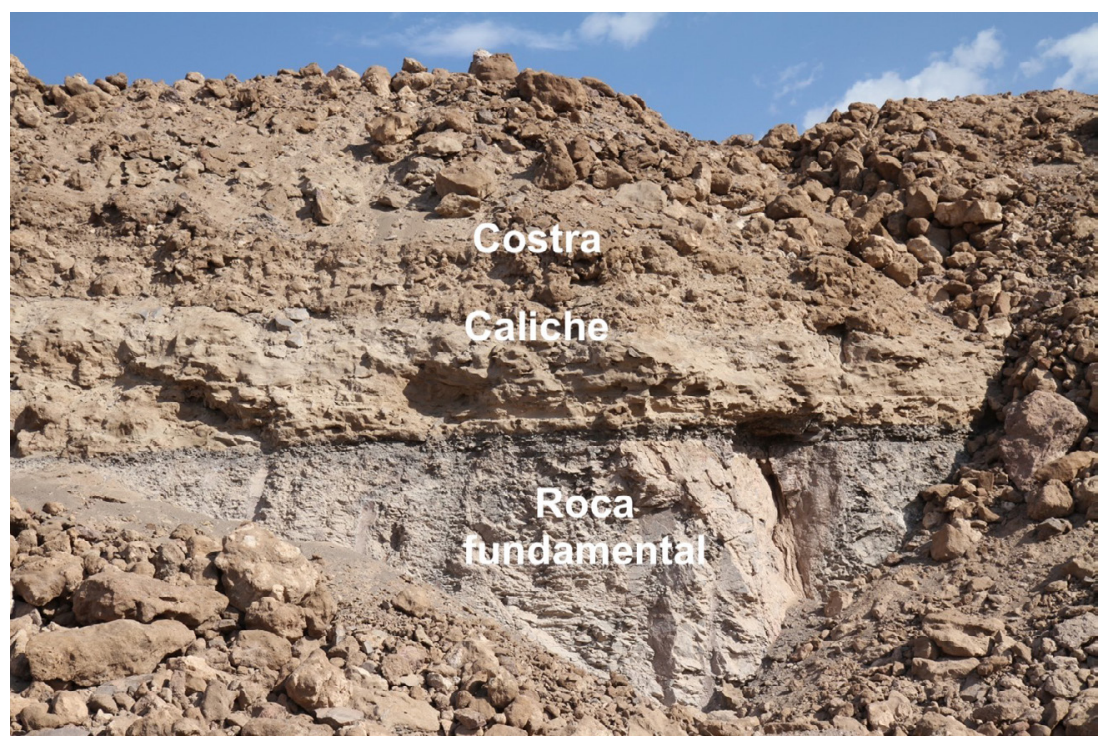

Figura 45 Perfil en un laboreo de la Oficina Santa Luisa ( $20^{\circ} 12^{\prime} \mathrm{S} / 69^{\circ} 48^{\prime}$ O) Se observa la Costra e inmediatamente debajo el Caliche que sobreyace al basamento de roca. Este es uno de los casos en que la tradicional secuencia que se describe para los yacimientos sedimentarios de nitratos, no esta presente.

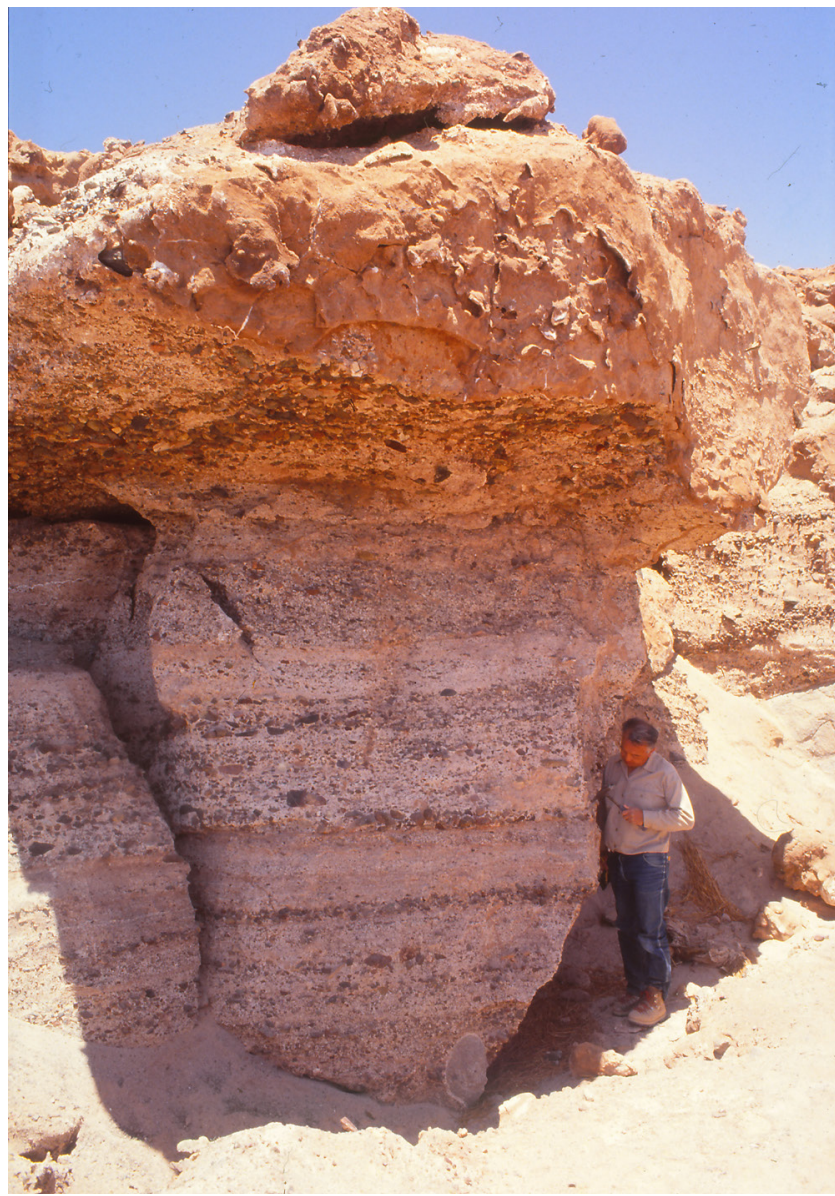

Figura 46 Secuencia sedimentaria donde se observa un estrato superior detrítico salino. Debajo una secuencia de estratos fluviales. El caliche está debajo de la persona. Un caso en que no existe la secuencia regular de los yacimientos sedimentarios que se describe tradicionalmente. 


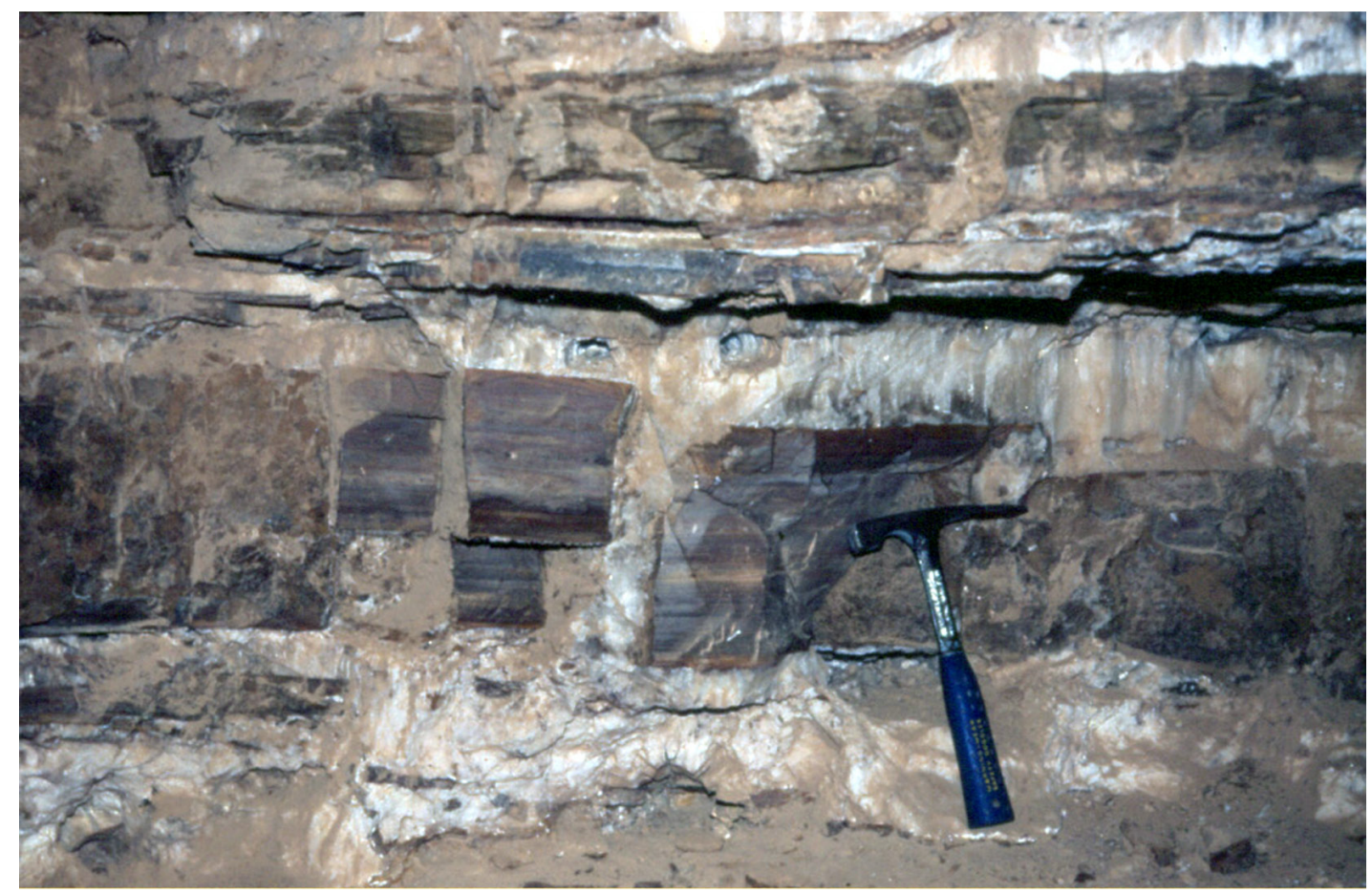

Figura 47 Yacimiento tipo manto con caliche blanco en los planos de contacto entre estratos de rocas calcáreas del Jurásico. Distrito de Zapiga.

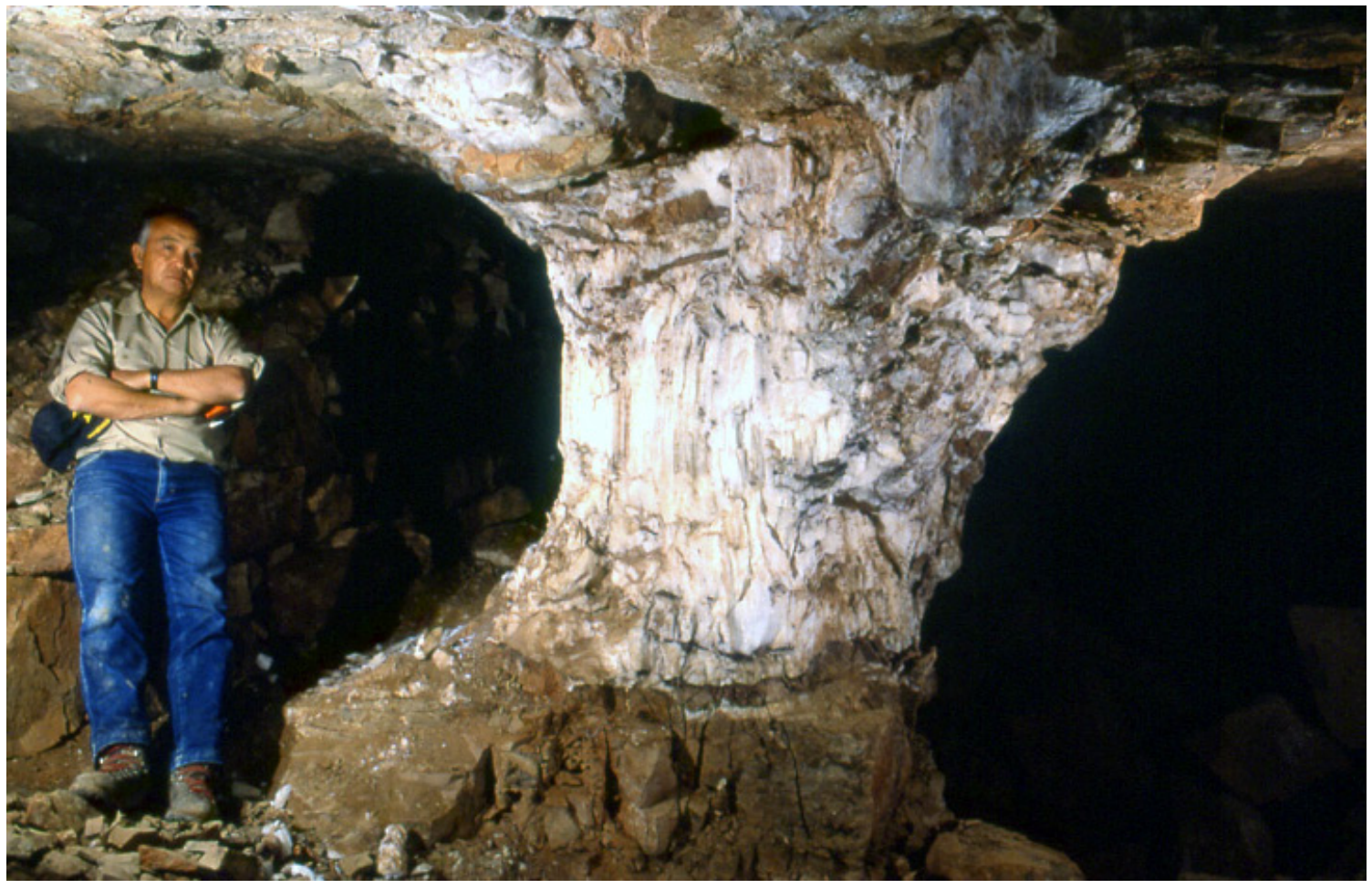

Figura 48 Manto de caliche blanco. Distrito de Zapiga. 


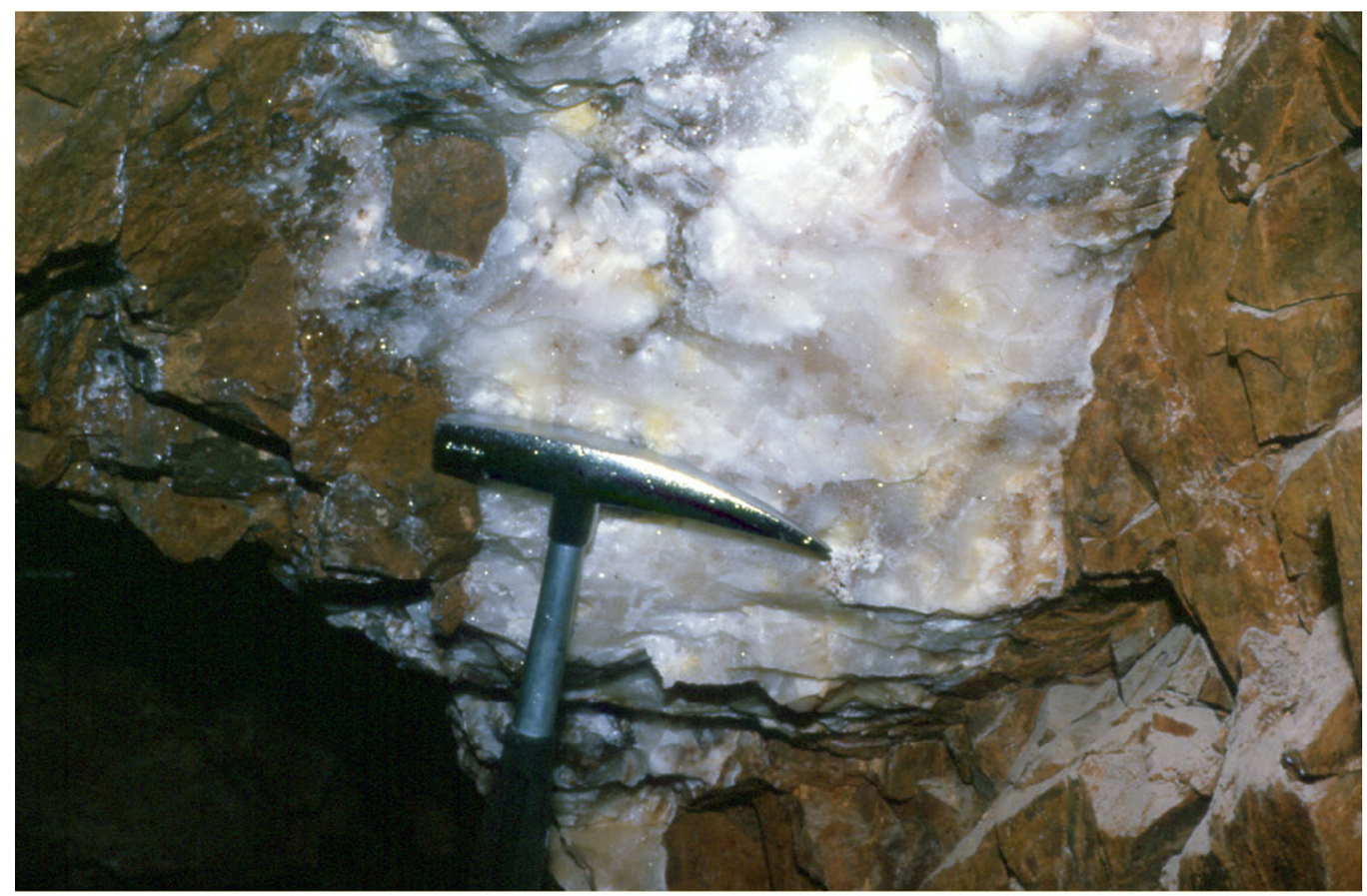

Figura 49 Veta de caliche blanco. Oficina Santa Rita (19 $\left.42^{\prime} \mathrm{S} / 69^{\circ} 58^{\prime} \mathrm{O}\right)$.

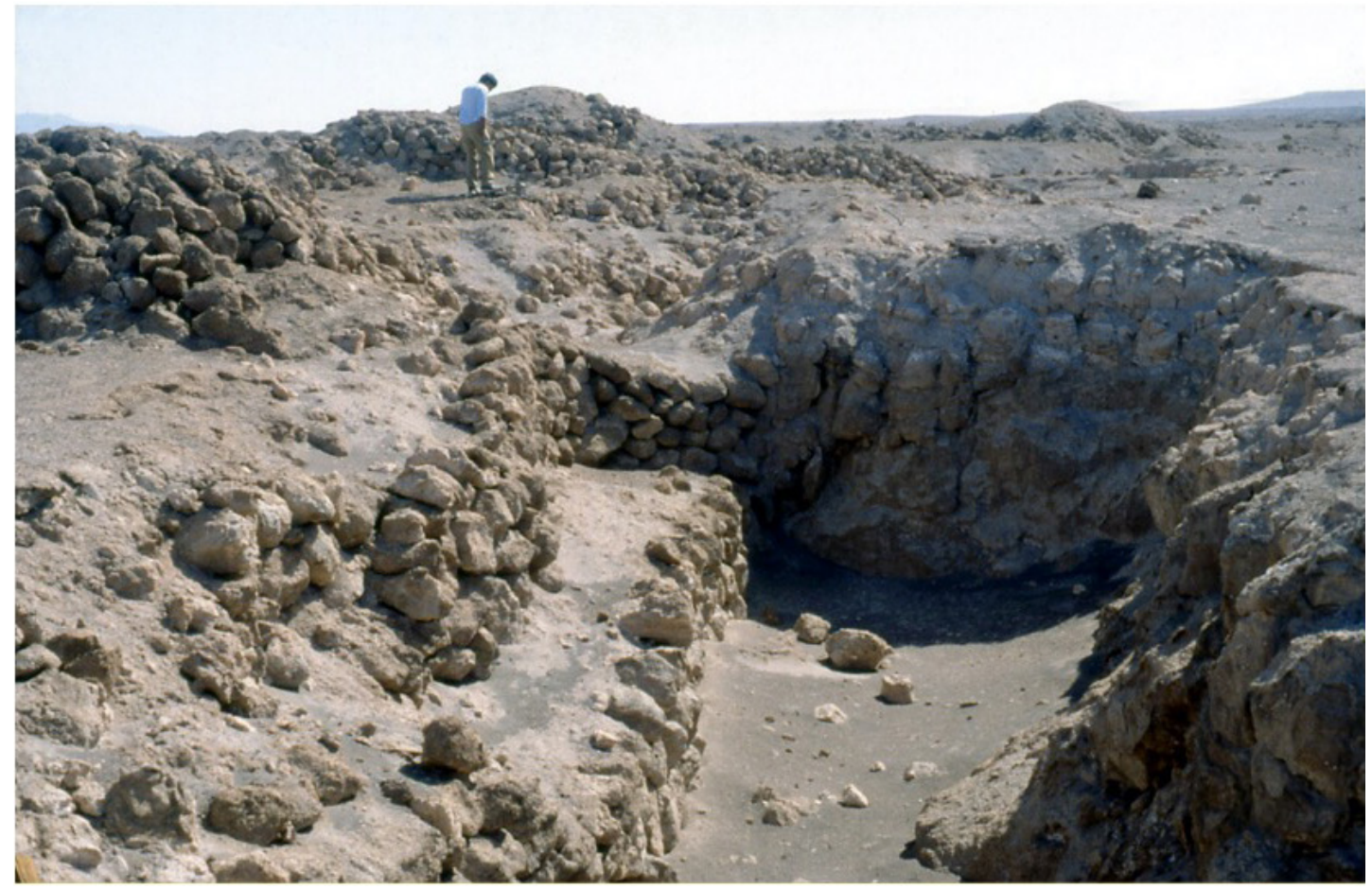

Figura 50 Calichera. Labor donde se explotan los yacimientos sedimentarios. 


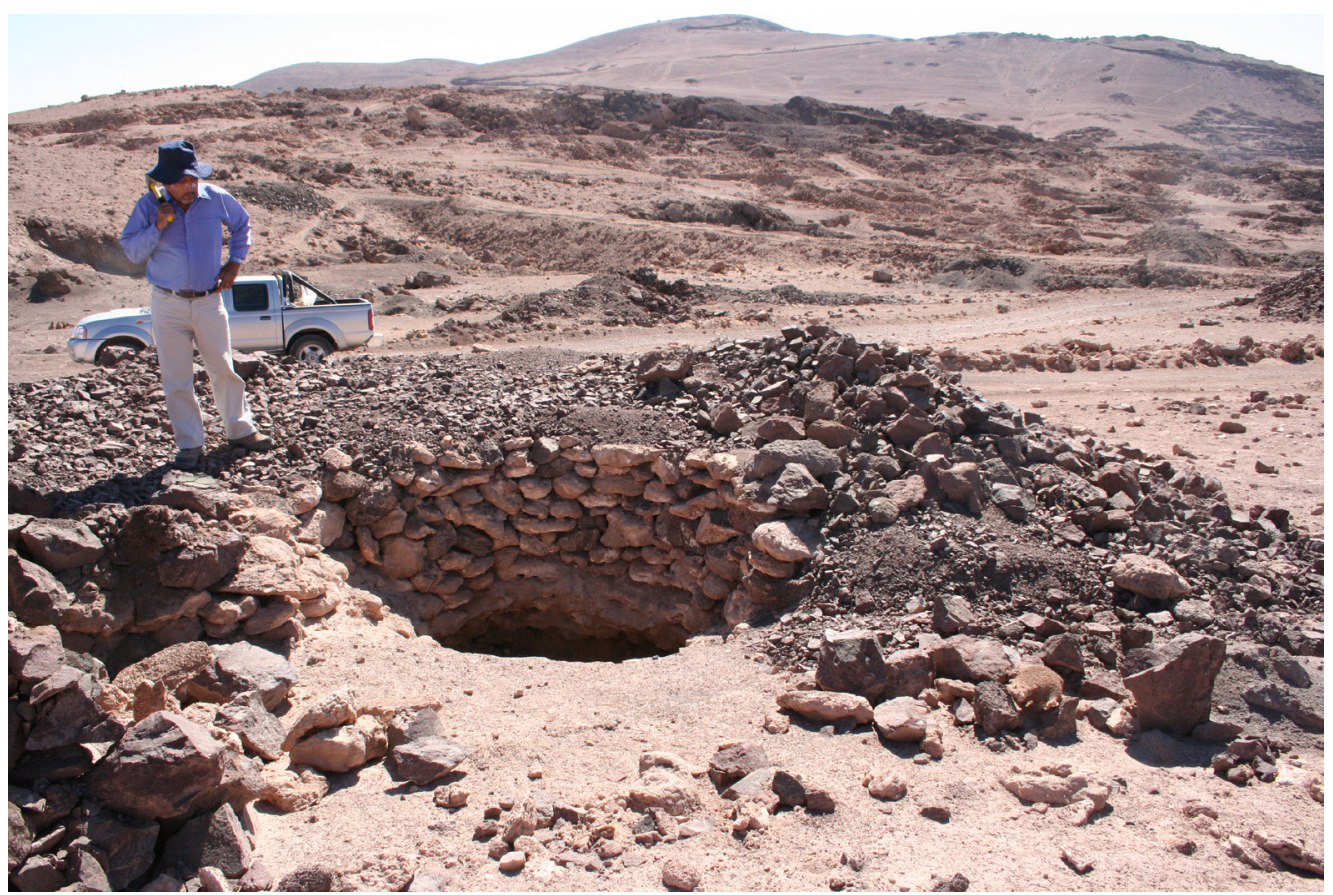

Bocamina (Pique) de un laboreo "en cuevas" donde se explotaron los yacimientos subterráneos en roca.

\subsection{LOS YACIMIENTOS}

Los YNY corresponden a un ensamble de minerales salinos que se emplaza, de diferentes maneras, en rocas encajadoras de distintas edades y litologías. Se presentan como cemento de rocas sedimentarias detríticas continentales, en secuencias sedimentarias lacustres o en brechas volcánicas, diseminados en rocas volcánicas, formando vetas y mantos hospedados en rocas volcánicas del Paleógeno o marinas del Jurásico, en "diques de barro" o neptúnicos y en costras de salares de la Depresión Central. Es común la existencia de distintos tipos de yacimientos en una misma área, especialmente en la parte oriental de la Depresión Central.

Las sales de estos depósitos son solubles en agua y corresponden, de manera principal, a nitratos, iodatos, cromatos y dicromatos asociadas a otras más comunes como cloruros, sulfatos y boratos. La presencia de cloratos y percloratos es detectada en los análisis químicos, pero no se conoce su expresión mineralógica. No hay un estudio definitivo sobre los elementos trazas, incluyendo el litio. Los cationes principales son $\mathrm{Na}^{+}, \mathrm{K}^{+}, \mathrm{Ca}^{+2}$ y $\mathrm{Mg}^{+2}$.
La mineralogía (Anexo, Tabla 1), producto de estos elementos, es compleja y ha sido documentada en dos etapas principales: una previa y otra posterior a los trabajos de Ericksen et al., (1974, 1986, 1989) y Mrose et al., (1970).

La clasificación inicial de los yacimientos es la de Whitehead (1920), quien los separó en antiguos, maduros y jóvenes, pero sin argumentos que fundamenten esa clasificación. Ericksen (1963) reconoció depósitos aluviales, en rocas y en salares en la clasificación más completa realizada con conocimiento de terreno de estos depósitos. Rivera y Stephens (1988) separaron yacimientos primarios de secundarios, pero esta división no se ajusta al marco geológico que proponen. Chong (1994), sobre la base de Ericksen (1963, 1981), usa la misma clasificación de ese autor, pero con el término "sedimentario", reemplazando al de aluvial y, además, generaliza un grupo de "yacimientos misceláneos".

En este trabajo se consideran yacimientos primarios y secundarios con el criterio de que los primeros son aquellos que corresponden a depósitos originales, como por ejemplo las vetas y mantos del grupo de Oficinas Pisssis, Cochrane y Domeyko 
en el área de Cerro Boquete $\left(23^{\circ} 58^{\prime} \mathrm{S} / 69^{\circ} 37^{\prime} \mathrm{O}\right)$ (Figura 55A) Los secundarios serían aquellos derivados de su removilización, especialmente durante cambios paleoclimáticos. De acuerdo a esto, describimos yacimientos sedimentarios con subdivisiones en sistemas aluviales; de paleolagos; en roca con subdivisiones en aquellos de rocas marinas jurásicas, como encajadoras o volcánicas paleógenas, y en salares de diferentes tipos. Admitimos que esta clasificacacion es descriptiva y que necesita una revision más estricta en sus categorías, tema en el cual trabajan estos autores. Como se ha mencionado, el término caliche no es sinónimo al descrito originalmente en Sedimentología (es decir, como un suelo con horizontes duros de carbonatos). El caliche ha sido descrito con muchos nombres artesanales-mineros de acuerdo con su apariencia física (blanco, negro, amarillo, canario, azufrado, apiedrado, achancacado, violeta, etc.) Esta nomenclatura está obsoleta, no es de uso práctico y hoy se mantienen los términos "caliche blanco" y "caliche negro". El primero está restringido a minerales de alta ley en nitratos y halita. El término "caliche negro", el más abundante, se aplica a la roca sedimentaria detrítica de color pardo claro, en la cual la mena es su cemento. Los tipos de caliche más característicos se exponen en las Figuras $52 \mathrm{~A}$ a la 52F.

\subsubsection{YACIMIENTOS SEDIMENTARIOS}

En estos depósitos, el caliche corresponde al cemento de rocas sedimentarias depositadas en ambientes desérticos con litología que incluye brechas, areniscas finas y gruesas, y conglomerados. Es común que se asocien vetas subordinadas y vetillas de nitratos y cloruros por removilización. Son los yacimientos de mayores dimensiones y, en su mayoría, se ubican en cuencas, en las partes distales de conos aluviales y cubren sierras de baja altura. En ellos se describe un perfil estándar en que se reconocen, desde arriba, las unidades "losa", "chuca", "costra", "caliche" y "conjelo/ coba". En operaciones mineras recientes se describieron como superficie ("losa"+"chuca"), sobrecarga (="costra"); explotable (="caliche") y asiento o subyacente (="conjelo o coba").
Las descripciones asumen una afinidad sedimentaria única con cambios litológicos y salinos relacionados con la evolución de los depósitos (Ericksen 1981; Chong 1984; Van Moort 1985). La unidad "chuca", descrita también como "panqueque", está formada por material clástico de grano fino, anhidrita, yeso y menor halita y, por sus características, en este trabajo, lo asimilamos al suelo tipo gypsysol. Está muy bien cementado y puede incluir en su base horizontes de tenardita, mirabilta, ulexita. Su espesor varía desde 60-80 $\mathrm{cm}$ hasta más de $1.5 \mathrm{~m}$. En algunos sectores presenta polígonos de desecación muy profundos y, localmente, sobreyace directamente a los niveles de caliche. Costra y caliche son unidades distintivas. Sin embargo, en algunos perfiles pueden formar un capítulo único de sedimentación con una diferenciación debido a lixiviación vertical. La "costra" está enriquecida en sulfatos, mientras que el "caliche" subyacente incluye sales más solubles como nitratos y cloruros (Figuras 43,44 y 45).

En este trabajo, y después de conocer numerosos yacimientos, se considera que este perfil no se puede tomar como standard para todos los yacimientos sedimentarios. De acuerdo a esto, consideramos que la "chuca" o "panqueque" es posterior e independiente del proceso de formación de los YNY sedimentarios. Esto está corroborado porque en muchos lugares donde este horizonte salino-sedimentario está presente, los nitratos están totalmente ausentes. En otros lugares, el perfil, donde se incluye el caliche, presenta varios capítulos sedimentarios suprayacentes o se observa la repetición de algunos horizontes salino-sedimentarios. (Figuras 44,45 y 46).

Otro tipo de yacimiento sedimentario corresponde a caliche incluido en sedimentitas lacustres que infrayacen a las costras salinas de un salar. Este tipo de depósito solo ha sido reconocido recientemente y fue explotado en forma intensiva hasta el año 2017 (Figura 42). Otros depósitos en paleolagos corresponden a aquellos formados en la parte distal de antiguos conos aluviales de eje norte-sur, en la Depresión Central. Estos lagos fueron relativamente profundos e incluyen estructuras de slumping (Figura 54). 
Un tercer tipo de yacimiento sedimentario es el que tiene, como roca encajadora, brechas volcánicas, como en el caso de algunos depósitos en Pedro de Valdivia $\left(22^{\circ} 36^{\prime} \mathrm{S} / 69^{\circ} 40^{\prime} \mathrm{O}\right)$, y otros del área de

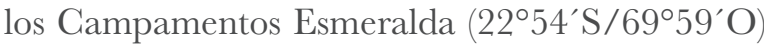
y Algorta $\left(22^{\circ} 52^{\prime} \mathrm{S} / 69^{\circ} 49^{\prime} \mathrm{O}\right)$.

Originalmente, a estas secuencias sedimentarias se les asignó una edad cuaternaria; sin embargo, las evidencias en terreno revelan que son bastante más antiguas. Por ejemplo, hay yacimientos que infrayacen a los depósitos salino-detríticos de la Cuenca de Llamará a los cuales se les asigna una edad cercana a los $6 \mathrm{Ma}$ (Bao et al., 1999).

Finalmente, se puede considerar un subtipo de yacimiento sedimentario aquellos formados en la parte distal de conos aluviales más jóvenes (Plioceno?), como los de la Oficina Puelma (231 $\left.11^{\prime} \mathrm{S} / 69^{\circ} 39^{\prime} \mathrm{O}\right)$.

Los Yacimientos sedimentarios han sido trabajados en laboreos abiertos desde la superficie, que se conocen del léxico salitrero como "Calicheras"(Figura 50).

\subsubsection{YACIMIENTOS ASOCIADOS A DIQUES CLÁSTICOS O NEPTÚNICOS}

Los diques salino-clásticos, tienen una amplia distribución en los YNY (Figuras 27 y 54B). Se forman como relleno a presión de fracturas desde la superficie y pueden presentar una zonación lateral debido a ciclos repetidos de inyección. Fueron denominados diques de arena por Ericksen (1981), quien indica que su contenido en nitratos es de alta ley. Esto último es comprobado por el hecho que hay laboreos donde se explotaron exclusivamente estos cuerpos

\subsubsection{YACIMIENTOS EN ROGA}

Son yacimientos de caliche blanco con altas leyes de nitrato y contenido de cloruro de sodio que se hospedan como vetas, cuerpos masivos irregulares o mantos que pueden alcanzar potencias superiores al metro (Figuras 47,48,49,54A y 54B). Las rocas huéspedes corresponden a dos grupos bien definidos en edad y litología y, en un caso,
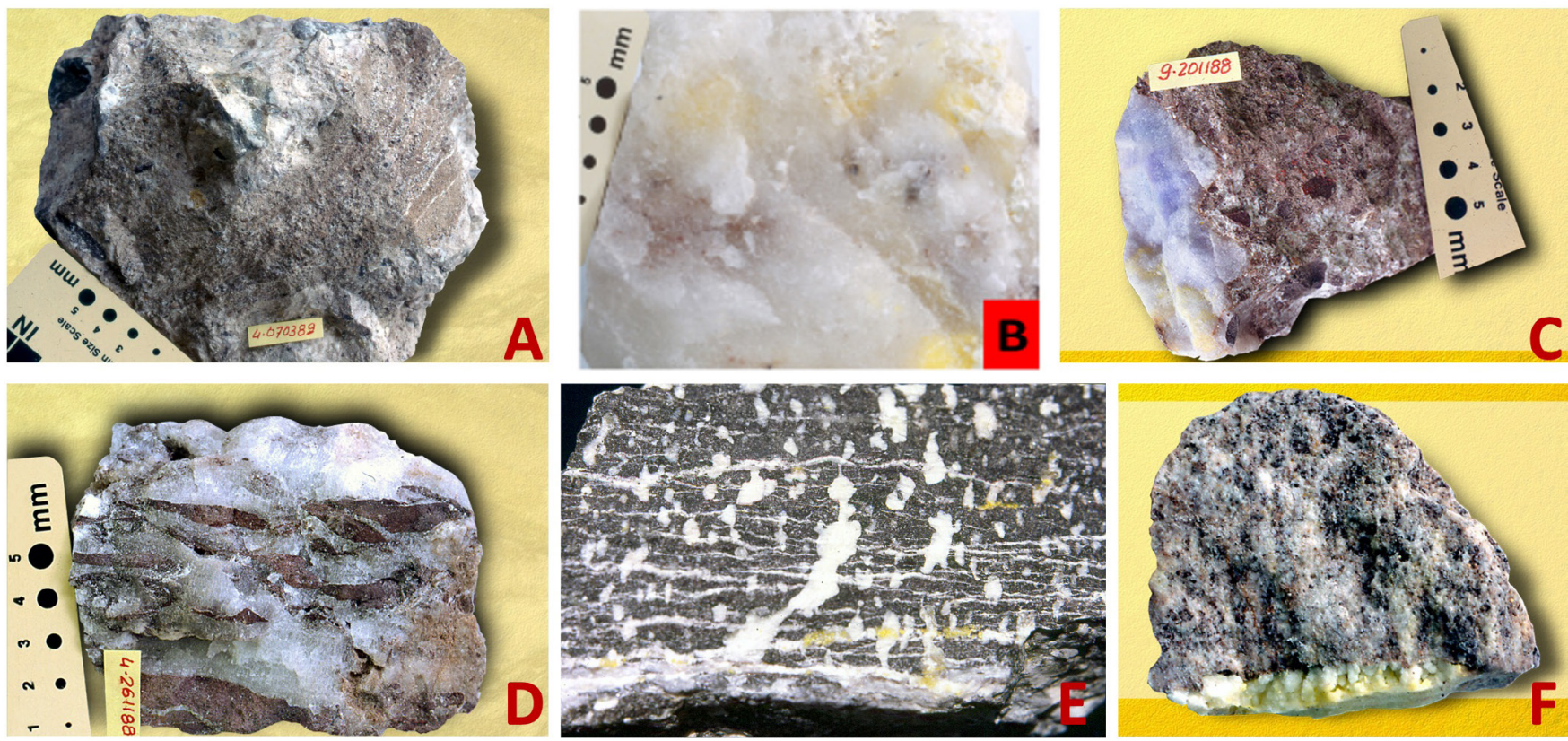

Figura 52 A) Típico "caliche negro" que, en este caso, corresponde a una roca sedimentaria detrítica de grano fino cementada por nitratos. B) Caliche blanco con pequeñas inclusions amarillas que corresponden a yodatos y/o cromatos. C) Una mezcla de caliche negro que corresponde a una roca clástica de grano medio a grueso cortado por una veta de caliche violeta con yodatos y cromatos. Se asume que el color violeta es impartido por la disociación del cloruro de sodio, debido a radioactividad, y el color violeta correspondería al ión $\mathrm{Na}^{+}$. D) Roca volcánica dacítica invadida pervasivamente por caliche blanco. E:) Lava amigdaloidal dacítica cortada por vetillas de nitrato blanco que incluye cromatos y/o yodatos. F) Roca volcánica invadida pervasivamente por nitratos y atravesada por una vetilla de nitrato blanco con yodatos y/o cromatos. 
son rocas sedimentarias marinas del Jurásico y, en el otro, volcánicas del Paleógeno. Las dimensiones de los cuerpos mineralizados varían desde centímetros a más de un metro de espesor, y se distribuyen en áreas de hasta decenas de $\mathrm{km}^{2}$. En el caso de los que tienen como roca encajadora secuencias marinas del Jurásico, las sales se distribuyen en vetas o en los contactos de los estratos, y es evidente que los aportes de las soluciones han sido cíclicos (Figura 47).
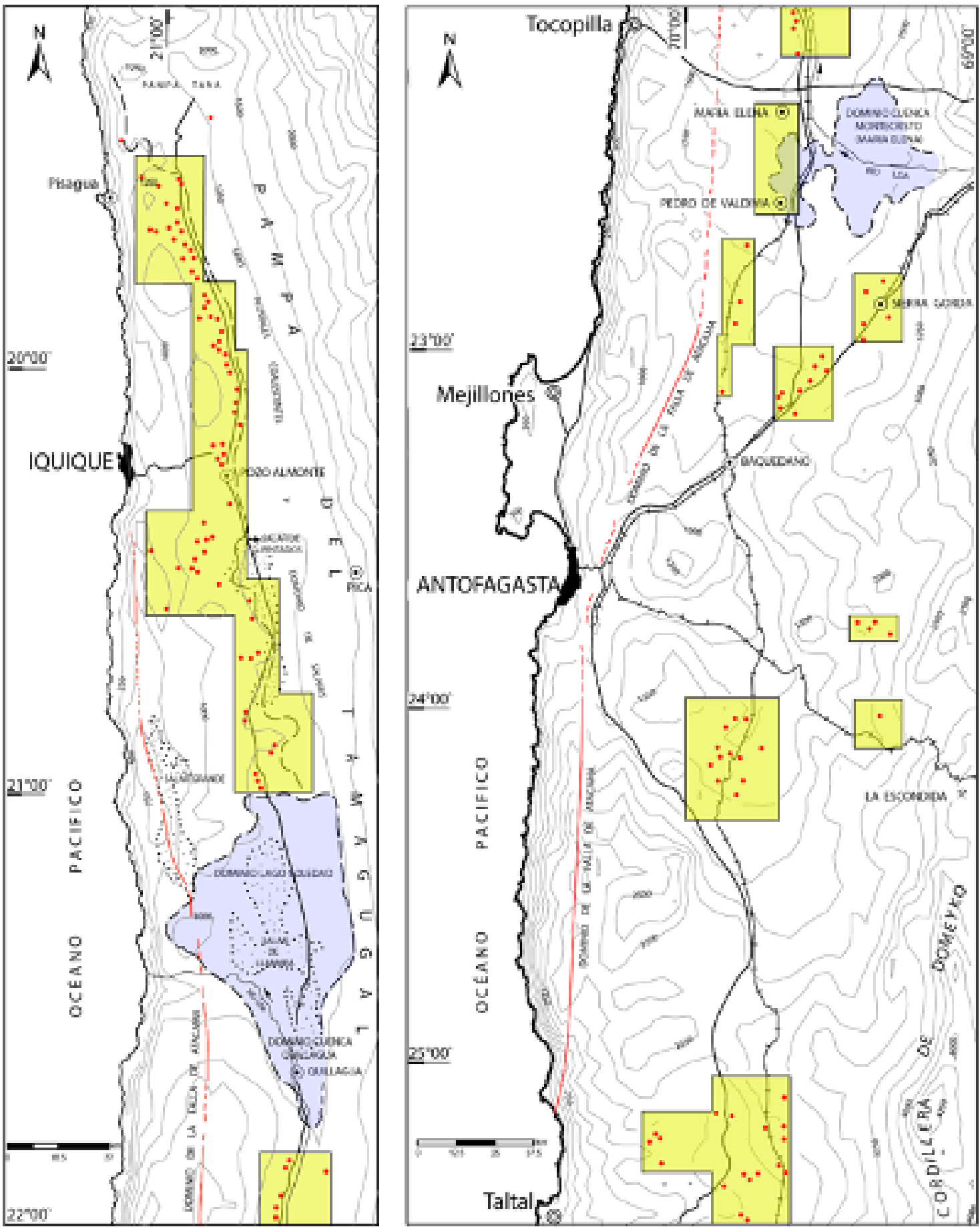

Figura 53 Ubicación de las Oficinas Salitreras en el Norte de Chile. Los puntos rojos representan las Oficinas y las áreas encerradas por líneas cortadas señalan áreas cubiertas por materiales aluviales recientes que cubren yacimientos (modificado de Chong, 1994). 
De este tipo de depósitos, los que están encajados en rocas jurásicas marinas se formaron en la parte más distal de la Pampa del Tamarugal, donde la Cordillera de la Costa constituye una verdadera barrera para los fluidos que vienen del este. Los yacimientos que encajan en rocas volcánicas paleógenas aparecen directamente relacionadas a éstas y, en casos, incluyen vetas de otras sales como sulfatos (Figura 55A). Estas vetas y mantos originales no guardan ninguna relación con procesos de sedimentación y aparecen estrictamente relacionados con las rocas volcánicas.

Los YNY en roca, en su mayoría, no afloran y fueron explotados mediante minería subterránea, utilizando una prospección inicial a través de piques, socavones y un rudimentario sistema de "room and pillar" que generó laboreos continuos con cientos de metros cuadrados de superficie y, en partes con altos de hasta $30 \mathrm{~m}$ (Figuras 51 y 56).

\subsubsection{YACIMIENTOS EN CUENCAS EVAPORÍTICAS}

En el caso de salares de la Cordillera de la Costa y de la Depresión Central, como Llamará, Salar Grande y La Gloria, hay YNY que están emplazados en el basamento donde posteriormente se formaron las cuencas de los salares. De acuerdo a esto, los yacimientos se reconocen hoy en los bordes de esos salares y, en algunos casos, debajo de las costras salinas, como en Llamará y el sector de Zapiga (19³8`s $69^{\circ} 57^{\prime}$ O). En el caso del Salar Grande, los depósitos están en sus bordes sur y oeste. En el caso de La Gloria, se encuentran en toda su periferia y probablemente debajo de las costras del salar.

En la Depresión Central, las concentraciones de nitratos también aparecen debajo de costras de salares, como en Pampa de Chaca (Mina Bullmine), donde los yacimientos se distribuyen en los sedimentos del lago original (Figura 42). Parte de las costras de diferentes Salares de las Pampitas presentan anomalías, pero no valores económicos de nitratos o yodo. Un mecanismo diferente se reconoce en el Salar del Carmen (233' $\left.\mathrm{S} / 70^{\circ} 17^{\prime} \mathrm{O}\right)$. Este no presenta concentraciones de nitrato en su subsuelo, pero si en las costras. De acuerdo a esto, en este salar se habrían "cosechado" nitratos cada cierto tiempo, concentrados por capilaridad de soluciones que provienen de la lixiviación de yacimientos ubicados al norte y transportadas por aguas subterránea (Ericksen, 1981). El término "cosechar" es artesanal y deriva de los mineros que se referían a recargas periódicas de nitratos en las costras. Tal proceso permitiría que, cada cierto tiempo, el nitrato podría ser "cosechado" después de períodos de resedimentación. El planteamiento parece poco plausible, porque no sería compatible si se considera una explotación de escala importante y que una "recarga" de este tipo tomaría un tiempo considerable.

\section{Comentarios acerca de la génesis de las sales y formación de los yacimientos}

Ningún trabajo relacionado con los depósitos de nitratos y yodo del norte de Chile puede eludir el origen de las sales y la formación de sus yacimientos. Emitir una teoría al respecto sigue siendo complejo, después de más de un siglo, tal como lo plantearon los pioneros Whitehead (1920) y Ericksen (1981). El primero comentó "se han sugerido muchas hipótesis bastante divergentes sobre el origen de los depósitos con la aceptación universal de ninguna". A su vez, Ericksen se refirió al tema diciendo: "in fact, they are so extraordinary that, were it not for their existence, geologists could easily conclude that such deposits could not form in nature".

La mayoría de los trabajos relacionados al tema se han preocupado principalmente de la génesis del nitrato, que se ha atribuido a fuentes tales como algas, vegetación en lagos salinos o agua marina, lixiviación de material amoniacal derivado del guano de las aves marinas, descomposición bacteriana, actividad volcánica, flujos de lodo enriquecidos en sales, nitrógeno atmosférico, de nieblas marinas o de lixiviación de rocas sedimentarias, volcánicas o marinas. A este respecto, las posibilidades que hoy entregan los sistemas analíticos acercan respuestas que algunos autores estiman definitivas para uno de los temas. De 
acuerdo a esto, los estudios isotópicos indican que los nitratos se habrían depositado desde la atmósfera, según plantearon originalmente Michalski $e t$ al. (2004).

Este trabajo no considera una discusión sobre la génesis de las sales y de los yacimientos de nitratos. Se busca únicamente plantear el tema y hacer un alcance sobre una teoría propia.

En primer lugar, se considera que las preguntas principales sobre los YNY son tres: i) Cuál es el origen de las elementos que forman la mena de los yacimientos, no solamente el de los nitratos, ii) Cómo se formaron los yacimientos; y iii) Cuál es la edad de ambos procesos. Hay numerosos trabajos recientes que dan por resueltos estos temas, por ejemplo, los de Pérez-Fodlich et al. (2014), Melchiore et al. (2018) y Michalski et al. (2004). Nuestras observaciones en terreno de los distintos yacimientos nos plantean algunos argumentos para trabajar en una hipótesis que apunta a un origen magmático de los elementos de los YNY, en conexión al volcanismo del Paleógeno, su posterior concentración, definida y cíclica por cambios climáticos más húmedos y, finalmente, una conservación de las sales por un predominio árido a hiperárido complementado con una geomorfología apropiada.

\section{Conclusiones}

El concepto de "Dominio Salino" se debe entender como un modelo conceptual que, en su contexto, ofrece una posibilidad de conocimiento $\mathrm{y}$ visión preliminar de conjunto, de un aspecto geológico, característico y diferente, del Desierto de Atacama. Desierto que, en el campo científico, se ha convertido en un "Laboratorio Natural" único. En este contexto, este modelo, planteado como se hace en este trabajo, se puede considerar un punto de partida. En el futuro, este "Dominio Salino", deberá complementarse y ampliarse en sus antecedentes, en la investigación de preguntas que en este se plantean y en el desarrollo de su potencialidad aplicada.

En lo que se refiere a antecedentes, se deberá incorporar el conocimiento de varias unidades geológicas salinas no incluidas en este trabajo,

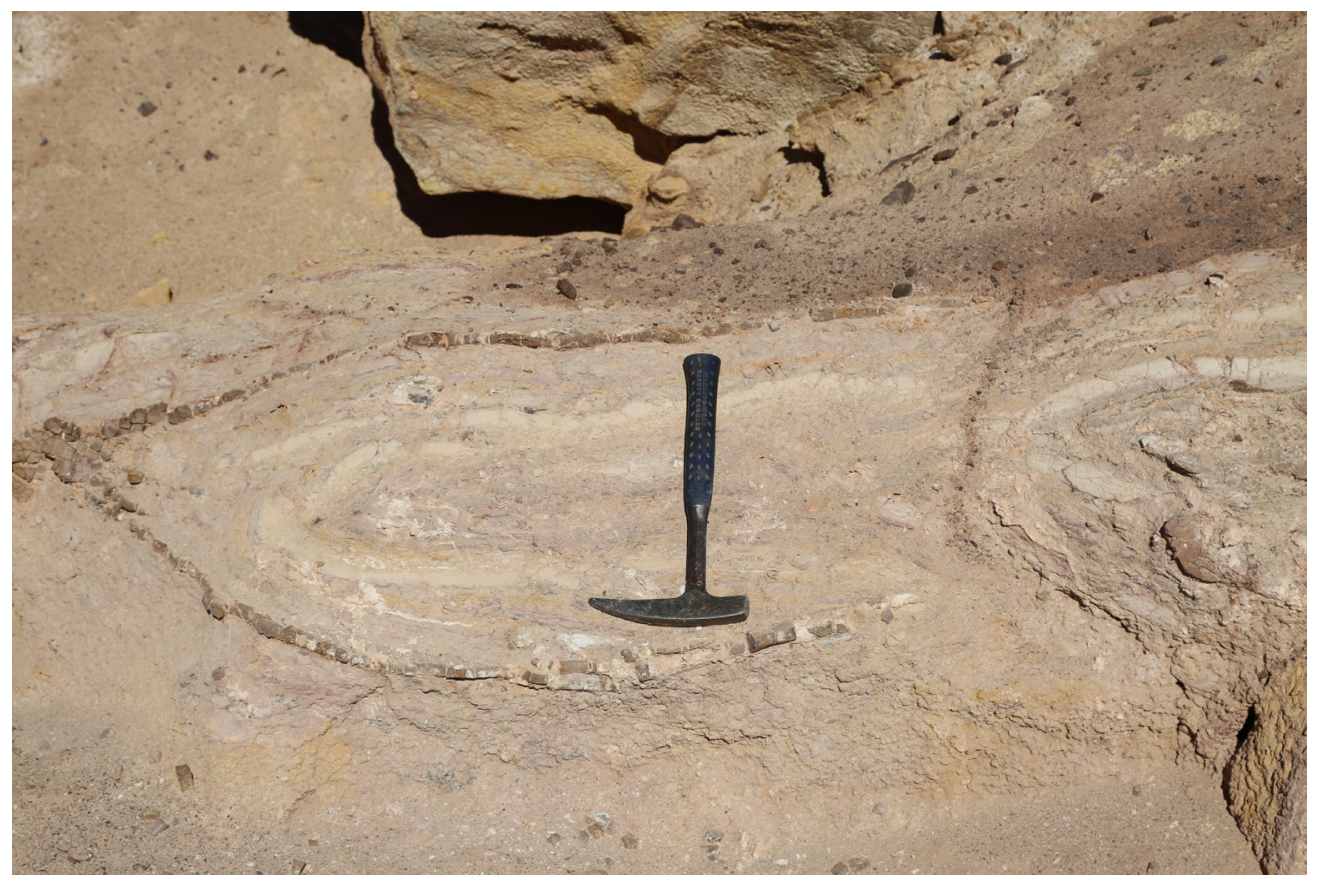

Figura 54 Estructuras de slumping en capas de caliche. Las rocas se incluyen en una secuencia lacustre formada en la parte distal de un gran sistema aluvial coalescente con un eje N-S, y por lo tanto no se habrían formado de acuerdo a la pendiente regional actual. 

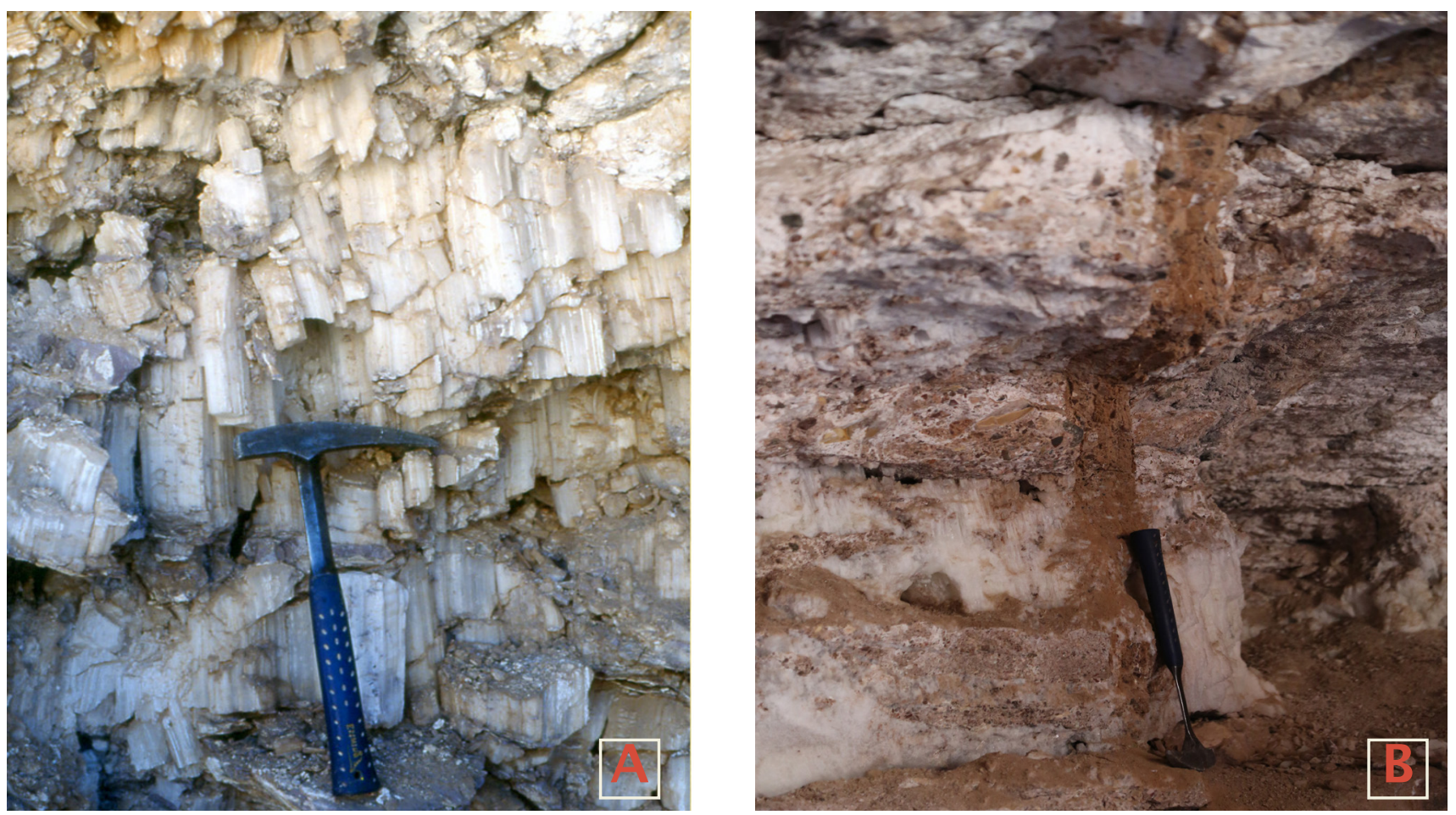

Figura 55 A) Manto de caliche blanco encajado en rocas volcánicas riolíticas. Estos cuerpos de caliche no tienen ninguna relación con procesos sedimentarios y las rocas encajadoras son exclusivamente riolitas del Paleógeno. B) Dique neptúnico enriquecido en nitratos cortando un manto de caliche blanco.

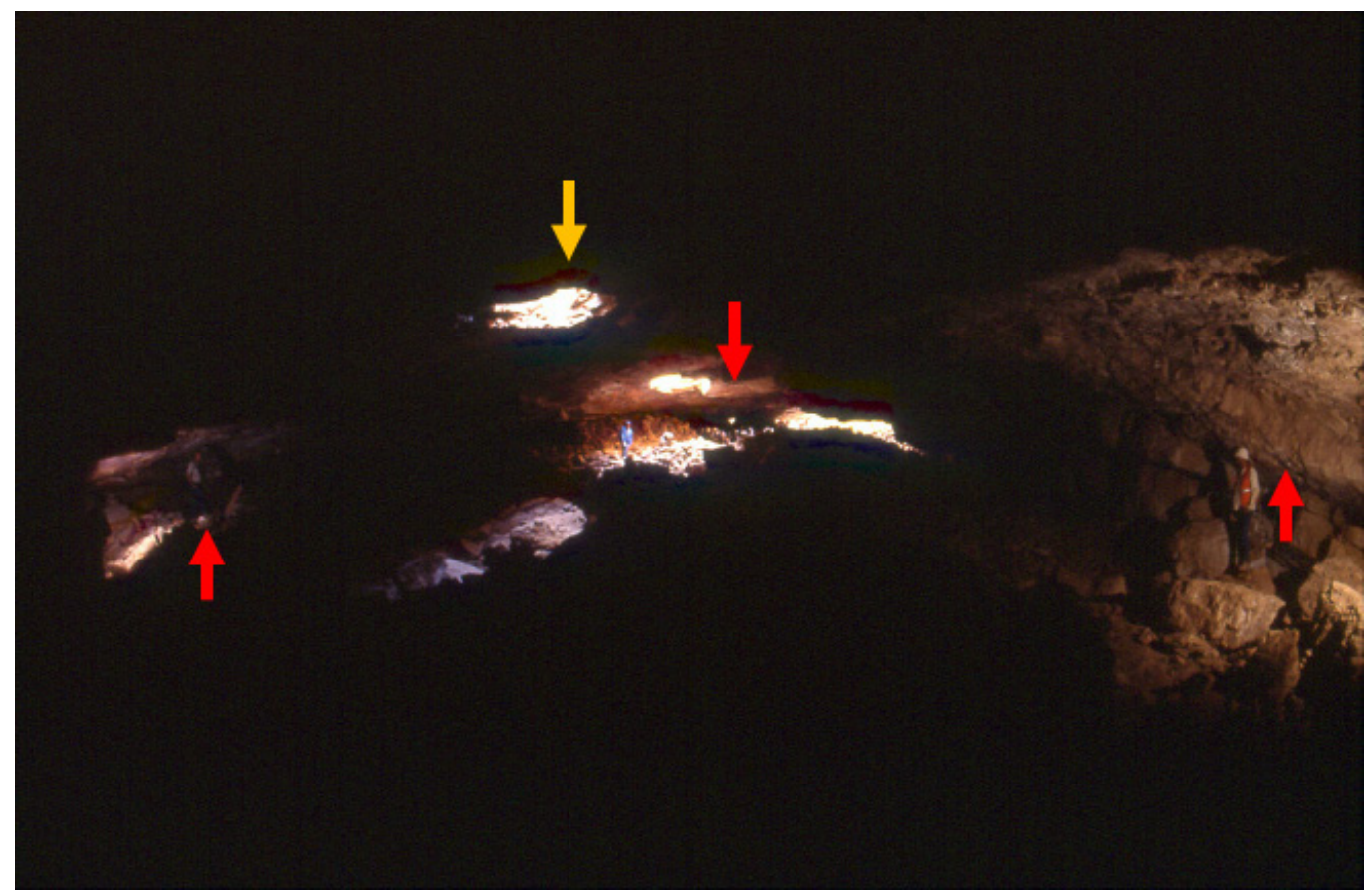

Figura 56 Interior de un laboreo subterráneo ("Cuevas" de explotación de "Caliche blanco" de alta ley), Las flechas rojas indican la posición de personas separadas del orden de $70 \mathrm{~m}$ entre si. La fecha amarilla indica un pique de extracción que alcanza la superficie a unos $12 \mathrm{~m}$ desde donde se observa la luz. La profundidad máxima de este laboreo es del orden de $25 \mathrm{~m}$. 
como es el caso de paleolagos salinos asociados a volcanismo del Cenozoico y el de algunas evaporitas marinas y continentales mesozoicas y cenozoicas. También deberá implementarse el conocimiento, tanto de las características y roles de las aguas salinas como el de las nieblas dinámicas de este desierto.

En relación a temas científicos, este trabajo plantea hipótesis de trabajo e incógnitas que se ubican en el campo de investigación de diversas especialidades, por ejemplo:

- Hoy podemos ver y conocer, de manera directa, la relación entre la actividad volcánica del Arco Mioceno-Presente y la formación y concentración de sales. Sin embargo, no se ha puesto atención en la misma relación que debe haber existido en la actividad del Arco Volcánico del Paleógeno.

- ¿Cuál puede haber sido la relación entre el magmatismo, el gran volumen de mineralización metálica del Norte de Chile y la presencia sincrónica de estos grandes volúmenes de sales?

- Los teóricos depósitos salinos fósiles que se asumen debajo de las rocas volcánicas, ¿ison una posibilidad real de exploración minera?

- Los cambios paleoclimáticos que se describen profusamente para el Cenozoico superior, ¿podrían haber sido similares en el Cenozoico Inferior?

- ¿Qué contexto geológico puede revelar el estudio exhaustivo y orientado de la mineralogía salina? ¿Cual es la cronología de los diversos depósitos salinos cenozoicos?

- ¿Hay razones para que las secuencias sedimentarias de los paleolagos salinos de este ambiente desértico no incluyan fósiles?

En lo que se refiere a la potencialidad del "Dominio Salino" en este "Laboratorio Natural" del Desierto de Atacama, el tema es hoy objetivo de variadas iniciativas de investigación:

- El Desierto de Atacama se interpreta como uno de los lugares de la Tierra que más se asemejan al tipo de terreno que se encontrará en Marte. Esta semejanza incluye el estudio de sales en ambientes hiperáridos como un tema principal.
- Hoy existe un gran desarrollo de la Geomicrobiología en ambientes desérticos del Norte de Chile. La presencia de "biosignatures" asociadas a sales es una de las líneas de investigación en las que se pone gran énfasis en Astrobiología.

- El estudio actual de climas y paleoclimas es intensivo en busca de explicaciones y soluciones al Cambio Climático Global. De nuevo, el estudio sistemático de las sales es una herramienta fundamental.

- La aplicación biotecnológica de la microbiota, asociada a ambientes salinos, es un tema de actualidad. Incluye la aplicación de presencia y actividad bacteriana que va desde la fabricación de cremas anti rayos uv hasta el potencial uso de nanopartículas anticancerígenas.

En el contexto descrito, se considera que el presente trabajo constituye un aporte complementario en el conocimiento de un campo que es relativamente desconocido, exclusivo del Desierto de Atacama y que tiene una importancia científica y aplicada en pleno desarrollo.

\section{Referencias}

Alonso R., 1986, Ocurrencia, posición estratigráfica y génesis de los depósitos de boratos de la Puna Argentina: Argentina, Universidad Nacional de Salta, Facultad de Ciencias Naturales, Tesis Doctoral (Inédita), $196 \mathrm{p}$.

Alpers C.N., Brimhall G.H., 1988, Middle Miocene climatíc change in the Atacama Desert, northern Chile: evidence from supergene mineralization at La Escondida: Geological Society of America Bulletin, 100(10), 16401656. https://doi.org/10.1130/0016$7606(1988) 100<1640: \mathrm{mmccit}>2.3$. со;2

Azua-Bustos, A., Caro-Lara L., Vicuña R., 2015, Discovery and microbial content of the driest site of the hyperarid Atacama Desert, Chile: Environmental Microbiology Reports, 7(3), 388-394. https://doi. org/10.1111/1758-2229.12261 
Azua-Bustos, A., Gonzalez-Silva, C., 2014, Biotechnological applications derived from microorganisms of the Atacama Desert: Biomed Research International, 909312, 1-7. https://doi.org/10.1155/2014/909312

Bao, R., Sáez, A., Servant-Vildary, S., Cabrera, L., 1999, Lake-level and salinity reconstruction from diatom analyses in Quillagua formation (late Neogene, Central Andean Forearc, northern Chile): Palaeogeography, Palaeoclimatology, Palaeoecology, 153, 309-335. http://dx.doi.org/10.1016/ S0031-0182(99)00066-8.

Barraza M.M., 2006, Suelos salinos sulfatados en ambientes áridos-hiperáridos en el Norte de Chile: Chile, Universidad Católica del Norte, Facultad de Ingeniería y Ciencias Geológicas, Memoria, $96 \mathrm{p}$.

Basadre, M., 1884, Riquezas Peruanas. Lima: Imprenta de La Tribuna, $224 \mathrm{p}$.

Benison K. C., 2019, The physical and chemical sedimentology of two high-altitude acid salars in Chile: sedimentary processes in an extreme environment: Journal of Sedimentary Research 89(2), 147-167. https://doi. org/10.2110/jsr.2019.9

Betancourt, J. L., Latorre, C., Rech,J. A., Quade, J., Rylander, K. A., 2000, A 22,000-Year record of monsoonal precipitation from Northern Chile's Atacama Desert: Science, 289 (5484), 1542-1546. https//doi.org/10.1126/ science, 289.5484

Bevacqua, P., 1992, Geomorfología del Salar de Atacama y Estratigrafía de su Núcleo y Delta. Segunda Región de Antofagasta, Chile: Chile, Universidad Católica del Norte, Facultad de Ingeniería y Ciencias Geológicas, Memoria,.284 p.

Bobenrieth, G. L., 1979, Proyecto Cordillera de la Costa Tocopilla -Río Loa: geología de los cuadrángulos Cerro Desamparado y Cerro Soledad, Vol. 2: Santiago, [informe inédito].

Brüggen, J.,1950, Fundamentos de Geología de Chile: Santiago de Chile, Instituto de Geografia Militar, 374 p.

Camara, B., Suzuki S., Nealson K. H., Wierzchos J., Ascaso C., Artieda O., de los Ríos A.,
2014, Ignimbrite textural properties as determinants of endolithic colonization patterns from hyper-arid Atacama Desert: International Microbiology, 17(4), 235-247. http://dx.doi.org/10.2436/20.1501.01.226

Carmona, V., Pueyo, J. J.,Taberner, C., Chong, G., Thirlwall, M., 2000, Solute inputs in the Salar de Atacama (N. Chile): Journal of Geochemical Exploration, 69, 449-460. https://doi.org/10.1016/ s0375-6742(00)00128-x

Casamiquela, R. M., 1972, Faunê terrestre présente et passée: Objets et Mondes, 12(2), 97-107.

Casamiquela, R. M., Sepúlveda, F., 1974, Catalogación crítica de algunos vertebrados fósiles chilenos : III. Los Megaterioideos sobre Megatherium medinae Philippi: Ameghiniana, 11(2), 97-123.

Cereceda, P., Osses, P., Larrain, H., Farías, M., Lagos, M., Pinto, R., Schemenauer R. S., 2002, Advective, orographic and radiation fog in the Tarapacá Region, Chile: Atmospheric Research, 64(1-4), 261-271. https://doi. org/10.1016/S0169-8095(02)00097-2

Cereceda, P., Larrain, H., Osses, P., Farías, M., Egaña, I., 2008, The spatial and temporal variability of fog and its relation to fog oases in the Atacama Desert, Chile: Atmospheric Research, 87(3-4), 312-323. https://doi. org/10.1016/j.atmosres.2007.11.012

Charrier, R., Pinto, I., Rodríguez, M.P., 2007, Tectonostratigraphic evolution of the Andean Orogen in Chile, in Moreno, T., Gibbons, W. (ed.), The Geology of Chile: Geological Society of London, $21-114$. https://doi.org/10.1144/goch.3

Chong, G.,1984, Die Salare in Nordchile. Geologic, Struktur und Geochemie: Geotek Forsch 67(1-2), 1-146.

Chong, G., 1988, The Cenozoic saline deposits of the Chilean Andes between 18 ${ }^{\circ} 00^{\prime}$ and $27^{\circ} 00^{\prime}$ South latitude. In Bahlburg, H., Breitkreuz, C., Giese, P. (Eds), The southern Central Andes. Lecture Notes in Earth Sciences 17: Berlin, Springer, 137-151. https://doi.org/10.1007/bfb0045179 
Chong, G., 1994, The Nitrate Deposits of Chile, in Reutter, K.J., Scheuber, E., Wigger, P.J. (eds), Tectonics of the Southern Central Andes. Berlin, Springer, Heidelberg, 303-316. https:/ / doi.org/10.1007/978-3-642-77353-2_22

Chong, G., Pueyo, J.J., Demergasso, C., 2000, Los yacimientos de boratos de Chile: Revista Geológica de Chile, 27(2), 99 - 119. https:// doi.org/10.4067/s07 16-02082000000100007

Chong, G., Mendoza, M., García Veigas, J., Pueyo, J.J, 1999, Evolution and Geochemical Signatures in a Neogene Forearc Evaporitic Basin: The Salar Grande (Central Andes of Chile): Paleogeography, Palaeoclimatology Palaeoecology, 151(1-3), 39-54. https://doi. org/10.1016/s0031-0182(99)00014-0

Chong, G., Demergasso, C., Echeverría, A., Pueyo, J., Escudero, L., Galleguillos, P., Zepeda, V., Jensen, A., Wilke, H., 2004, Microorganisms in gypsum structures in extreme environments of the Atacama Desert, in 10th International Symposium on Microbial Ecology. Cancún, México.

Chong G., Demergasso G., Ibáñez R., Lisboa P., Echeverría A., Galleguillos P., Gutiérrez J., 2005, Cyanobacterias of Cripthoendolithic communities in arid environments, in International Workshop "Biodiversity, Molecular Biology and Biogeochemistry of Thermophiles", Petropavlovsk-Kamchatksky, Russia.

Chong G., Demergasso, C., Echeverría, A., 2006, Microorganisms in gypsum structures of desertic-semidesertic environments. Desierto de Atacama, Northern Chile, in 11th International Symposium on Microbial Ecology (ISME-1 1), Viena, Austria.

Chong, G., Cortez, P., Escudero, L., Pueyo, J., Demergasso, C., 2015, Geomicrobiology in an acid hypersaline system in Northern Chile, in Congreso Geológico de Chile, La Serena, Chile.

Coira, B., Davidson, J., Mpodozis, C., Ramos V., 1982, Tectonic and magmatic evolution of the Andes of Northern Argentina and Chile: Earth Science Review, 18 (3-4), 303 - 332. https:// doi.org/10.1016/0012-8252(82)90042-3
Cortez, P., 2014, Caracterización geológica de los Salares Gorbea e Ignorado y su asociación con su microbiótica: Chile, Universidad Católica del Norte, Facultad de Ingeniería y Ciencias Geológicas, Memoria, 200 p.

Davila, A. F., Hawes, I., Ascaso, C., Wierzchos, J., 2013, Salt deliquescence drives photosynthesis in the hyperarid Atacama Desert: Environmental Microbiology Reports, 5(4), 583587. https://doi.org/10.1111/1758-2229.12050

Demergasso, C., Chong, G., Galleguillos, P., Escudero, L., Martinez-Alonso, M., Esteve, I., 2003, Microbial mats from the Llamara salt flat, northern Chile: Revista Chilena de Historia Natural ,76(3), 485-499. https:/ /doi. org/10.4067/s07 16-078x2003000300012

Demergasso, C., Casamayor, E. O., Chong, G., Galleguillos, P., Escudero, L., Pedros-Alio, C., 2004, Distribution of prokaryotic genetic diversity in athalassohaline lakes of the Atacama Desert, Northern Chile: FEMS Microbiology Ecology, 48(1), 57-69. https:// doi.org/10.1016/j.femsec.2003.12.013

Demergasso, G., Chong, G., Escudero, L., Pueyo, J., Pedrós-Alió, G., 2007, Microbial precipitation of arsenic sulfides in Andean salt flats: Geomicrobiology Journal, 24(2), 111-123. https://doi. org/10.1080/01490450701266605

Demergasso, G., Escudero, L., Casamayor, E. O., Chong, G., Balague, V., Pedros-Alio, C., 2008, Novelty and spatio-temporal heterogeneity in the bacterial diversity of hypersaline Lake Tebenquiche (Salar de Atacama): Extremophiles 12(4), 491-504. https://doi. org/10.1007/s00792-008-0153-y

Demergasso, G., Dorador, C., Meneses, D., Blamey, J., Cabrol, N., Escudero, L., Chong G., 2010, Prokaryotic diversity pattern in high-altitude ecosystems of the Chilean Altiplano: Journal of Geophysical ResearchBiogeosciences, 115, G00D09. https://doi. org/10.1029/2008jg000836

Ericksen, G.E., 1963, Geology of the salt deposits and the salt industry of northern Chile: U.S. Geological Survey: Washington DC, 164 p. https://doi.org/10.3133/ofr6331 
Ericksen, G.E., 1981, Geology and origin of the Chilean Nitrate Deposits: U.S. Geological Survey: Washington DC, 37 p. https://doi. org/10.3133/pp1 188

Ericksen, G.E., 1983, The Chilean Nitrate Deposits: American Scientist, 71(4), 366-374. Ericksen, G.E., Evans, H., Mrose, M., McGee, J., Marinenko, J., Konnert, J., 1989, Mineralogical studies of the Nitrate Deposits of Chile. VI. Hectorfloresite, $\mathrm{Na}_{9}\left(\mathrm{IO}_{3}\right)\left(\mathrm{SO}_{4}\right)_{4}$. A new saline mineral: American Mineralogist, 74(9-10), 1207-1214.

Ericksen, G.E., Mrose, M.E., Marinenko, J. W., 1974, Mineralogical studies of the Nitrate Deposits of Chile. IV. Bruggenite, $\mathrm{Ca}\left(\mathrm{IO}_{3}\right)_{2}$. $\mathrm{H}_{2} \mathrm{O}$. A new saline mineral: Research of the U.S. Geological Survey, 2(4), 471-478.

Ericksen, G.E., Mrose, M., Marinenko, J., McGee, J.,1986, Mineralogical studies of the nitrate deposits of Chile. V. Iquiqueite, $\mathrm{NaK}_{3}(\mathrm{CrO})$ $\mathrm{B}_{24} \mathrm{O}_{39}(\mathrm{OH})_{12} \mathrm{H}_{2} \mathrm{O}$ A new saline mineral: American Mineralogist, 71(5-6), 830-836.

Escudero, L., Bijman, J., Chong, G., Pueyo, J., Demergasso, G., 2013a, Geochemistry and microbiology in an acidic, high altitude $(4,000 \mathrm{~m})$ salt flat. High Andes, northern Chile: Advanced Material Research, 825, 2832. https://doi.org/10.4028/www.scientific. net/amr.825.28

Escudero, L. V., Casamayor, E. O., Chong, G., Pedros-Alio, G., Demergasso, C., 2013b, Distribution of microbial arsenic reduction, oxidation and extrusion genes along a wide range of environmental arsenic concentrations: Plos One, 8(10), 1-14. https://doi.org/10.1371/journal. pone. 0078890

Escudero, L., Bijman, J., Guajardo, M., Pueyo, J. J., Chong, G., Demergasso, C.,2015, Organotrophic and Mixotrofic Sulfur Oxidation in an Acidic Salt Flat in Northern Chile: Advanced Material Research, 1130, 63-67. https://doi.org/10.4028/www. scientific.net/amr.1130.63

Escudero, L., Oetiker, N., Gallardo, K., TebesCayo, C., Guajardo, M., Nuñez, C.,
Davis-Belmar, C., Pueyo J. J., Chong, G., Demergasso, G., 2018, A thiotrophic microbial community in an acidic brine lake in Northern Chile: Antonie Van Leeuwenhoek, 111(8), 1403-1419. https:// doi.org/10.1007/s10482-018-1087-8

Evenstar, L., Hartley, A., Stuart, G., A., Neilson, J.C., 2015, Climatic and halokinetic controls on alluvial lacustrine sedimentation during compressional deformation, Andean forearc, northern Chile: Basin Research, 28(5), 1-24. https://doi.org/10.1111/bre.12124

Farías M., Charrier, R., Comte, D., Martinod, J., Hérail G., 2005, Late Cenozoic deformation and uplift of the western flank of the Altiplano: Evidence from the depositional, tectonic, and geomorphologic evolution and shallow seismic activity (northern Chile at $19^{\circ} 30$ S): Tectonics, 24(4), 1-27. https:// doi.org/10.1029/2004tc001667

Farías, M. E., Contreras, M., Rasuk, M. C., Kurth, D. , Flores, M. R., Poire, D. G., Novoa, F., Visscher, P. T., 2014, Characterization of bacterial diversity associated with microbial mats, gypsum evaporites and carbonate microbialites in thalassic wetlands: Tebenquiche and La Brava, Salar de Atacama, Chile: Extremophiles 18(2), 311-329. https://doi.org/10.1007/ s00792-013-0617-6

Federov, A. V., Dekens, P. S., McCarthy, M., Ravelo, A. C., DeMenocal, P. B., Barreiro, M., Pacanowski, R.C., Philander, S. G., 2006, The Pliocene paradox (Mechanisms for a permanent El Niño): Science, 312(5779), 1485-1489. https://doi.org/10.1126/ science. 1122666

Finstad, K. M., Probst, A. J., Thomas, B. C., Andersen, G. L., Demergasso, C., Echeverría, A., Amundson, R. G., Banfield, J. F. 2017, Microbial community structure and the persistence of cyanobacterial populations in salt crusts of the Hyperarid Atacama Desert from Genome-Resolved Metagenomics: Frontiers in Microbiology 8(1435), 1-10. https://doi.org/10.3389/fmicb.2017.01435 
Gallardo, K., Candia, J. E., Remonsellez, F., Escudero, L. V., Demergasso, C. S. 2016, The ecological coherence of temperature and salinity tolerance interaction and pigmentation in a non-marine vibrio isolated from Salar de Atacama: Front Microbiol 7, 1943. https://doi.org/10.3389/ fmicb.2016.01943

García, M., Hérail, G., 2005, Fault-related folding, drainage network evolution and valley incision during the Neogene in the Andean Precordillera of Northern Chile: Geomorphology, 65(3-4), 279-300. https:// doi.org/10.1016/j.geomorph.2004.09.007

Garreaud, R. D., Vuille, M., Clement, A.C., 2003, The climate of the Altiplano: Observed current conditions and mechanisms of past changes: Palaeogeography, Palaeoclimatology, Palaeoecology, 194(1-3), 5-22. https://doi. org/10.1016/S0031-0182(03)00269-4

Garreaud, R. D., Vuille M., Compagnucci R., MarengoJ., 2009, Present-day South American climate: Palaeogeography, Palaeoclimatology, Palaeoecology, 281(3-4), 180-195. https:// doi.org/10.1016/j.palaeo.2007.10.032

Garzione, G.N., Hoke, G.D., Libarkin,J.C., Whiters, S., McFadden, B., Eiler, J., Ghosh, P., Mulch, A., 2008, Rise of the Andes: Science 320, 1304-1307. https://doi.org/10.1126/ science. 1148615

Geyh, M. A., Grosjean, M., Núñez, L., Schotterer, U., 1999, Radiocarbon reservoir effect and the timing of the Late-Glacial/Early Holocene humid phase in the Atacama Desert (Northern Chile): Quaternary Research, 52(2), 143-153. https://doi.org/10.1006/ qres.1999.2060

Glossary of Geology, 2011, Glossary of Geology, 5 Ed, Neuendorf, K.,Mehl Jr., J., Jackson,(Eds.) American Geosciences Institute.

Gregory-Wodzicki, K. M., 2000, Uplift history of the Central and Northern Andes: a review: Geological Society of America Bulletin, 112(7), 1091-1105. https://doi. org/10.1130/0016-7606(2000)112<1091:uh otca $>2.0 . \operatorname{co} ; 2$
Grosjean, M., van Leeuwen, J. F. N., van der Knaap, W. O., Geyh, M. A., Ammann, B., Tanner, W., Veit H., 2001, A 22,000 C-14 year BP sediment and pollen record of climate change from Laguna Miscanti (23 degrees S),Northern Chile: Global and Planetary Change, 28(1-4), 35-51.https:// doi.org/10.1016/S0921-8181(00)00063-1

Gutiérrez-Preciado, A., Saghaï, A., Moreira, D., Zivanovic, Y., Deschamps, P., López-García, P., 2018, Functional shifts in microbial mats recapitulate early Earth metabolic transitions: Nature Ecology \& Evolution, 2(11), 1700-1708. https://doi.org/10.1038/ s41559-018-0683-3

Hartley, A.J., Chong, G., 2002, Late Pliocene age for the Atacama Desert: Implications for the desertification of western South America: Geology 30,43-46.http://doi.org/10.1130/00917613(2002)030<0043:LPAFTA > 2.0.CO;2

Hartley, A., 2003, Andean uplift and climate change: Journal of the Geological Society, 160(1), 7-10. https://doi. org/10.1144/0016-764902-083

Hartley, A. J., Chong, G., Houston, J., Mather, A. E., 2005, 150 million years of climatic stability: evidence from the Atacama Desert, northern Chile: Journal of the Geological Society, 162(3), 421-424 https://doi. org/10.1144/0016-764904-071

Hinman, N., Cabrol, N., Gulick, V., WarrenRhodes, K., Tebes, C., Chong, G., Demergasso, C., 2017, Initial investigation of endoevaporitic gypsum habitats of Salar de Pajonales, Chile, en Astrobiology Science Conference, Arizona, US.

Hofstetter, B., Fuenzalida, H., Cecioni, G., 1957, Chile. In Lexique Stratigraphique International: Paris, Centre de Recherche Sciences, $444 \mathrm{p}$.

Houston, J., Hartley, A., 2003, The central Andean west-slope rainshadow and its potential contribution to the origin of hyper-aridity in the Atacama Desert: International Journal of Climatology, 23(12),1453-1464. https:// doi.org/10.1002/joc.938 
Houston, J., 2006, Evaporation in the Atacama Desert: An empirical study of spatiotemporal variations and their causes: Journal of Hydrology, 330(3-4), 402-412.https:// doi.org/10.1016/j.jhydrol.2006.03.036

Keller, G., Adatte, T., Stinnesbeck, W., Stüben, D., Kramar, U., Berner, Z., L., von Salis Perch-Nielsen K.,1997, The CretaceousTertiary transition on the shallow Saharan Platform of southern Tunisia: Geobios, 30(7), 951-975. https://doi.org/10.1016/ s0016-6995(97)80218-5

KennettJ. P., 1977, Cenozoic evolution of Antarctic glaciation, the Circum-Antarctic Ocean, and their impact on global paleoceanography: Journal of Geophysical Research, 82(27), 3843-3860. https://doi.org/10.1029/ jc082i027p03843

Lamb, S., Davis, P., 2003, Cenozoic climate change as a possible cause for the rise of the Andes: Nature, 425, 792-797. https://doi. org/10.1038/nature02049

Lamb, S., Hoke, L., 1997, Origin of the high plateau in the Central Andes, Bolivia, South America: Tectonics, 16(4), 623-649. https:// doi.org/10.1029/97tc00495

Lara, J., Escudero, L., Ferrero, M., Chong, G., Pedros-Alio, C., Demergasso, C., 2012, Enrichment of arsenic transforming and resistant heterotrophic bacteria from sediments of two salt lakes in Northern Chile: Extremophiles 16(3), 523-538. https://doi. org/10.1007/s00792-012-0452-1

Latorre, C., Betancourt, J. L., Arroyo, M. T. K., 2006, Late Quaternary vegetation and climate history of a perennial river canyon in the Río Salado basin $\left(22^{\circ} \mathrm{S}\right)$ of Northern Chile: Quaternary Research, 65(3), 450-466. https://doi.org/10.1016/j. yqres.2006.02.002

Lee, G. J. D., McMullan, P. E., O'Kane, C. J., Stevenson, A., Santos, I. C., Roy, C. , Ghosh, W., Mancinelli, R. L., Mormile, M. R., McMullan, G., Banciu, H. L., Fares, M. A., Benison, K. C., Oren, A., Dyall-Smith, M.
L., Hallsworth, J. E., 2018, NaCl-saturated brines are thermodynamically moderate, rather than extreme, microbial habitats: Fems Microbiology Reviews, 42(5), 672-693. https://doi.org/10.1093/femsre/fuy026

Mansfield, G.R., Boardman, L., 1932, The Nitrate Deposits of the United States. United States Department of the Interior: Geological Survey Bulletin, 838. https://doi. org/10.3133/b838

Melchiore, E., Sickman, J., Talyn, B., Noblet, J., 2018, Isotope stratigraphy: Insights on paleoclimate and formation of nitrate deposits in the Atacama Desert, Chile: Journal of Arid Environments, 148, 45-54. https://doi. org/10.1016/j.jaridenv.2017.09.013

Meneses, D., Dorador, C., Urtuvia V. \& Demergasso, C., 2008, Bacteria from Salar de Atacama producing interesting commercial compounds polyunsaturated fatty acids (PUFA"s) and cold active enzymes, in International Symposium for Microbial Ecology, Cairns, Australia.

Michalski, G., Böhlke, J.K., Thiemens, M., 2004, Long term atmospheric deposition as the source of nitrate and other salts in the Atacama Desert, Chile: New evidence from mass independent oxygen isotopic compositions: Geochimica et Cosmochimica Acta, 68, 4023-4038. https://doi. org/10.1016/j.gca.2004.04.009

Moraga, A., Chong, G., Fortt, M.A., Henríquez, H.,1974, Estudio Geológico del Salar de Atacama. Provincia de Antofagasta: Boletín del Instituto de Investigaciones Geológicas $\mathrm{N}^{\circ} 29,56 \mathrm{p}$.

Mrose, M., Fahey, I., Ericksen, G.E., 1970, Mineralogical studies of the nitrate deposits of Chile, m. Humberstonite, $\mathrm{K}_{3} \mathrm{Na}_{7} \mathrm{Mg}_{2}\left(\mathrm{SO}_{4}\right)_{6}\left(\mathrm{NO}_{3}\right)_{2} \cdot 6 \mathrm{H}_{2} 0$. A new saline mineral: American Mineralogist, 55, 1518-1533.

Nealson, K. H., Conrad, P. G., 1999, Life: past, present and future: Philos Trans Royal Society London B, 354, 1923-1939. https:// doi.org/10.1098/rstb.1999.0532 
Parro, V., de Diego-Castilla, G., Moreno, M., Blanco, Y., Cruz, P., Rodríguez, J., Fernández D., Gómez, F., Gómez, M., Rivas, L., Demergasso, C., Echeverría, A., Urtuvia, V., Ruiz, M., García, M., Postigo, M., Sánchez, M., Chong, G., Gómez J., 2011, A microbial oasis in the hypersaline Atacama Subsurface discovered by a life detector chip: Implications for the search for life on mars: Astrobiology, 11(10), 969-996. https://doi. org/10.1089/ast.2011.0654

Pederson, L.R., 1966, La industria minera del Norte Chico, Chile. Desde la Conquista a 1963: Department of Geography, University,Evanston, Illinois.USA.

Pérez-Fodich, A.,Reich, M.,Alvarez, F.,Sneyder, G., Schoenberg, R., Vargas, G., Muramatsu, Y., Fehn U., 2014, Climat change and tectonic uplift triggered the formation of the Atacama Desert giant nitrate deposits: Geology42(3), 251-254. https://doi. org/10.1130/g34969.1

Quezada, A.,Vásquez, P.,Sepúlveda, F., Blanco, N., Tomlinson, A., 2012, Mapa Compilación Geológica Area Quillagua - Salar Grande, Región de Tarapacá. Escala 1:100.000. Servicio Nacional de Geología y Minería. Santiago de Chile.

Rasuk, M. C., Kurth, D., Flores, M. R., Contreras, M., Novoa, F., Poire, D., Farias, M. E., 2014, Microbial characterization of microbial ecosystems associated to evaporites domes of gypsum in Salar de Llamara in Atacama desert: Environmental Microbiology, 68(3), 483-494. https://doi.org/10.1007/ s00248-014-0431-4

Rautenbach, G. F., Davis-Belmar, C. S., Demergasso, C. S., 2011, Method of Treating a Sulphide Mineral, Google Patents, WO2010009481A2

Ravelo, A. C., Andreasen, D. H., Lyle, M., Lyle, A. O., Wara, M. W., 2004, Regional climate shifts caused by gradual global cooling in the Pliocene epoch: Nature, 429(6989), 263. https://doi.org/10.1038/nature02567
Rech, J.A., Quade, J., Betancourt, J.L., 2002, Late Quaternary paleohydrology of the Central Atacama Desert (lat $22^{\circ}-24^{\circ} \mathrm{S}$ ), Chile: Geological Society of America Bulletin, 114, 334-348. https://doi.org/10.1130/0016$7606(2002) 114<0334:$ lqp otc $>2.0$. co;2

Rech, J. A., Currie, B. S., Michalski, G., Cowan, A. M., 2006, Neogene climate change and uplift in the Atacama Desert, Chile: Geology, 34(9), 761-764. https://doi.org/10.1130/ g22444.1

Reich, M., Palacios, G., Vargas, G., Luo, S., Cameron, E. M., Leybourne, M. I., Parada, M.A., Zuñiga A., You, C.-F., 2009, Supergene enrichment of copper deposits since the onset of modern hyperaridity in the Atacama Desert, Chile: Mineral. Deposita, 44, 497-504. https://doi.org/10.1007/ s00126-009-0229-3

Riquelme, R., Hérail, G., Martinod, J., Charrier, R., Darrozes, J., 2007, Late Cenozoic geomorphologic signal of Andean forearc deformation and tilting associated with the uplift and climate changes of the Southern Atacama Desert $\left(26^{\circ} \mathrm{S}-28^{\circ} \mathrm{S}\right)$ : Geomorphology 86 (3-4), 283-306. https:// doi.org/10.1016/j.geomorph.2006.09.004

Risacher, F., Fritz, B., 2009, Origin of salts and brine evolution of bolivian and chilean Salars: Aquatic Geochemistry, 15(1), 123 - 157. https://doi.org/10.1007/ s10498-008-9056-x

Risacher, F., Alonso, H., Salazar, C., 2003, The origin of brines and salts in Chilean salars: a hydrochemical review: Earth Science Reviews 63(3-4), 249 - 293. https://doi. org/10.1016/s0012-8252(03)00037-0

Rivera, S., ,Stephens, A.J., 1988, Cuerpos geotermales fósiles de edad Terciario Inferior y mineralización asociada en la Región de Antofagasta, en Actas V Congreso Geológico. Chile Santiago 1: B-39-64

Ritter, B., Binnie, S., Finlay, M., Wennrich, V., Dunai, T., 2018, Evidence for multiple 
Plio-leostocene lake episodes in the hyperarid Atacama Desert: Guaternary Geochronology, 44,1 - 12. https://doi.org/10.1016/j. quageo.2017.11.002

Sáez, A., Godfrey, L.V., Herrera, C., Chong, G., Pueyo, JJ., 2016, Timing of wet episodes in Atacama Desert over the last $15 \mathrm{ka}$. The Groundwater Discharge Deposits (GWD) from Domeyko Range at $25^{\circ} \mathrm{S}$ : Quaternary Science Reviews, 145, 82-93. http://doi. org/10.1016/j.quascirev.2016.05.036.

Salfity, J.A., 1985, Lineamientos transversales al rumbo andino en el noroeste argentino. Antofagasta, en IV Congreso Geológico Chileno, Actas 1, 2-119 2-137.

Sayes, J. 1978, Cuadrángulos Collacagua y Laguna del Huasco, Provincia de Iquique- $1^{\text {a }}$ Región. Instituto de Investigaciones Geológicas: 43 p., 1 mapa escala 1:100.000.

Scanlon, B.R., Keese, K.E., Flint, A.L., Flint, L.E., Gaye, C.B., Edmunds, W.M., Simmers, I., 2006, Global synthesis of groundwater recharge in semiarid and arid regions: Hydrological Processes, 20(15), 3335-3370. https://doi.org/10.1002/hyp.6335

Serrano, A.E., Escudero, L.V., Tebes-Cayo, C., Acosta, M., Encalada, O., FernándezMoroso, S., Demergasso, C., 2017, First draft genome sequence of a strain from the genus Fusibacter isolated from Salar de Ascotan in Northern Chile: Standards in Genomic Sciences, 12, 1-9. https://doi.org/10.1186/ s40793-017-0252-4

Servicio Nacional de Geología y Minería (SERNAGEOMIN), 2019, Anuario de la Minería de Chile. Servicio Nacional de Geología y Minería, Santiago. 269 p.

Servicio Nacional de Geología y Minería (SERNAGEOMIN), 2018, Anuario de la Minería de Chile. Servicio Nacional de Geología y Minería, Santiago. 268 p.

Sillitoe, R., Mckee, E.,1996, Age of supergene oxidation and enrichment in the Chilean porphyry copper province: Economic Geology, 91 (1), 164. https://doi. org/10.2113/gsecongeo.91.1.164
Skarmeta, J., Marinovic, N., 1981, Hoja Quillagua, Región de Antofagasta. Carta Geológica de Chile, escala 1:250.000, No 31. Instituto de Investigaciones Geológicas, Santiago de Chile.

Spiro, B., Chong G., 1996, Origin of sulfate in the Salar de Atacama and the Cordillera de la Sal. Initial results of an isotopic study, en Actas del Troisième Symposium International sur la Géodinamique Andine. ORSTOM/Geosciences Rennes. Saint Malo France. 703-706.

Stoertz, G.E., Ericksen, G.E., 1974, Geology of salars in Northern Chile: USGS Professional Paper No. 811, Washington, USA, 65 p.

Sträter, E., Westbeld, A., Klemm, O., 2010, Anthropogenic pollution in coastal fog of Northern Chile: Environmental Science and Pollution Research, 17, 15631573 (2010). https://doi.org/10.1007/ s1 1356-010-0343-x

Tosdal, R.M., Clark, A.H., Farrar, E., 1984, Cenozoic polyphase landscape and tectonic evolution of the Cordillera Occidental, southern Peru: Geological Society of America Bulletin 95 (11), 1318-1332. https://doi. org/10.1130/0016-7606(1984)95<1318:cpl ate>2.0.co;2

Valero-Garcés, B., Grosjean, M., Schwalb, A., Geyh, M., Messerli, B., Kelts, K., 1996, Limnogeology of Laguna Miscanti: evidence for mid to late Holocene moisture changes in the Atacama Altiplano (Northern Chile): Journal of Paleolimnology, 16,1-21. https:// doi.org/10.1007/bf00173268

Valero-Garcés, B., Grosjean, M., Kelts, K., Schreier, H., Messerli, B., 1999, Holocene lacustrine deposition in the Atacama Altiplano facies model, climate and tectonic forcing: Palaeogeography, Palaeoclimatology, Palaeoecology, 151, 101-125. https://doi. org/10.1016/s0031-0182(99)00018-8

Valero-Garcés, B.,Delgado-Huertas, A., Navas, A., Edwards, L., Schwalb, A., Ratto N., 2003, Patterns of regional hydrological variability in Central southern Altiplano 
